\title{
OCEANIC CREATIVE PRACTICE: RE-EVALUATING \\ INDIGENOUS SPATIAL STRATEGIES AS RELEVANT TO \\ TWENTY-FIRST CENTURY CREATIVE EXPLORATION AND \\ PRACTICE
}

BY

JODI MARIE MEADOWS

\begin{abstract}
A thesis
submitted to the Victoria University of Wellington in fulfillment of the requirements for the degree of Master of Design Innovation (Culture and Context)
\end{abstract}

Victoria University of Wellington

(2015) 


\section{Acknowledgements}

This Masters experience has been the most challenging, emotional, yet best thing I have ever done. To finally have the chance to solely focus on Oceania in my research has been both liberating and satisfying. The effect of this research will remain with me for many years to come. I would like to take this time to thank everyone that have listened, helped and supported me throughout this process. First to my supervisors Nan O'Sullivan and April Henderson, your interest and dedication to this research project has been invaluable. Nan you have been my rock throughout this process, from the many hours spent discussing aspects of this research, to your favourite tool- the red pen, and for keeping me mindful and grounded throughout this entire process I thankyou immensely. April, thank-you for your wisdom and vast knowledge of Pacific literature, without your recommendations and guidance this research would not be what it has become. To my partner Stewart and his family thank-you, your support, interest and willingness to listen has been greatly appreciated. To Liz Richardson and the Te Rōpu Āwhina whānau, your belief in me gave me the confidence to stand up and be proud of my identity. You taught me not to shy away from Oceania in my academic work but to embrace it and let it enhance how I develop throughout this growth process at Victoria University Wellington. To David Hakaraia, you have stood by me and been my mentor throughout both my undergrad and now my Masters. Thank-you for your encouragement and advice, you have been instrumental in keeping me strong and confident throughout my tertiary experience. To Bu and Gandy, through all of the challenges, tribulations and achievements we have faced as a family this year nothing has faltered your constant support for my education, au lomani iko. You have both supported me in any way possible and have always been there no matter what. Thankyou for always supporting me in my chosen endeavors. My amazing editors: Uncle, Alex, Michelle, Mata and Gandy thank-you for volunteering your time to read over my work. Also thank-you to everyone who have spent time (even hours) listening to my rants, I think that we have all discovered that it is indeed possible for me to tie any conversation topic back to my something in my Masters. On the subject of rants, to all of the 2014 Masters kids-we did it! We came, we saw, we critiqued, we stressed and then finally...we conquered! 


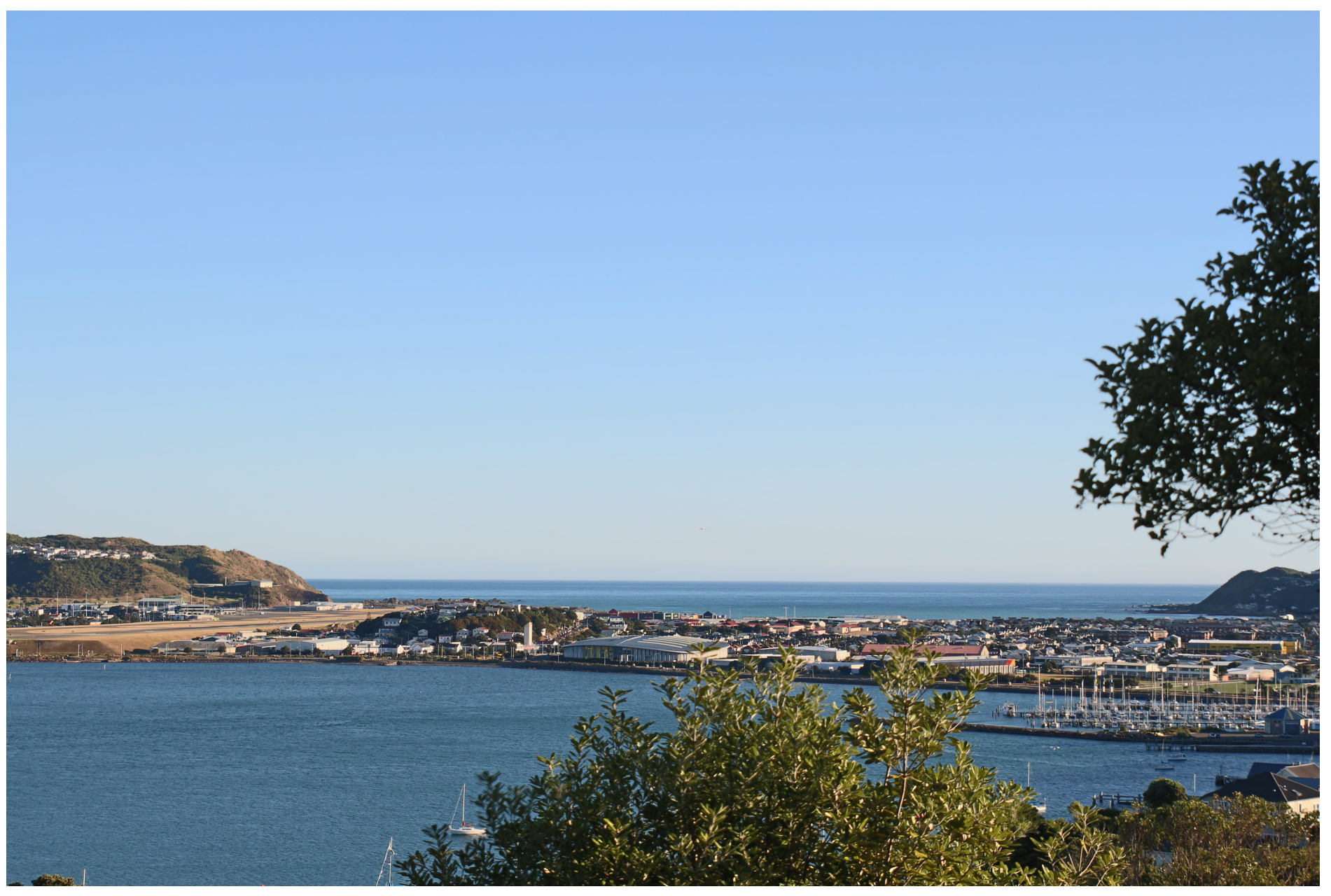




\section{Table of Contents}

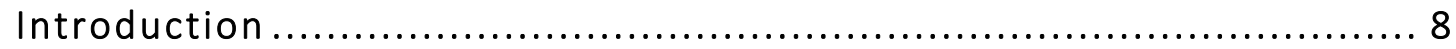

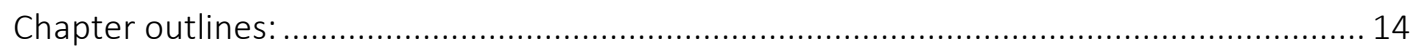

Chapter one (Migration) ........................................... 19

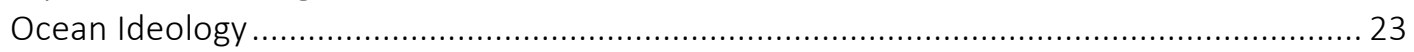

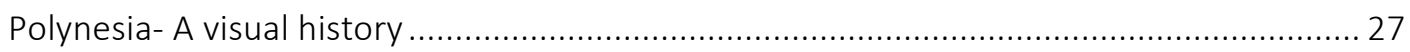

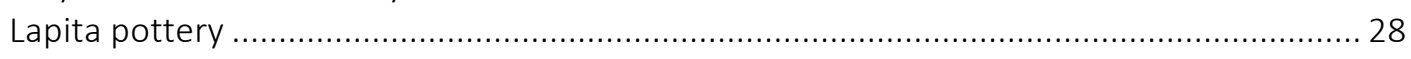

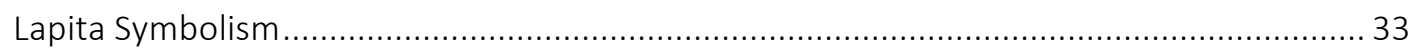

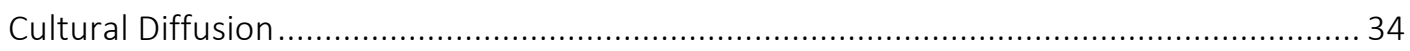

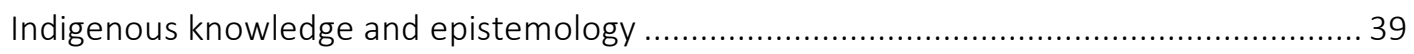

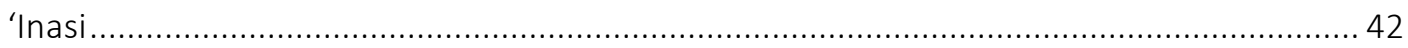

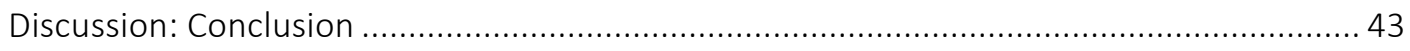

Chapter 2: Vā .................................................. 46

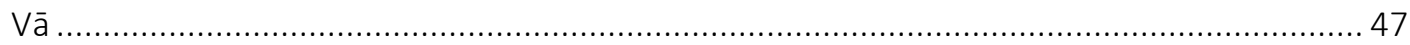

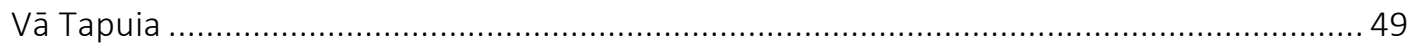

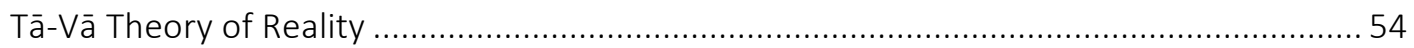

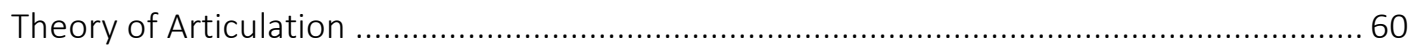

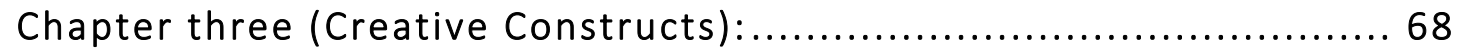

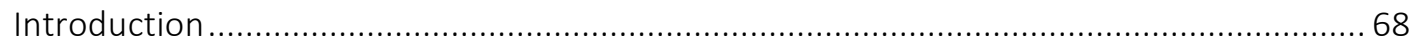

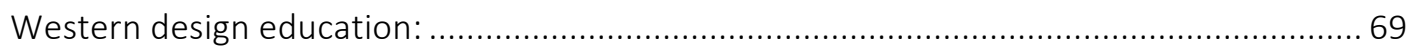

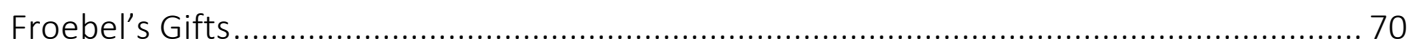

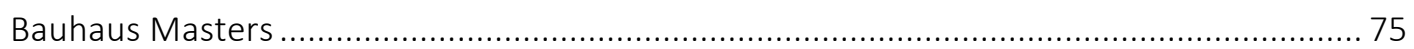

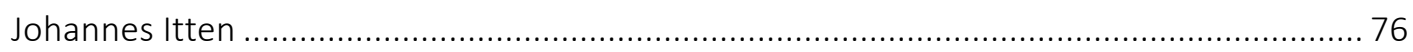

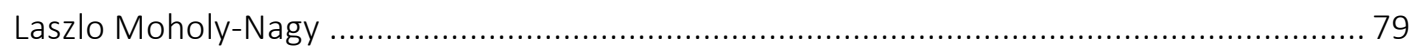

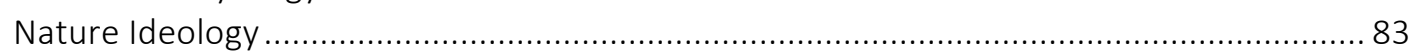

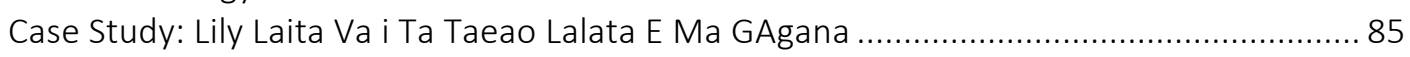

Discussion: Interstitial Space vs. Vā in Oceanic Creative Practice ....................................... 89

Chapter four: Va-ticulation ........................................ 92

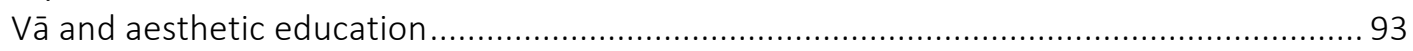

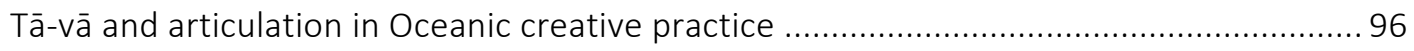

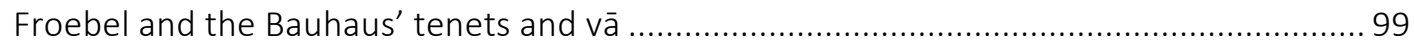

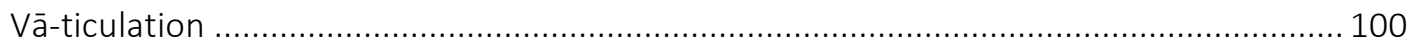

Chapter 5: Creative Oceanic Examples................................. 103

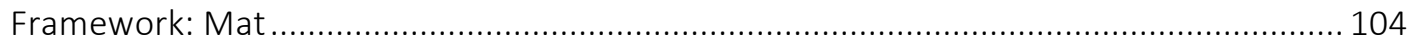

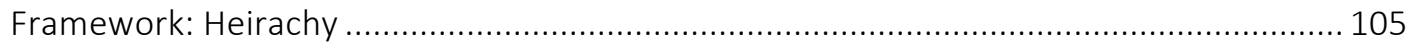

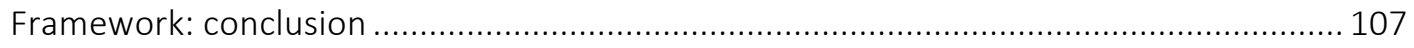

Key creative practitioners and their work 108

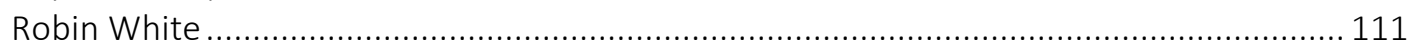

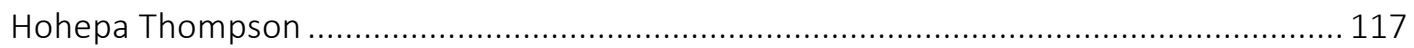

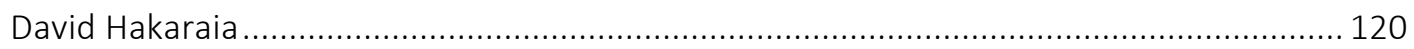

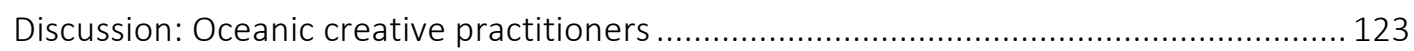

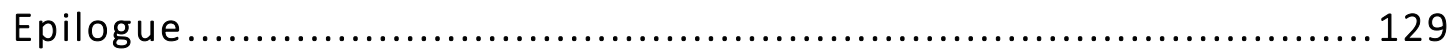

Oceanic creative practice manifesto................................... 142

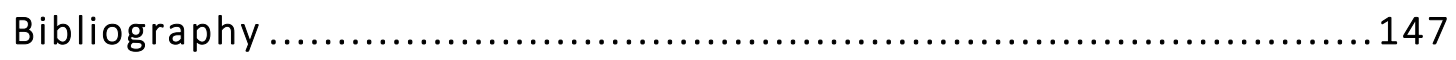




\section{Karakia mo te tango inga rakau kawakawa}

Traditional Māori incantation used when picking leaves from the kawakawa tree

Mai ea te Tupua

Clear the pathway to the godly beings, which is symbolised in the male elements

Mai ea te tawhito

Clear the pathway to the ancient ones

Mai ea te kahui o nga ariki

Clear the pathway to the exalted ones

Mai ea ta whiwhi atu kinga Atua

O i ka ta kinga te mauri ko te mauri i ahua noa mai

Let the sacred rituals of the life force commence, the life force that has come from the spiritual realm

Ki runga ki enei taura, ki runga ki enei tauira,

Place the life force upon these pupils; place the life force upon these scholars

Kia tau te mauri ki runga ki enei tama

Let the life force be placed upon the female and the male elements

He tukunga no te whaiorooro a tane te waiora

The life force that came from the forest of Tane, from the spring of creation

Tenei te matatau kia eke whakatu tawera ki te rangi

This is the knowledge of the ancestors from the forest that is uplifted

Uhi wero tau mai te mauri hau mai e

Let it be placed upon, let it be debated, so that through this the life essence may come through strongly

Ui e, taiki e. 


\section{Introduction}

"Oceania is vast, Oceania is expanding, Oceania is hospitable and generous, Oceania is humanity rising from the depths of brine and regions of fire deeper still, Oceania is us. ${ }^{\prime 1}$

\section{- Epeli Hau'ofa}

This research investigates how indigenous visual spatial strategies can be used to assist in the definition of a framework that helps characterise Oceanic perspectives and methods of creative practice. Cultural diversity in the New Zealand context holds important potential for explaining expressions of use and continuing the development of Oceanic creative practice. I will assert that the indigenous spatial strategy known as $v \bar{a}$ (space) holds important potential to help understand the significance of collective relationships within the Oceanic creative community. $V \bar{a}$ is an indigenous spatial strategy that captures the process of engaging with and nurturing connections that, I argue, should be at the forefront of the definition for Oceanic creative practice. By comparing established Eurocentric understandings of creative disciplines and processes to indigenous understandings and methodologies, this research will posit indigenous spatial strategies as not only relevant but pivotal to 21st-century creative exploration and practice. This research will contribute to the outlining of a framework that helps to define the authentic values held within Oceanic creative practice.

By identifying these values, this study offers a clarity to the term Oceanic creative practice. The purpose of this research is to establish initial connections that

\footnotetext{
${ }^{1}$ Epeli Hau'ofa, "Our Sea of Islands," The Contemporary Pacific 6, no. 1 (1994): 160.
} 
instigates new and enlivens existing dialogues that will support Oceanic creative practice to start the discussion I will posit the question:

How can indigenous visual spatial strategies be used to assist in the definition a framework that helps characterize Oceanic perspectives and methods of creative practice?

This research stems from a personal feeling of uneasiness, a yearning to feel something more, to feel a sense of collectivity between all Oceanic creative practitioners within the New Zealand creative sector. The range of diverse cultures enriches the national identity of New Zealand. Statistics now state that both biculturalism and multiculturalism has become a significant part of the genetic identity of the population ${ }^{2}$. Oceanic cultures, particularly Polynesian, have become a part of the New Zealand identity.

"Oceania refers to a world of people connected to each other...As far as I'm concerned, anyone that has lived in our region and is as committed to Oceania is an Oceanian"'3. My choice to favor the term 'Oceanic creative practice' has been a deliberate choice. The term Oceania has been already established by many as a fitting description of the Pacific region and 'creative practice' is intended as a highly inclusive term that engages with creative the process and encourages diversity of output. This term is centralized around the word Oceania as defined by Epeli Hau'ofa (1939-2009). In his essay Our Sea of Islands Hau'ofa confronts the problematic notions of the name Pacific Islands stating that it "is the prevailing one

\footnotetext{
2 "2006 Census Data- Quickstats About Culture and Identity," ed. Statistics New Zealand(Statistics New Zealand, 2006).

3 "The Ocean in Us," The Contemporary Pacific (1998): 402.
} 
used everywhere; it denotes small areas of land sitting atop submerged reefs or seamounts. ${ }^{\prime 4}$ Hau'ofa bemoans that the name Pacific Islands as a construct of European origin that belittles the region to land only seen above sea level. This definition sees the ocean as a separator between the islands. Hau'ofa instead chooses to refer to the Pacific region as Oceania. Although Oceania is not a new term, Hau'ofa states "Oceania denotes a sea of islands with their inhabitants." ${ }^{5}$ In this case the sea is considered as a connection between all Islands in the region. This view brings with it a history of the sea-faring ancestors of Oceania, people highly skilled in ocean navigation, people who built complex trade networks between Island nations and most importantly people who believed in freedom of mobility. These people saw Oceania as vast and interconnected ${ }^{6}$. That history is in the blood of all Oceanic people?

The exploratory nature of Oceania's sea-faring peoples continues today into new paths of migration. Engrained in generations of explorers the need for travel brought many Oceanic people into new urban centers, New Zealand is one of these ${ }^{8}$. Here the networks expand establishing new relationships and important to this research a continuation of the evolution of their indigenous art forms in a new context. Hau'ofa and a number of Oceanic scholars argue for Oceania not to be seen through the belittling eyes of colonialism but recognise it as the intrinsic connector

\footnotetext{
""Our Sea of Islands," 153.

${ }^{5}$ Ibid.

${ }^{6}$ Ibid., 154-55.

${ }^{7}$ lbid., 156.

8 Ibid., 155.
} 
of both past and present ${ }^{9}$. Hau'ofa posits Oceania to be "a more holistic perspective in which things are seen in the totality of their relationships. ${ }^{10}$

This research is centered on assisting in the definition of a framework that is recognisable as Oceanic creative practice by its connections and relationships to Oceania. "For a new Oceania to take hold it must have a solid dimension of commonality that we can perceive with our senses...artists must work with others, for creativity lies in all fields ${ }^{\prime \prime 1}$. This research will illustrate the importance of making connections and nurturing relationships as central to the framework of Oceanic creative practice. "Oceania is vast, Oceania is expanding, Oceania is hospitable and generous, Oceania is humanity rising from the depths of brine and regions of fire deeper still, Oceania is us. ${ }^{12}$

Important to this research is some appreciation of the motivations behind the instigation of this thesis. My own cultural identity is traced back to two places, Fiji and Europe. I was raised in a bi-cultural household by my European grandfather and Fijian Bubu (the Fijian word for grandmother). Oceania resonates most strongly for me within Fijian culture but it would be misleading to place myself in a singular place of origin. The scene of my upbringing took place in a colonial style house in the South Island of New Zealand. Every room adorned with Fijian cultural elements

\footnotetext{
${ }^{9}$ Ibid.; Albert Wendt, "Towards a New Oceania," Mana Review: A South Pacific Journal of Language and Literature 1, no. 1 (1976); Hufanga Okusitino Mahina, "Ta, Va, and Moana: Temporality, Spatiality, and Indigeneity," Pacific Studies 33, no. 2 (2010); T Teaiwa, "What Remains to Be Seen: Reclaiming the Visual Roots of Pacific Literature," Pmla-publications of The Modern Language Association of America 125, no. 3 (2010).

${ }^{10} \mathrm{Hau}$ 'ofa, "Our Sea of Islands," 152-53.

${ }^{11}$ Epeli Hau'ofa, "The Ocean in Us," Voyaging Through the Contemporary Pacific, Lanham, MD: Rowman and Littlefield (2000): 56.

${ }^{12}$ Hau'ofa, "Our Sea of Islands," 160.
} 
and the garden quizzically features an unfertile banana tree. Being raised in a multicultural environment taught me to embrace and see the value in all types of cultural diversity and love my own mixed culture that makes up my identity. European culture and Fijian culture are both equally respected and celebrated within my household.

An ever-growing interest in creative practice, led me to Victoria University School of Design, majoring in Culture+ Context. Under the broad umbrella of the Culture+ Context program I undertook Pacific Studies as a minor where Oceanic nations were investigated. Perhaps stemming from my multifaceted cultural identity, this approach helped me to engage both my interest in Design and the cultures of the Pacific. I began connecting by learning about socio-cultural, geographical, economic, and historical issues relevant to indigenous Oceanic experience with design early in my undergraduate degree. In the final 100 level Pacific Studies assessment the students have an opportunity to respond to the material in an Akamai project through either performance or an art based item ${ }^{13}$. Choosing to collage, my work responded to and reinterpreted symbols on a tapa that was given to my Bubu on her wedding day. This was a pivotal moment as it the first time during my university experience that I engaged Oceanic symbolism and narrative in my creative work. Having not previously considered Pacific Studies and design together in my design projects the Akamai project ignited an interest in the use of traditional and contemporary Oceanic aesthetics and symbols in creative works.

\footnotetext{
${ }^{13}$ Akamai meaning smart/cleaver/intelligent is where students of PASI101 'The Pacific Heritage' present critical and creative interpretations of readings, theories and concepts explored through this course.
} 
This Masters thesis contributes to a developing passion and my on-going interest for understanding the motivations and ways in which Oceanic creative practitioners in New Zealand and beyond have, and continue to work with Oceanic aesthetics and ideologies in their respective practices. This research aims to contribute towards forming a framework of inclusive and holistic practices that establishes a recognisable body of work as Oceanic creative practice.

One way New Zealand born Oceanic people are maintaining a connection to their homelands is through contemporary expressions of Oceanic art. Oceanic art historian Karen Stevenson describes the emergence of Pacific Art as a creative movement towards reconnecting with identity and Oceanic places ${ }^{14}$. What we see in the early part of the twenty first century is a growing interest in Oceanic art and artists. My aspiration is to encourage Oceanic creative practice to encompass more than the practice of Fine Art. My vision for Oceanic creative practice is that it unites all creative people expressing their Oceanic-ness within creative practice. By reinterpreting traditional visual culture into contemporary expressions, creative practitioners continue to identify the commonalities between their creative works, establishing $v \bar{a}$ as vital to the connection. This research represents the beginning of a conversation for Oceanic creative practice and how we might think about bringing together all creative expressions under an umbrella of unified ideologies and discourse without hindering the diverse ways that these understandings can be explored creatively. What is currently considered as traditional visual culture encompasses many different types of creative practices. These practices are unified

\footnotetext{
${ }^{14}$ Karen Stevenson, The Frangipani Is Dead: Contemporary Pacific Art in New Zealand, 19852000(Wellington, N.Z: Huia, 2008).
} 
because of the indigenous interconnected understanding from which they grew. Although a more complex and somewhat colonial context exists that incorporates western ideologies with indigenous Oceanic ideologies, ideas of unity, collective approaches and interconnectedness can still exist when working in Oceanic creative practice in New Zealand. By engaging in the elucidatory discussion this research encourages, Oceanic creative practice can continue to establish these vital connections and relationships. As a result this research will not only discuss visual spatial strategies from an indigenous perspective, but it will also seek to uncover similar applicable Eurocentric understandings. Through the evaluation of each individual strategy, this research aims to identify correlations that weave together these connections and relationships to be held at the heart of Oceanic creative practice.

\section{Chapter outlines:}

Chapter one (Migration): This first chapter will establish New Zealand as the context from which this research has stemmed and outline three definitive points of connection. To clarify the motivation for this research I will identify and interpret seminal texts and relevant discourse surrounding the constructs of: ocean ideology, the visual history of Polynesia and indigenous spatial strategies of place and space. This chapter will also discuss discourse that has been critical to my research trajectory and the posing of my research question. 
Chapter one establishes Oceania and its people as closely connected on various platforms through emigrational history. The visual culture of Oceania embodies these connections as physical expressions and representations of place and space and space and time. Chapter two looks more closely at formulating relationships and connections through the indigenous spatial strategy vā. Arguing that $v \bar{a}$ is the essence of all relationships ensuring all connections are nurtured and protected.

Chapter two (Vā): Chapter two will focus on explaining the relevance of spatial strategies to Oceanic creative practice. This chapter will begin with a definition of $v \bar{a}$ offered by Oceanic academic Albert Wendt. Furthering this definition of $v \bar{a}$, other academics will be identified that further explain $v \bar{a}$ in relation to the Samoan understanding of teu le vā (to look after/care for/nurture relationships) and Tongan understandings of vā tapuia (sacred relationships), as indigenous spatial strategies that establish and nurture relationships within vā. Having established an understanding of $v \bar{a}$ this chapter will move on to discuss two theoretical constructs, the Tongan theory of reality, $t \bar{a}-v \bar{a}$ (time-space) and the more Eurocentric theory of articulation. Particular authors of importance at this point are Stuart Hall and his research on articulation theory and Okusitino Māhina and his research on the $t \bar{a}-v \bar{a}$ theory of reality. $V \bar{a}$ adds dimension, depth and a tensile quality to the understanding of connections, while articulation offers a valuable way of understanding a topic through the dissemination of different ideas respondent to time. 
Having established the relevance of $v \bar{a}$ the next chapter focuses more directly on core principles that can be directly engaged with in Oceanic creative practice. Chapter three will also introduce other European models of artistic education to substantiate $v \bar{a}$ as a relevant model in modern aesthetic education, in New Zealand.

Chapter three (Creative Constructs): This chapter will introduce Frederich Froebel's (1782-1852) methodology in kindergarten education and highlight three twentieth century European creative practitioners that were educated under Froebel's revolutionary kindergarten system. The purpose to this discussion is to highlight the shared understanding of unity within $v \bar{a}$, Froebel, Bauhaus educators, Johannes Itten and Lazslo Moholy-Nagy, and Richard Buckminster-Fuller. This dialogue establishes an interconnection between the creative approaches of both Oceania and contemporary, more Eurocentric methods. In doing so establishing a symbiotic and fluid relationship that is culturally inclusive, and respective of diversity.

\section{Chapter Four (Vā-ticulation:}

By bringing together $v \bar{a}, t \bar{a}-v \bar{a}$ and articulation within vā-ticulation, relationships are understood as tensile, fluid connections. This chapter has been named Vā-ticulation because I believe $v \bar{a}, t \bar{a}-v \bar{a}$ and articulation, when thought of together, substantiate the relevance that spatial strategies offer Oceanic creative practice. This chapter will also discuss the similarities in philosophies and approaches to creative practice 
between Froebel, Itten, Moholy-Nagy and Buckminster-Fuller and discuss how their ideologies strongly align with vā. By validating vā as a vital spatial strategy I will then establish $v \bar{a}$ as intrinsic to the development of a framework that will enable Oceanic creative practice to be identified. I will argue that by characterising a framework based on vā-ticulation, the authenticity of creative work as Oceanic can be substantiated and more fully appreciated as such.

Chapter five (Creative Oceanic Examples): Having established my argument for the interconnection of vā-ticulation and art as being at the heart of a framework that characterises Oceanic perspectives and methods of creative practice, this chapter will highlight how the principles embedded in vā-ticulation are translated into Oceanic creative practice. At this stage I will offer a woven structure as a metaphor to function as a framework, to outline the potential use in Oceanic creative practice. To further demonstrate how this research is currently being applied within Oceanic creative practice this chapter will also discuss some key practitioners and their work. The prospect of a woven framework characterised in this research is intended to serve as a platform for an on-going working definition for Oceanic creative practice in New Zealand and in other relevant Oceanic centers.

This research will end in the form of a manifesto for Oceanic creative practice.

Epilogue: Creative Oceanic Manifesto: The conclusion of this research will be an epilogue. Following on from the well-established tradition of establishing a 
definitive action through the writing of a manifesto, the epilogue will outline the beginnings of an Oceanic Creative Practice Manifesto that I will argue defines the core principles from which the framework of Oceanic Creative Practice can germinate. My reasoning behind presenting a manifesto at the end of this research is to provide a succinct synopsis that other researchers or creative practitioners can identify with and build from. 


\section{Chapter one (Migration)}

There are men and women killing one another in the Pacific now because Strangers stepped on Natives' beaches. We have to write our history of the Pacific as the history of Native and Stranger Bound Together because we are bound together by that past reaching into the present. [Sic] -Greg Dening

This chapter will use the beach as a metaphor to represent the marginal space between traditional and contemporary Oceanic creative practice in New Zealand. This chapter will establish connections between ocean ideology, Polynesian visual culture, and place and space, by analysing how each of these links contribute to the discourse of Oceanic creative practice in New Zealand. By referencing the ocean this chapter will introduce and evaluate two seminal texts that have been instrumental in highlighting the ocean as an intrinsic connector between all Oceanic nations. These seminal texts are the essays "Towards a new Oceania" by Albert Wendt and "Our sea of islands" by Epeli Hau'ofa ${ }^{15}$. Both authors are two of the most prolific visionaries in Pacific studies scholarship. This chapter also will introduce other relevant seminal texts and discourse that have been critical in inspiring this research trajectory.

To clarify the context from which ocean ideology has emanated and to understand the connections between the ocean, Polynesian visual culture and Oceanic creative practice in New Zealand, this chapter will present a brief history of the Lapita

Greg Dening, "Mr Bligh's Bad Language: Power, Passion and Theatre on the Bounty,"(Cambridge University Press, Cambridge, 1992), 178.

${ }^{15}$ Wendt, "Towards a New Oceania."; Hau'ofa, "Our Sea of Islands." 
people. Considered the sea-faring people of Oceania, the Lapita people are named after their most well known art form, Lapita pottery. The symbolism featured on some of the pottery renders it as part of the roots of visual culture in Polynesia. Through the discussion of cultural diffusion, this chapter will suggest how the spatial strategy of place and space has disseminated Oceanic symbolism into the New Zealand context. This explanation will aid in the understanding of the continuity between visual cultures seen in Polynesia and the contemporary creative expressions seen in New Zealand. Using David Gegeo's explanation of kula ni fuli and kula ni tua as an indigenous spatial strategy this research will identify connections within place and space and ratify their importance to formulating a framework for Oceanic creative practice in the New Zealand context.

Beaches are the representational space of in-between-ness. As described by Greg Dening in his book Mr Bligh's Bad Language, the beach "is a marginal space where neither otherness nor familiarity holds sway, where there is much invention and blending of old and new ${ }^{\prime 16}$. This description is the instigator from which I have approached my ideology for Creative Oceanic practice in New Zealand.

The production of creative work within the space of a beach is, I believe, the perfect space to begin the development of a framework for Oceanic creative practice. A marginal space I believe, is needed to build a partnership between traditional and contemporary creative notions in order to exist in harmony. I understand the beach as a marginal space, a space on the edge; in-between the intersections of space and

\footnotetext{
${ }^{16}$ Dening, "Mr Bligh's Bad Language: Power, Passion and Theatre on the Bounty," 179.
} 
place where a relationship between ever-changing contemporary creative expressions can advance Oceanic creative practice in New Zealand.

Where a researcher is based can change the view of the Oceanic region. For example New Zealand indigenous research often segregates indigenous people of Aotearoa and Oceanic people. This research project will consider New Zealand and Māori people as part of the Oceanic region. New Zealand is a hub of multiculturalism, and has a thriving Oceanic creative community as a result. The 1960's and 70's saw a peak in the migration of Oceanic people leaving their home islands and migrating to urban centers in New Zealand ${ }^{17}$. Oceanic people came in search of better jobs and hoped this would aid in a better future for their family. In New Zealand during this time of migration the country was experiencing a boom in the economy and a shift towards urban-based industrial production. Immigration laws were relaxed instigating the arrival of Pacific people into New Zealand in search of jobs and better opportunities ${ }^{18}$. Since the initial wave of migration to New Zealand and to other urban centers, the populations in Oceanic island nations have diminished greatly. Even to the point with some countries that more people now reside in New Zealand then in their home country ${ }^{19}$. These migrations have not come without loss of cultural knowledge. Often native languages are not carried

\footnotetext{
${ }^{17}$ Peggy Fairbairn-Dunlop and Gabrielle Sisifo Makisi, Making Our Place: Growing up Pi in New Zealand(Palmerston North, N.Z: Dunmore Press, 2003), 29.

${ }^{18}$ Ibid.

${ }^{19}$ Galumalemana Hunkin-Tuiletufuga, "Pasefika Languages and Pasefika Identities: Contemporary and Future Challenges," in Tangata O Te Moana Nui: The Evolving Identities of Pacific Peoples in Aotearoa /New Zealand, ed. Cluny Macpherson, Paul Spoonley, and Melani Anae(Palmerston North, N.Z: Dunmore Press, 2001), 198.
} 
through the generations of Oceanic people living in New Zealand ${ }^{20}$. With the loss of language comes loss of rituals and knowledge of traditional crafts.

The exposure that the average New Zealander has to the many cultures that exist on our land is an experience that should be recognised as a significant part of who we are as a nation. There should be a balance between maintaining connections to your indigenous roots and blending with other cultures around you ${ }^{21}$. The concern with the dispersal of so many indigenous people out of their homelands in Oceania is that the people will become too integrated into the urban culture of the societies they physically live in, rather than their indigenous culture. Finding ways of keeping awareness for the core values of Oceanic culture is a challenge presenting itself in many urban centers that house Oceanic people. Old practices understood by the elder generations are in many ways the holder of key values in each Oceanic culture. Finding ways to learn from the elder generations in the ways of their culture is essential to the preservation of core values. Moving forward with knowledge gained from elder generations is important to maintain connections with the past, especially in urban settings away from the homeland.

The migration of Pacific people out of their island homelands and into urban areas has resulted in Auckland housing the largest Pacific population in Oceania ${ }^{22}$. Paralleling the increasing number of Pacific migrants "the number of artists referencing a Pacific identity grew steadily between 1985 and 2000 " and continue to grow with the

\footnotetext{
${ }^{20}$ Ibid., 202.

${ }^{21}$ Stuart Hall, "Cultural Identity and Diaspora," Framework, no. 36 (1990): 225.

${ }^{22}$ Stevenson, The Frangipani Is Dead: Contemporary Pacific Art in New Zealand, 1985-2000, 22.
} 
increasing Oceanic population in New Zealand ${ }^{23}$. Migration is central to the way in which current Oceanic creative practice has developed ${ }^{24}$. New Zealand has become a space where a multitude of indigenous and contemporary notions are both living and growing. The population of Oceanic Islanders living in New Zealand is largely a Polynesian one; nearly half are of Samoan ancestry, with Cook Islanders and Tongans the next largest groups. ${ }^{25}$. As a result of having many Oceanic people connected to Polynesian origins in New Zealand, this research largely draws from the viewpoints, language, and academic sources of Polynesian authors.

\section{Ocean Ideology}

Two prolific academics in Pacific studies also align their thoughts with the ocean. Albert Wendt's essay "Towards a New Oceania" and Epeli Hau'ofa's essay "Our Sea of Islands" are recognised as two of the most commonly referenced writings in Pacific studies academia.

The ocean is the connector between all lands and such lands can therefore be viewed as a conjoined mass rather than separate entities. 'Our Sea of Islands' is perhaps the most influential writing to support this way to thinking. Hau'ofa asks the people of Oceania to challenge the "belittling view that has been unwittingly propagated, mostly by social scientists who have sincere concern for the welfare of Pacific peoples" and realise that their connection with Oceania does not end in the

\footnotetext{
${ }^{23}$ Ibid.

${ }^{24}$ Ibid.

25 "Statistics New Zealand 2013"
} 
confines of islands separated by the ocean ${ }^{26}$. He challenges his readers to look at Oceania beyond what can be seen on the surface, above the ocean. He wants attention to be brought to the land that is under the ocean ${ }^{27}$. If all Oceanic people adopt this view, suddenly Oceania is far broader than what it seems at first. There is a gulf of difference between viewing the Pacific as 'islands in a far sea' and as 'a sea of islands ${ }^{\prime 28}$. This point is central to Hau'ofa's argument and establishes the Ocean as an intrinsic connector, these connections between all of the islands are seen as fluid, strong and unified.

Albert Wendt's essay "Towards a New Oceania" written in 1976 has become a seminal text within the field of Pacific Studies. Wendt is well known for both his academic writing and his creative writing. "Towards a New Oceania" criticizes the problems that Wendt saw with how Oceania was being depicted through a western colonial view at the time the essay was published. His dissatisfaction expressed in this essay critiques two types of western discourse.

The first critique is of Oceania as imbued through a romanticized view imposed on the region by "Hollywood films, in the insanely romantic literature and art by outsiders about the Pacific, in the breathless sermons of our elite vampires and in the fevered imaginations of our self-styled romantic revolutionaries ${ }^{29}$. Wendt argues that literature and creative works should stimulate the imagination through

\footnotetext{
${ }^{26}$ Hau'ofa, "Our Sea of Islands," 159.

${ }^{27}$ Ibid., 155 .

${ }^{28}$ Ibid., 153 .

${ }^{29}$ Wendt, "Towards a New Oceania."
} 
a feeling of love within Oceania not from a romanticized lens situated outside the region looking $\mathrm{in}^{30}$.

The second critique is towards work done by anthropologists, sociologists and other academics working in the social science sphere within the region. Wendt asserts that "Oceania deserves more than an attempt at mundane fact; only the imagination in free flight can hope- if not to contain her- to grasp some of her shape, plumage and pain". ${ }^{31}$ This quote indicates Wendt's dissatisfaction with the state of research in and about Oceania stating that the scholarship at the time objectified Oceania and confined the region to a narrow view ${ }^{32}$. By believing that Oceania shouldn't embrace a western stereotyped savage or romanticized perception, Wendt argues Oceania should become a place where research doesn't just exist, it belongs ${ }^{33}$.

The underlying argument in this essay is that researchers should express a connection to Oceania that is stronger than observed fact. He argues that in Oceania, imagination should be allowed to grow and be expressed ${ }^{34}$. For Oceania to move beyond the rippling effects of colonialism Wendt argues that this must be a movement forward inspired by the past, but not an attempt to relocate back into

\footnotetext{
${ }^{30}$ Ibid., 82.

${ }^{31}$ Ibid., 71.

${ }^{32}$ Ibid.

33 Ibid., 75 .

${ }^{34}$ Ibid., 76 .
} 
what we consider traditional culture ${ }^{35}$. Traditional culture is hard to define because traditional is grounded in culture and culture is an ever-evolving living body ${ }^{36}$.

A key aspect to Wendt's essay is his advocacy for the engagement of the imagination and creative expression when working within Oceania. This key point offers an important connection to this research by acknowledging that to move past confining colonial influences and mentalities, creative practitioners in Oceania must see the past as creative inspiration to move into the future. At the very beginning of his essay Wendt states that Oceania feeds his imagination ${ }^{37}$. Through the inclusion of poems in his essay Wendt demonstrates a way in which creative practice can integrate into academic practice. By juxtaposing the poems into academic writing, Wendt reveals how each process is empowered by the other, strengthening the overall message of his piece.

Through stating that culture has and will always be ever evolving, Wendt argues that creative practice in Oceania is the embodiment and expression of Oceania's diversity and should be encouraged and celebrated. The diversity of Oceania's creative outputs ground the identity of the region and informs the statement that Oceania makes on a global scale. Oceanic creative practice should engage with and reflect culture in aesthetics resulting in a much more engaging and relevant surrounding that embodies and reflects the cultures of Oceania ${ }^{38}$. Wendt explains

\footnotetext{
$35 \mathrm{Ibid}$.

${ }^{36}$ Ibid., 75 .

37 Ibid., 71.

${ }^{38}$ Ibid., 81.
} 
that the diversity of cultures in Oceania should engage with creative practice ${ }^{39}$.

Oceania's rich heritage of creative repertoire including oratory, visual and performance practices demonstrates that artistic creativity is at the heart of Oceania and, in order to move past colonial influences, these practices must be reengaged within the present day. Wendt highlights many different artists that were engaging in Oceanic creative practice at the time and he advocates for the continuation of such work. He sees this artistic renaissance as being the key to achieving a genuine decolonization of Oceania ${ }^{40}$.

\section{Polynesia- A visual history}

In order to fully understand and appreciate Wendt's argument about creative expression it must first be understood that the indigenous knowledge within Oceania was first communicated orally and visually. In Teresia Teaiwa's essay "What Remains to Be Seen: Reclaiming the Visual Roots of Pacific Literature" the origins of the oral and visual customs in Oceania is discussed in detail ${ }^{41}$. Teaiwa argues that before colonialism the oral re-telling of myths, and the visual creation of Lapita pottery, tattooing and tapa making, constituted the literature in Oceania.

Understanding that Oceanic literature was originally a visual and oral form of communication helps to understand why visual cultural diffusion has been a prominent factor in the emergence of Oceanic art examples in the New Zealand art sector.

\footnotetext{
${ }^{39} \mathrm{lbid}$.

${ }^{40} \mathrm{lbid} ., 85$.

${ }^{41}$ Teaiwa, "What Remains to Be Seen: Reclaiming the Visual Roots of Pacific Literature."
} 


\section{Lapita pottery}

Lapita people are named after the most consistent artifact found by archeologists in Oceania, Lapita pottery. A group from the Lapita culture is believed to have migrated from the South East Asia region. By evaluating radiocarbon dates of Lapita pottery, archeologists Patrick V Kirch and Terry Hunt and Matthew Spriggs have placed the earliest sites spanning 3,500 years ago (Melanesian region) and the most recent 3,000 years ago (central Polynesian region) ${ }^{42}$. This timeline of migration converts to between 15 and 25 human generations. Much of the Lapita pottery has been found on or near the beach, leading to the conclusion that Lapita people were seafaring people and would have most likely navigated the region in canoes ${ }^{43}$. In order to understand the significance of place and how the diffusion of symbolism has progressed creative practice in Oceania, a history of migration will be presented.

The settlement of Oceania was a slow process that involved multiple migrations of people over many millennia. Earlier migrations peopled the continental high island of "near Oceania," such as New Guinea, some 40,000 years ago. A later stage of settlement of Oceania saw the arrival of the Lapita people, a cultural group that migrated further eastward during the second millennium B.C to eastern Melanesian islands and western Polynesia. Unlike earlier settlers, the Lapita people spoke a

\footnotetext{
${ }^{42}$ Patrick V Kirch, "Lapita and Its Aftermath: The Austronesian Settlement of Oceania," Transactions of the American philosophical society (1996): 61. Matthew Spriggs, "Dating Lapita: Another View," Lapita design, form and composition (1990). Patrick V Kirch and Terry L Hunt, "Radiocarbon Dates from the Mussau Islands and the Lapita Colonization of the Southwestern Pacific," Radiocarbon 30 , no. 2 (1988); "The Spatial and Temporal Boundaries of Lapita," Archaeology of the Lapita Cultural Complex: A critical review (1988).

${ }^{43}$ (Brown and Brunt, Art in Oceania, 51)
} 
language within the Austronesian language family ${ }^{44}$. Although Lapita people were not the first or only cultural group moving between Oceanic islands it is widely believed that certain groups of Lapita people are connected to the development of what we now consider to be Polynesian culture ${ }^{45}$.

The most prominent forms of physical evidence that support the belief that Lapita people resided in Polynesia are the deposits of Lapita pottery found in the southwest of Oceania. These sites were namely Tonga and Samoa in the Polynesian region, and Fiji, which is located between the Polynesian and Melanesian borders. Lapita pottery is a distinctive art form produced by Lapita peoples. The Lapita pottery series were vessel-type containers made from a clay and sand mixture and were hand-formed with the aid of paddle and anvil tools to help shape and sometimes carve into the vessels ${ }^{46}$. Dentate stamping and incised motifs were applied to particular shaped vessels, "most commonly being bowls, bowls with feet, flat bottomed dishes and carinated jars with flaring rims ${ }^{\prime 47}$. Other vessel shapes were left undecorated. The vessels were fired on an open fire most likely stoked using coconut shells to raise the fire temperature, resulting in a red brown colouring ${ }^{48}$. The pottery is decorated to varying degrees by dentate stamped symbols. Early fragments of Lapita pottery were the most intricately decorated,

\footnotetext{
${ }^{44}$ Patrick Vinton Kirch, The Lapita Peoples: Ancestors of the Oceanic World(Cambridge, Mass: Blackwell Publishers, 1997), 57.

$45 \mathrm{Ibid}$., 64. The history the involvement of Lapita culture in the development of Polynesian culture is extensively discussed by Patrick V. Kirch in his essay "Lapita and its aftermath: the Austronesian settlement of Oceania". Kirch has extensively published on the Lapita culture and pottery during his academic career and examines this material from an archeological perspective. Kirch, "Lapita and Its Aftermath: The Austronesian Settlement of Oceania."

${ }^{46}$ Kirch, The Lapita Peoples: Ancestors of the Oceanic World, 120.

${ }^{47} \mathrm{lbid}$.

${ }^{48}$ Ibid.
} 
while later examples of Lapita pottery displayed a more minimal expression of decoration ${ }^{49}$. In reference to research done by Jack Golson, Kirch reiterates the close symbolic relationships between Lapita potteries found in southwest Oceania, indicating what Golson has named a "community of culture" ${ }^{50}$. In continuity with Sidney Mead's discovery, Kirch discusses the motifs imprinted onto some of the Lapita vessels as all connected within the 'grammar of Lapita design'51. Mead identifies a series of basic design elements and motifs commonly found on decorated Lapita vessels, claiming that some symbols are more specific to particular Lapita settlements (see fig. $1 \& 2$ ) $^{52}$. Mead suggests that the creators of Lapita pottery followed a systematic creation process interlinked within a creative practice rubric ${ }^{53}$. As observed by Green, some basic motifs had inter-regional applicability but the rubric must have allowed for segregated Lapita communities to also develop their own local motifs as some motif patterns were only found on other vessels ${ }^{54}$.

\footnotetext{
${ }^{49}$ S. M. Mead et al., "Memoir No. 38. The Lapita Pottery Style of Fiji and Its Associations. Parts 3 \& 4 : Pages 44-98," The Journal of the Polynesian Society 82, no. 4 (1973): 62.

${ }^{50}$ Kirch, The Lapita Peoples: Ancestors of the Oceanic World, 130. The paper written by Jack Golson can be found here: Jack Golson, "Report on New Zealand, Western Polynesia, New Caledonia and Fiji," (1961): 176.

${ }^{51}$ Mead et al., "Memoir No. 38. The Lapita Pottery Style of Fiji and Its Associations. Parts 3 \& 4: Pages 44-98." The book referred to in this text was co-written by Sidney Mead, Lawrence Birks, Helen Birks and Elizabeth Shaw. The book focuses on three Lapita sites, two in Fiji (Yanuca and Natunuku) and Tonga. For a detailed description of the symbolism specific to these sites and a list of more generalised Lapita symbols see The Lapita pottery style of Fiji and its associations written by the above authors.

${ }^{22}$ Definition of motifs: "Motifs are more complex units created by some combination of one or more design elements according to a set of process rule. Motifs themselves then generally recur in repeated patterns across the surface of a vessel." Kirch, The Lapita Peoples: Ancestors of the Oceanic World, 126-27.

${ }^{53}$ Mead et al., "Memoir No. 38. The Lapita Pottery Style of Fiji and Its Associations. Parts 3 \& 4: Pages 44-98," 19.

${ }^{54}$ Roger Curtis Green, New Sites with Lapita Pottery: And Their Implications for an Understanding of the Settlement of the Western Pacific(University of Auckland, Department of Anthropology, 1978); Roger C Green, "Lapita," The prehistory of Polynesia 6o(1979).
} 
)

E1, 1

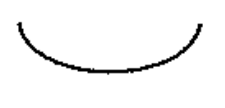

E1.2

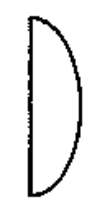

E1. 3

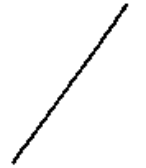

E5. 2

E6

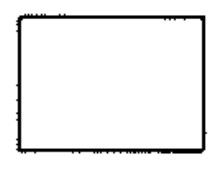

EIO

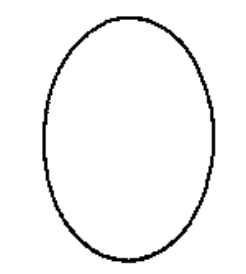

E21

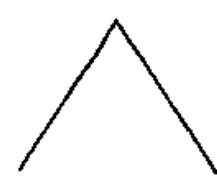

E7. 1

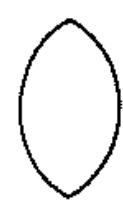

E4. 1

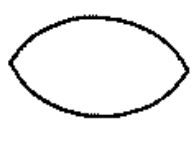

E4. 2

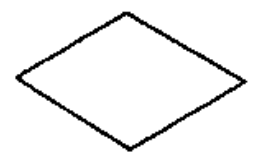

E9
E20

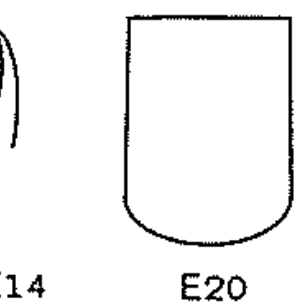

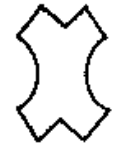

E12

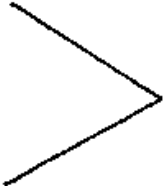

E7. 2

E8
)

E14

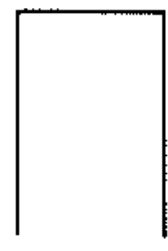

E22

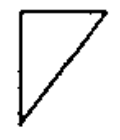

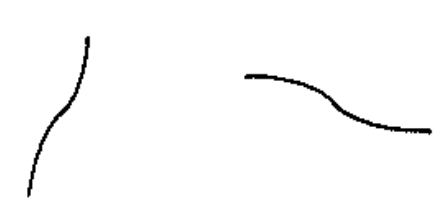

E24.1

E24. 2

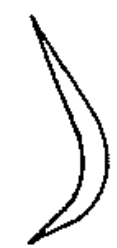

E25.1

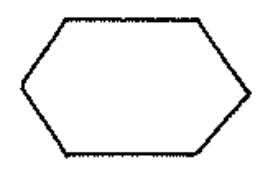

E13

Figure 5.2 Basic design elements from which the array of Lapita decorative motifs was constructed. (After Sharp 1988)

Figure 1: Lapita Symbols ${ }^{55}$

\footnotetext{
55 Patrick Kirch. The Lapita peoples: ancestors of the Oceanic world. (Cambridge: Blackwell Publishers), 1997, 127.
} 
Early, widespread Lapita motifs:

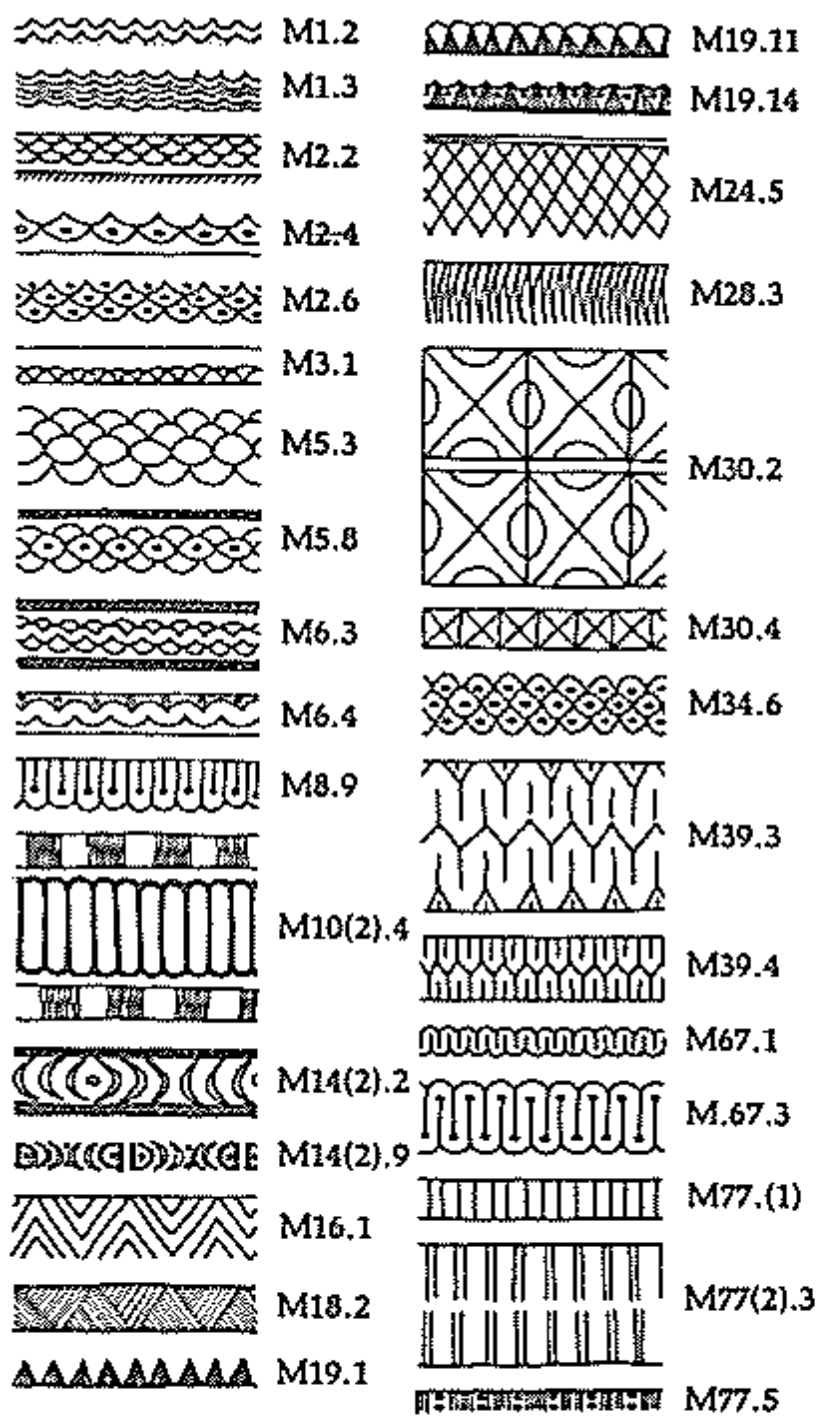

Western motifs:
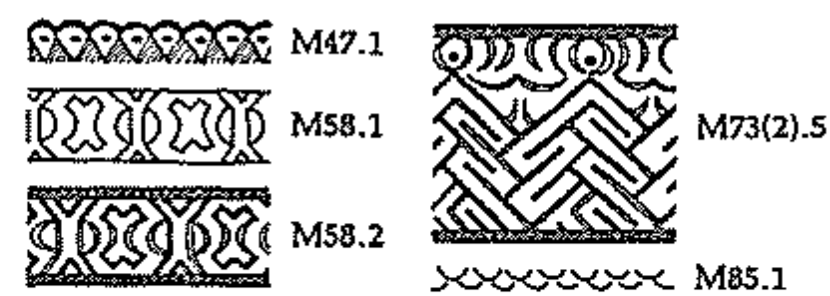

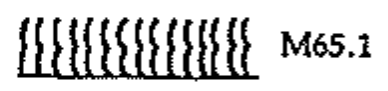

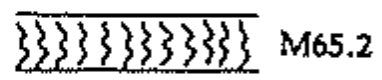

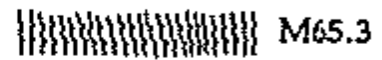

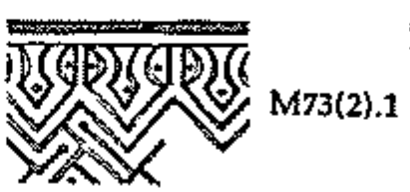

werewe M85.1

Non

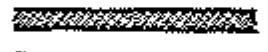

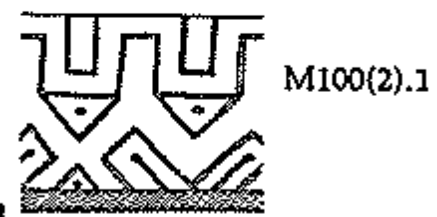

Figure 5.1 Selection of early, widespread Lapita motifs, and of certain motifs typical of the Western Lapita province. (After Green 1979a)

Figure 2: Lapita motifs ${ }^{56}$

${ }^{56}$ Patrick Kirch. The Lapita peoples: ancestors of the Oceanic world. (Cambridge: Blackwell Publishers), 1997, 125. 


\section{Lapita Symbolism}

The use of symbols and motifs did not end with Lapita pottery but has continued into many other art forms produced by Polynesian people. When examined as a collective, the symbol designs seen on Lapita pottery indicate a type of formal 'grammar'57. Having extensively researched Lapita pottery, Rodger Green purports "...the designs in tattooing and on bark cloth and the design motifs used in these media ethnographically still exhibited numerous parallels with those of the Lapita design system ${ }^{\prime 5^{8}}$. Kirch suggests that this artistic code was not only linked to the creation of Lapita pottery but also other art forms during this time such as tattooing. "There can be little doubt that the Lapita potters had a well-developed cognitive model of this design system, which they transmitted from one generation to the next: special linguistic terms for design elements and motifs were probably part of this emic artistic code ${ }^{\prime 29}$. Polynesian tattoo and tapa (bark cloth) are two common art forms that are both inherently based on symbolism very similar to those seen on Lapita pottery. This embedded approach to creative practice allows for a "continuous cultural transmission" of Lapita designs into the ever-evolving forms of creative expression in Oceania ${ }^{60}$. Oceanic creative practice has developed through migration and exchange networks, both of which are still operating and influencing creative practice today in New Zealand. For Lapita designs to be

\footnotetext{
${ }^{57}$ Kirch, The Lapita Peoples: Ancestors of the Oceanic World, 119.

${ }^{58}$ Roger C Green, "Lapita Design Analysis: The Mead System and Its Use; a Potted History," Lapita Design, Form and Composition (1990): 38.

${ }^{59}$ Kirch, The Lapita Peoples: Ancestors of the Oceanic World, 125.

${ }^{60}$ Ibid.
} 
reinterpreted in tattoo and tapa, and continue to be interpreted into contemporary

Oceanic creative practice, demonstrates that the grammar of Lapita designs have been established as a primary root of Oceanic creative practice.

1

2

4

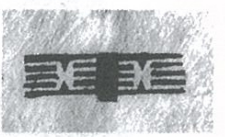

5

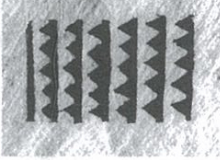

6

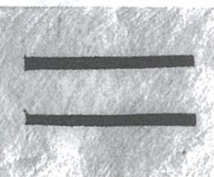

7

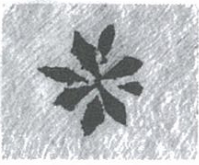

8

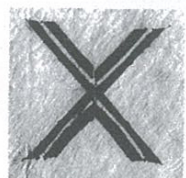

9

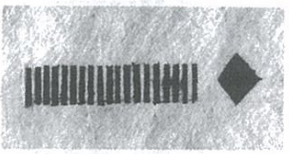

10

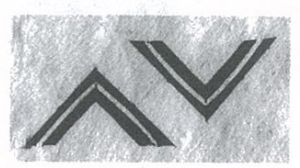

11

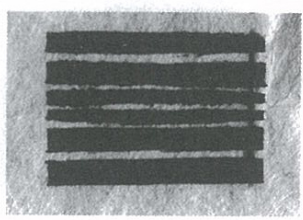

12

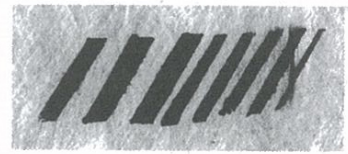

13

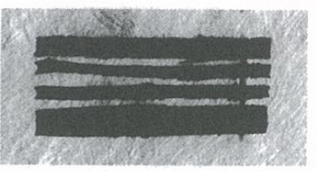

14

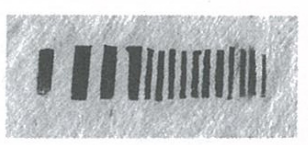

15

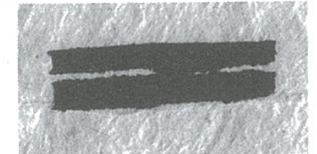

16

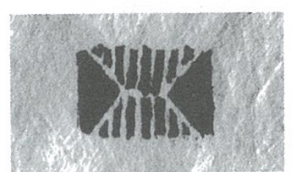

17

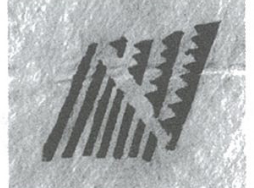

18

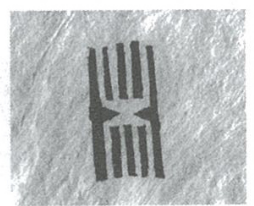

19

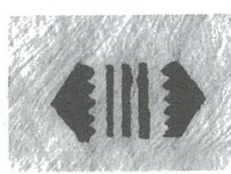

20

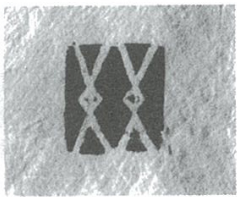

21

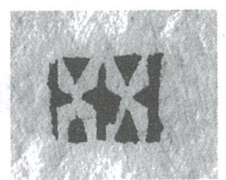

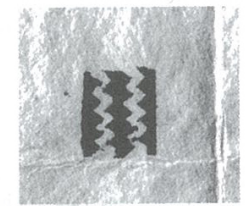

23

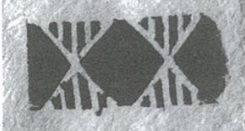

24

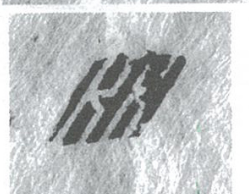

25

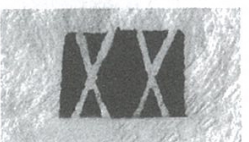

26

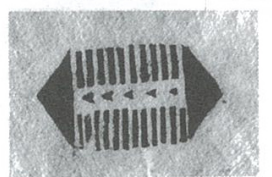

27

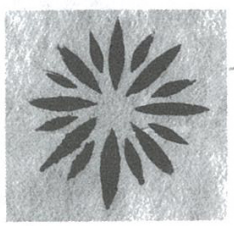

28

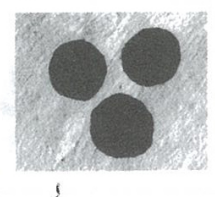

Figure 3: Draudrau motifs and terminology. N.D. vegetable dye on barkcloth ${ }^{61}$

\section{Cultural Diffusion}

To best understand the shift in this discussion, from the visual history of Lapita people into the discussion of place and space as a spatial strategy in the Pacific

\footnotetext{
${ }^{61}$ Catherine Spicer and Rondo B B Me, An Ancient Art in the New Millennium. Suva: Catherine Spicer and Rondo B B Me. 2004.103-4.
} 
diaspora living in New Zealand, cultural diffusion needs to be defined. Cultural diffusion is as defined by Michael Hann is "the process by which cultural traits, material objects, ideas, artistic styles, inventions, innovations or patterns of behavior are spread from one social geographic context to another." ${ }^{62}$

Cultural diffusion is a process that connects many different cultures on a global scale. This term is helpful when thinking of the evolution of Oceanic creative practice within the routes of migration that Oceanic people have taken throughout their history of existence. The combination of the collective migration of a group from the Lapita culture and the vast trade networks operating after the settlement of central Polynesia aids in the understanding of how cultural diffusion may have taken place within this context of space and time ${ }^{63}$. As discussed earlier in this chapter, the roots of Oceanic literature were grounded in visual and oral forms of communication. Visual cultural diffusion has been a prominent factor in the emergence of Oceanic art in the New Zealand creative sector. "Pacific artists were and still are innovating the past, reinterpreting icons for a new generation" ${ }^{64}$ In his essay "'Indigenous material culture, colonial arts and crafts and New Zealand Museums" Conal McCarthy presents a discussion of the emergence of Maori art. McCarthy explains that when Māori were confronted with a having to merge with a

\footnotetext{
${ }^{62}$ Michael Hann, Symbol, Pattern and Symmetry: The Cultural Significance of Structure(A\&C Black, 2013), 2.

${ }^{63} \mathrm{~A}$ group from the Lapita culture is believed to have migrated from the South East Asia region. By evaluating radiocarbon dates of Lapita pottery, archeologists Kirch and Hunt (1988a, \& 1988b) and Spriggs (1990) have placed the earliest sites spanning 3,500 years ago (Melanesian region) and the most recent 3,000 years ago (central Polynesian region) (Kirch, 1996, pp. 61). This timeline of migration converts to between 15 and 25 human generations.

${ }^{64}$ Stevenson, The Frangipani Is Dead: Contemporary Pacific Art in New Zealand, 1985-2000, 32.
} 
new European settler society in New Zealand, Māori collectively chose to participate in the emergence of the Māori art scene ${ }^{65}$. For the same reasons as discussed above, the participation of Māori artists in the practice of Māori art came about through the indigenous understanding of continuous cultural transmission. It is understood through Lapita design systems that indigenous symbols were not only connected to specific forms but could evolve with culture. Within this holistic space of understanding, relationships formed by visual symbolism are allowed to move, twist and grow in a sinuous way in order to remain balanced between space and time ${ }^{66}$. This understanding allowed Māori artists to merge their traditions with contemporary creative practice in a successful harmony between being rooted in tradition and also moving Māori culture forward in a considered way. As with other languages spoken in Oceania, Māori do not have a word for art as such, the closest word to describe the output of artistic production is taong $a^{67}$. What is considered taonga in Māori culture is translated through their indigenous ontological perspectives where everything is intrinsically connected.

\footnotetext{
${ }^{65}$ Conal McCarthy, "Indigenous Material Culture, Colonial Arts and Crafts and New Zealand Museums," in Craft, Community and the Material Culture of Place and Politics, 19th-2oth Century(Farnham, Surrey: Ashgate Publishing Limited, 2014), 63. ${ }^{66}$ Ibid.

${ }^{67}$ Taonga is the Māori word for treasure or anything prized - applied to anything considered to be of value including socially or culturally valuable objects, resources, phenomenon, ideas and techniques. John C Moorfield, "Te Aka Online Maori Dictionary," http://www.maoridictionary.co.nz/search?idiom $=\&$ phrase=\&proverb=\&loan=\&keywords=taonga\&se $\operatorname{arch}=$.
} 


\section{Kula ni fuli (place) and Kula ni tua (space)}

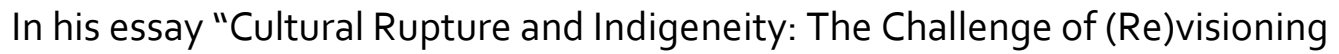
"Place" in the Pacific", Gegeo interprets the idea of belonging through his own native culture of Kwara'ae and Lau descent from the Malaitan region of the Solomon Islands ${ }^{68}$. In this essay he argues for the recognition of indigenous cultures in a contemporary setting. People of a bi-cultural or multi-cultural identity have ties to more than one place of origin, family is the strongest connection an individual has to a place. Family is a direct link to the enactment of culture, the experiences had within a family contributes to a living indigenous culture. A large part of indigenous culture relies on the connection you feel with the past, where you or your ancestors have come from ${ }^{69}$. There should be a balance between maintaining connections to your indigenous roots and blending with other cultures around you ${ }^{70}$. Gegeo believes in maintaining a connection with your own culture but also in being open to other cultures, letting this exposure enhance your own identity ${ }^{71}$.

Gegeo explains that, according to Kwara'ae epistemology, there are two interpretations of belonging: the first is 'kula ni fuli,' referring to a place in which you can claim has part of you always embedded in it, a place that you will always belong and will always be welcome $\mathrm{in}^{72}$. The second is 'kula ni tua,' meaning a place in

\footnotetext{
${ }^{68}$ D W Gegeo, "Cultural Rupture and Indigeneity: The Challenge of (Re)Visioning "Place" in the Pacific," The Contemporary Pacific 13, no. 2 (2001): 491.

${ }^{69}$ Hall, "Cultural Identity and Diaspora," 224.

70 Ibid., 227.

${ }^{71}$ Gegeo, "Cultural Rupture and Indigeneity: The Challenge of (Re)Visioning "Place" in the Pacific," 504.

${ }^{72}$ Ibid., 493.
} 
which you inhabit but which you only remain connected to while you are physically in that place ${ }^{73}$. 'Kula ni tua' is a temporary place and can be left to belong to another once you have left. For the Oceanic diaspora, their homeland is and will always be their 'kula ni fuli' however, New Zealand is what some Oceanic people would consider 'kula ni tua'. The part in which this becomes complicated is when New Zealand also becomes their 'kula ni fuli', which raises the question: is it possible for your identity to be embedded in two places at the same time?

Gegeo recognises that the situation of island people has moved into a more contemporary setting. With this progression, he argues that Oceanic culture should continue developing with modernity ${ }^{74}$. Although the physical movements of Oceanic people have not specifically changed, the mentality upon migrating to a new land appears to have been skewed ${ }^{75}$. The migration of indigenous people Gegeo perceives as a chance to advance their culture ${ }^{76}$. One should experience another culture's ways of life and take it as a chance to compare your culture with another whilst taking pieces of your experience and incorporating it into your own identity. As long as you consider your homeland as 'kula ni fuli' and you stay true to the roots of your identity, there is always room to grow and nurture culture. Culture is made to develop; we would never progress if culture stood still.

As a result of my research I support the dispersal of so many indigenous people out of island nations in Oceania. However the migration away from island homelands

\footnotetext{
73 Ibid., 494 .

${ }^{74}$ lbid., 502.

75 lbid., 501.

${ }^{76}$ Ibid.
} 
can lead to a feeling of disconnection. People may become too integrated into the foreign culture they now reside in. It is therefore paramount that awareness is kept for the core values of Oceanic culture, which is a challenge presenting itself in many urban centers that Oceanic people are domiciled in. Elder generations are responsible for upholding the transferal of cultural practices, which is critical if these practices are to continue into younger and future generations. The communication of knowledge from elder generations and involvement of younger generations is how core values should to be upheld in future Oceanic culture. Moving forward with knowledge gained from the elders, it is important to keep specific and definitive aspects of culture alive and relevant, in adopted lands.

\section{Indigenous knowledge and epistemology}

In other writing, Gegeo discusses the importance of development models that are embedded in indigenous knowledge in a third world context. More specifically Gegeo discusses the importance of indigenous epistemology in the future of rural developments in the West Kwara'ae villages in Malaita, Solomon Islands. Gegeo discusses the importance of indigenous epistemology and knowledge as contributing to the 'emancipating discourse of gwaumauri'anga ${ }^{177}$. Indigenous epistemology is considered to be "...a cultural group's ways of thinking and of creating and reformulating knowledge using traditional discourses and media of

\footnotetext{
77 "Indigenous Knowledge and Empowerment: Rural Development Examined from Within," The Contemporary Pacific 10, no. 2 (1998): 298. Gwaumauri'anga is a traditional Kwara'ae perspective that encompasses the essence of living a "good life" in Kwara'ae culture.
} 
communication (e.g. face-to-face interaction) and anchoring the truth of the discourse in culture ${ }^{\prime 78}$. Using this definition the importance of understanding how knowledge is formulated is critical for Oceanic creative practice. To successfully communicate how indigenous spatial strategies can connect and guide requires the understanding and engagement of indigenous epistemology. Epistemology sits above knowledge and becomes a space in which we theorize knowledge in a particular topic area. The process of theorizing knowledge ensures that the knowledge has stemmed from the beliefs of a collective group. Indigenous knowledge is therefore the common beliefs of a collective cultural group. Indigenous epistemology operates as an understanding of perspective, contextualizing a specific knowledge in a foundation that interconnects all knowledge systems. Creative practice is a physical embodiment of knowledge. Indigenous epistemology is helpful when engaging in indigenous knowledge, because it helps us understand why specific knowledge should be connected to present and future creative practice. Indigenous knowledge tells us how to go about a certain practice. Indigenous epistemology demands that we understand why a practice is relevant to a specific context, and allows us to sufficiently understand how indigenous knowledge can be integrated with new knowledge in order to instigate a positive change within the creative Oceanic community. Indigenous epistemology is an avenue to begin to disseminate integrated understandings embedded within knowledge to establish reasoning behind the future use of a particular knowledge in a new context.

\footnotetext{
${ }^{78}$ Ibid., 290.
} 
Gegeo further expands on this definition by stating that, "rural development discourse and practice must also include how a group theorizes about creating new knowledge $\mathrm{e}^{\prime 79}$. Elaborating on this statement, Gegeo suggests new knowledge is formed through the precedent of traditional knowledge and the incorporation of relevant new knowledge, often from a source outside of that culture ${ }^{80}$. New knowledge that has been selected and appropriated by the local community plays an integral role in the "future ways of knowing and understanding the reasons for particular views that will help with the world view of a community ${ }^{\prime \prime 21}$. The decision to integrate new knowledge into cultural understanding is a choice made solely by the community and not as a result of outside influence. This choice maintains awareness and contributes to the underlying philosophy of rural development from a Kwara'ae perspective.

Throughout his essay Gegeo argues that the appropriate rural development of Kwara'ae people lies within maintaining a holistic perspective driven by Kwara'ae perspectives rooted in indigenous epistemology and indigenous knowledge ${ }^{82}$. Although this argument is specifically linking indigenous epistemology and knowledge to the rural development of Kwara'ae people, these points can also be successfully applied to the development of other areas outside the rural region. The bases from which Gegeo defines indigenous knowledge integrates traditional knowledge and select new knowledge that is has been adopted by the local community. This is a space where all creative practices in Oceania concur with

\footnotetext{
79 Ibid.

${ }^{80}$ Ibid., 291.

${ }^{81}$ Ibid.

${ }^{82}$ Ibid.
} 
Gegeo's explanation of knowledge.

'Inasi

Important to this study is Charmaine 'llaiu, the author of "Inasi: Tonga's Reason For its Western Fale". The Tongan cultural understanding of 'inasi is a belief that looks to advance one's status in Tongan hierarchy by appropriating other cultures into their own culture ${ }^{83}$. The practice of 'inasi allows culture to advance in a direction that is dictated specifically by the people of that culture. Much can be learnt from the ideas taught by 'inasi. Instead of viewing modernism as condemning to tradition, they see it as an opportunity for the enhancement of Tongan culture ${ }^{84}$. The new tools and materials that were offered to Tongan people intrigued them, and they saw it as a chance to use the missionaries to teach them about new materials to make their houses stronger ${ }^{85}$. 'Ilaiu argues that because of Tongans' cultural knowledge of 'inasi, the interaction between Tongans and Western missionaries was more a relationship of exchange and learning from one another than it was about Western domination ${ }^{86}$. Through the cultural understanding of 'inasi Tongan people found a way to incorporate new ideas into their culture. Indigenous people appropriated western architecture into Tongan houses, consciously making informed decisions under moral cultural beliefs.

\footnotetext{
${ }^{83}$ Charmaine 'llaiu Talei, "'Inasi: Tonga's Reason for Its Western Fale" (paper presented at the Cultural Crossroads: 26th Society of Architectural Historians Australia New Zealand Conference, Auckland, 2-5 July 2009), 4.

${ }^{84}$ Ibid., 3 .

${ }^{85}$ Ibid., 5 .

${ }^{86}$ Ibid.
} 
Gegeo and 'llaiu both offer understandings of indigenous knowledge that invite 'new knowledge' into the evolution of indigenous knowledge. This way of understanding indigenous knowledge promotes the idea of culture being living and ever-evolving. For Oceanic creative practice, the concept of 'inasi aids an understanding of how practitioners can adequately contribute to the production of indigenous knowledge in the future. The key message both authors stress when introducing new knowledge is that the decision to integrate new knowledge into society is made by the society as a collective. The reason behind the decision stemming from a collective is to ensure that the new knowledge is positively helping a society to progress forward. This approach discussed by Gegeo and 'llaiu maintains a focus on Oceanic people's needs and maintains a strong tie to culture.

\section{Discussion: Conclusion}

This chapter has discussed and analysed three fundamental connections embedded in the understanding of how Oceanic creative practice has developed and been maintained in the New Zealand context. Ocean ideology as understood through the seminal texts of Wendt and Hau'ofa designates the Pacific region as Oceania. This notion centralizes the ocean to be the heart of the people of Oceania and negates the colonial naming of Oceania as the Pacific region as it is inherently embedded in segregating and disconnecting connotations. Pertaining to the beliefs held particularly by Hau'ofa, Oceania connects all island people as people of Oceania, a 
space that is vast, fluid and embedded in the living histories of Oceania as a region of mobile sea-faring people.

Also discussed earlier in this chapter was the ancestral history of Polynesian oceanic people, which are linked back to Lapita people. Lapita pottery and the symbolism depicted on some examples of the pottery establishes, through the slow migration of Lapita peoples throughout parts of Polynesia, these symbols as the roots of visual culture in Polynesia. Although motifs seen on Lapita pottery were often regional expressions, the research presented by Mead established that there was in fact an interconnecting code of grammar within the symbols seen in Lapita pottery. This visual code was likely carried through into other artistic forms such as tapa and tattoo.

To establish how an interconnected visual symbolism has continued not only in specific Oceanic cultures, but also into artistic work made by Oceanic people in New Zealand, this chapter discussed the interconnecting ideology of place and space. Gegeo through his two essays suggests that through the indigenous Kwara'ae knowledge system one can maintain two points of connection within their identity. These indigenous knowledge systems are kula ni fuli (place) and kula ni tua (space). This discussion aids the understanding of how Oceanic people can reside physically in New Zealand and yet maintain a strong connection back to their homeland. Both Gegeo and 'llaiu further this point by explaining that the evolvement of indigenous knowledge is carried through the understanding of indigenous epistemologies. Both authors explain that their culture's indigenous epistemology allows the formation of 
knowledge to eventuate through the adoption of new knowledge in order to enhance indigenous knowledge. By implicating ocean ideology, the visual history of Polynesia and the indigenous spatial strategy of place and space this chapter has explained the interconnection between all three topics and established how they all aid in the understanding of how connections, whether visual or embedded in understandings of indigenous knowledge, inform the basis of Oceanic creative practice in New Zealand. These explanations in turn begin to answer my overall research question: what indigenous visual spatial strategies subsist and remain relevant when devising a framework that characterises Oceanic perspectives and methods of creative practice? 


\section{Chapter 2: Vā}

"Herein, people are thought to walk forward into the past and walk backward into the future, both taking place in the present, where the past and the future are constantly mediated in the ever-transforming present"

Hūfanga Okusitino Māhina ${ }^{87}$

$V \bar{a}$, a Polynesian indigenous concept of space, the tā-vā theory of reality, and the theory of articulation are significant constructs important to the consideration of how connections are formed within Oceanic creative practice. This chapter specifically discusses how $v a \overline{~ i s ~ d e f i n e d ~ t h r o u g h ~ S a m o a n ~ a n d ~ T o n g a n ~ c u l t u r a l ~}$ understandings. $V \bar{a}$ is a spatial strategy that identifies and contextualizes the space in-between social relationships. For the purpose of this research I will understand $v \bar{a}$ as the binding force between two or more entities, this understanding includes all that is animate and/or inanimate ${ }^{88}$. Defined by Wendt, this assertion outlines an initial definition for $v \bar{a}$. This chapter will further elaborate the definition of $v \bar{a}$ by introducing and explaining tauhi vā (Tongan), teu le vā and vā tapuia (Samoan) as indigenous spatial concepts that further substantiate relationships within $v \bar{a}$. This study will describe and define both the $t \bar{a}-v \bar{a}$ theory of reality and articulation theory as theoretical constructs that build upon the meaning of $v \bar{a}$. The $t \bar{a}-v \bar{a}$ theory of reality as defined by Hūfanga 'Okusitino Māhina is based on the Moana (Oceanian) concept of $t \bar{a}$ and $v \bar{a}$. Furthering this exploration, this study will describe and depict the theory of articulation as a bringing together of relevant and relayed

\footnotetext{
${ }^{87}$ Hufanga Okusitino Mahina, "Ta, Va, and Moana: Temporality, Spatiality, and Indigeneity," Pacific Studies 33, no. 2 (2010): 170.

${ }^{88}$ Albert Wendt, "Tatauing the Post-Colonial Body," SPAN: Journal of the South Pacific Association for Commonwealth Literature and Language Studies 42-43(1996): 4.
} 
components to make a whole. This chapter aims to establish $v \bar{a}$ as an indigenous spatial strategy that establishes connections, and grows relationships within space. By highlighting $v \bar{a}$, the $t \bar{a}-v \bar{a}$ theory of reality and the theory of articulation, this chapter will substantiate that importance of connections within a framework for Oceanic creative practice.

Vā

To understand the scope of $v \bar{a}$ I will investigate how scholars articulate their understanding of $v \bar{a}$ in theory and practice. In his 1996 essay "Tatauing the PostColonial Body" Wendt offers a definition for vā that many other scholars have adopted.

"Vā is the space between, the inbetweenness, not empty space, not space that separates but space that relates, that VA holds separate entities and things together in the Unity-in-All, the space that is context, giving meaning to things." ${ }^{89}$

Wendt defines $v \bar{a}$ as the relative space between entities or things together in a unity. He explains vā as having a symbiotic connection to relationships, which nourishes these relationships as they grow and change over time ${ }^{90}$. What I see as crucial to the successful maintenance of $v \bar{a}$ is, first and foremost, recognizing the

\footnotetext{
89 "Afterword: Tatauing the Post-Colonial Body," Inside out: Literature, cultural politics, and identity in the new Pacific (1999): 402.

${ }^{90}$ Ibid.
} 
presence of connections between the self and everything around them. Once a connection has been recognised it can begin to grow stronger, evolve and participate in the order of other connections. In a New Zealand context or any other urban context, it is easy to get caught up in a global culture mentality where capitalism is the driving force of progression. Staying rooted in Oceania, which includes engaging with vā, ensures that the individual will be part of the collective and that this mentality will continue through the generations.

Pacific studies scholar Sa'iliemanu Lilomaiava-Doktor in her essay "Beyond "migration": Samoan population movement (Malaga) and the geography of social space (Vā)" analyses how vā subsists along migration paths of Oceanic people ${ }^{91}$. By referring to the second wave of Oceanic migration into urban centers, LilomaiavaDoktor examines the Samoan indigenous concepts of mobility (malaga), and space $(v \bar{a})$ as relative to place, distance and connectedness" ${ }^{\prime 22}$. Lilomaiava-Doktor argues for indigenous knowledge to be considered at the forefront of theoretical understandings when researching "scholarly dichotomies of village/metropolitan and local/global" in Oceania. Lilomaiava-Doktor argues for malaga and vā to be considered at the forefront of understanding the ontological and epistemological reasoning to how the Samoan diaspora understand migration, not as a dislocation or "severance of ties" but to show "migration as a culturally informed, historically grounded response to modernity and globalization"93. Indigenous understandings of movement within space encompasses malaga as a process undertaken to maintain

\footnotetext{
${ }^{91}$ Sa'iliemanu Lilomaiava-Doktor, "Beyond "Migration": Samoan Population Movement (Malaga) and the Geography of Social Space (Vā)," Contemporary Pacific 21, no. 1 (2009).

$9^{2}$ Ibid., 1.

${ }^{93} \mathrm{lbid}$.
} 
relationships, harmonizing $v \bar{a}$ and ensuring relationships are nurtured holistically by both parties. Lilomaiava-Doktor highlights that $v \bar{a}$ is a "highly complex phenomena" and features in many different Oceanic dialects. Tauhi vaha'a as explained by Konai Helu Thaman (a prolific Tongan academic in Pacific education) is seen as the "foundation for peace and intercultural understanding"94. Vā is the harmonic space between entities that balance relationships within and between Oceania ${ }^{95}$.

\section{Vā Tapuia}

Melani Anae researches the concept of native anthropology, her research focuses specifically on education for Pacific Islanders. Through her reference of Tuiatua Tupua Tamasese Efi's essay, "Su'esu'e manogi: In search of fragrance: Tui Atua Tupua Tamasese Ta'isi and the Samoan indigenous reference" Anae explains that $v \bar{a}$ upholds the sacred relationship between man and all things animate and inanimate ${ }^{96}$. Anae links herself to $v \bar{a}$, from the Samoan understanding, on two different levels. Vā tapuia "exists where a genealogical relationship can be traced, not necessarily through blood ties, but from relationships which have evolved through interactions between people and things in the vā tapuia thus generating "a sacred essence" a "life force" beyond human reckoning"97. Relationships, which

\footnotetext{
${ }^{94}$ Konai Helu Thaman, "Tauhi Vaha'a: A Possible Foundation for Peace and Intercultural Understanding," Intercultural Education (2004): 32.

${ }^{95}$ Lilomaiava-Doktor, "Beyond "Migration": Samoan Population Movement (Malaga) and the Geography of Social Space (Vā)," 13.

${ }^{96}$ Melani Anae, "Teu Le Va: Toward a Native Anthropology," Pacific studies 33, no. 2-3 (2010): 222. Reference for essay mentioned can be found here: Tui Atua Tupua Tamasese Efi, "Keynote Address: Bio-Ethics and the Samoan Indigenous Reference" (paper presented at the K. Mila-Schaaf (2008), Workshop Report. Regional Pacific Ethics of Knowledge Production Workshop, 2007).

${ }^{97}$ Anae, "Teu Le Va: Toward a Native Anthropology," 224. This quote takes reference from: Efi, "Keynote Address: Bio-Ethics and the Samoan Indigenous Reference," 3.
} 
evolve through interactions in the vā tapuia, create a scared connection between people in close relation ${ }^{98}$. This demonstrates that although $v \bar{a}$ tapauia primarily exists between genealogical links, these links don't necessary need to be through a blood relation. This interpretation opens vā tapuia to also include strong relationships that, through a commitment between two or more people or things, reflect the same commitment, care and nurture as a genealogical link requires. Therefore allowing vā tapuia to exist in other relationships that are not necessarily interconnected by kinship genealogy.

Efi discusses $v \bar{a}$ tapuia as a term that stems from the root word tapu (sacred) ${ }^{99} \cdot V \bar{a}$ tapuia also signifies the relationships that exist between human relations and the inanimate world. Samoan creation myths reference volcanic action as an essential part to the creation of the physical world. The reference to volcanic action as a source of creation therefore connects the mountains, earth, rock, and stone as having "a life and a soul...so even though they don't grow, they exist as a consequence of a life force that remains connected ${ }^{100}$. The western world has a tendency to understand the constructs of nature and culture as indelibly separate entities. The concept of a volcano being held at the center of creation emanates from the indigenous understanding that volcanic activity created the Islands of Oceania. This has now been substantiated and proven by scientific evaluations of

\footnotetext{
${ }^{98}$ Anae, "Teu Le Va: Toward a Native Anthropology," 224.

${ }^{99}$ Efi, "Keynote Address: Bio-Ethics and the Samoan Indigenous Reference," 116.

${ }^{100}$ Ibid., 118.
} 
islands in Oceania ${ }^{101}$. This understanding of creation interlinks volcanic activity with the formation of mountains, earth, rock and stone, all of which sustain the life of humans and other animate organisms. To sustain this argument Efi states, "the heat that comes from rubbing two stones together and from the flames of the fire that emerges to warm our bodies and cook our food links the inanimate with humans in a fundamental way: the one would not exist without the other" $[\mathrm{sic}]^{102}$.

These sacred spaces and taboo relationships, between the inanimate and animate as identified through vā tapuia, also outline behavioral boundaries that exist when one engages with a person or entity that is considered of higher social status than oneself ${ }^{103}$. "The respect or faaloalo that must be shown by people to all things is a respect for the sacred essence, the sacred origins, of their beginnings ${ }^{\prime 104}$. This statement describes that the relationship between "biological beginnings" between humans and "earlier creations" and denotes humans as a younger member within the genealogy of creation. Relaying humans as a younger generation within the genealogy of creation places humans in a cycle, constantly searching for wisdom; in Samoan this is called tofa sa'ili which translates to mean wisdom (tofa) and search $\left(s^{\prime}{ }^{\prime} i\right)^{105}$. Efi defines tofa sa'ili as "forever seeking to understand the human condition, our strengths and our weaknesses, and attempting to find balance and

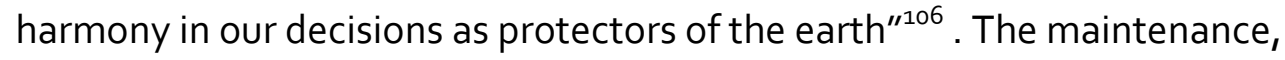

\footnotetext{
${ }^{101}$ Vincent E Neall and Steven A Trewick, "The Age and Origin of the Pacific Islands: A Geological Overview," Philosophical Transactions of the Royal Society B: Biological Sciences 363, no. 1508 (2008).

${ }^{102}$ Efi, "Keynote Address: Bio-Ethics and the Samoan Indigenous Reference," 118-19.

${ }^{103}$ Ibid., 116.

${ }^{104}$ Ibid.

${ }^{105}$ Ibid., 121.

${ }^{106}$ Ibid.
} 
preservation and harmonising of these scared relationships lies in the role of teu le $v \bar{a}$ and the collective understanding of how to teu le $v \bar{a}$.

\section{Teu le vā}

Teu le vā "incorporates fa'asamoa- the holistic framings of its associated institutions and concomitant values (see Anae 1998a)- as a way of knowing, of living and acting out of and within our multileveled social, cultural and political relationships ${ }^{107}$. In the realm of education and migration, the issue of Pacific research and more specifically, researching about the Pacific is commonly addressed. Teu le vā is considered of particular value in these disciplines, Anae explains "to teu le vā requires that one regards these (inter) actions as sacred in order to value, nurture and, if necessary, tidy up the vā" ${ }^{108}$. Anae furthers this description by saying "more often than not, it is complex, multi-layered and fraught with difficulties. But if all parties have the will, the spirit and the heart for what is at stake then positive outcomes will be achieved. ${ }^{109}$ This understanding of teu le vā offered by Anae allows the connections established through vā to be seen as sinuous type connections, similar to sinew and muscle on a body, these can morph and stretch giving movement to connection, before the connecting relationship breaks. Wendt defines teu le vā as the act of nurturing relationships explaining "'ia teu le $v \bar{a}$ ' is to

\footnotetext{
${ }^{107}$ Anae, "Teu Le Va: Toward a Native Anthropology," 225. "Fa'asamoa- In the manner of Samoans, the Samoan way; according to Samoan custom and tradition" For further explanation see: "Fofoa-IVao-'Ese: The Identity Journeys of Nz-Born Samoans" (ResearchSpace@ Auckland, 1998). ${ }^{108}$ "Teu Le Va: Toward a Native Anthropology," 224.

${ }^{109}$ Anae, M. (2010). Research for better Pacific schooling in New Zealand: Teu le va- a Samoan perspective. pp. 13
} 
Cherish/nurse/care for the $\overline{v a ̆}^{{ }^{110}}$. He outlines that this way of thinking as central to maintaining the unity of collective communities ${ }^{111}$.

The cognate term of teu le vā in Tongan is tauhi vā. Pacific studies scholar Tevita Ka'ili describes the social dimension of tauhi vā as the nurturing of the "sociospatial connection" between people ${ }^{112}$. The traditional understanding of Tongan genealogy "weaves together connections of kāinga (kin members) as well as fonva (land and its people $)^{\prime 113}$. Ka'ili demonstrates how tauhi vā operates in daily life by discussing how Tongan people formally introduce themselves when meeting for the first time. Tongan people will firstly state their name and continue on to outline their genealogy identifying names of both parents and grandparents ${ }^{114}$. The process of identifying their genealogy includes naming full names of each family member and the respective villages that each are tied to ${ }^{115}$. This formal introduction process is employed to reveal any socio-spatial connections between themselves and the other person. If this process reveals any kinship ties, these people are immediately interconnected. Enacting tauhi vā is now essential in order to maintain and care for the socio-spatial bonds that they have just discovered.

\footnotetext{
${ }^{110}$ Wendt, "Afterword: Tatauing the Post-Colonial Body."

${ }^{111}$ Ibid.

${ }^{112}$ Tevita O. Ka'ili, "Tauhi Va: Nurturing Tongan Sociospatial Ties in Maui and Beyond," The Contemporary Pacific 17, no. 1 (2005): 89.

${ }^{113}$ Ibid.

${ }^{114}$ Ibid., 91.

${ }^{115}$ Ibid.
} 


\section{Tā-Vā Theory of Reality}

Contemporary scholar Māhina a Tongan anthropologist, over many published articles, explains his $t \bar{a}-v \bar{a}$ (time-space) theory of reality. This research specifically focuses on his article titled "Ta, Va, and Moana: Temporality, spatiality, and indigeneity", an article that outwardly draws from and summarizes other previously published articles by Māhina that also discuss his tā-vā theory of reality ${ }^{116}$. Māhina's $t \bar{a}-v \bar{a}$ theory of reality will feature in discussions throughout this thesis; it is therefore pertinent that this chapter outlines a clear summation of his article. This initial discussion will review this particular article in detail to explain the indigenous Tongan concepts of tā (time) and $v \bar{a}$ (space) and how these concepts interconnect in the $t \bar{a}-v \bar{a}$ theory of reality.

Māhina argues that the $t \bar{a}-v \bar{a}$ theory of reality is applicable to all fields of study due to the generality and formality that informs the theory. For the purpose of summarizing this article I will explain how Māhina has described tāand $v \bar{a}$ as existent on a series of interconnected levels. Firstly, ontologically tā and $v \bar{a}$ are the common medium that brings everything into one single level of reality ${ }^{117}$. Epistemologically, he recognises that $t \bar{a}$ and $v \bar{a}$ are arranged in different ways around cultures; he specifically compares Moana and western interpretations of $t \bar{a}$

\footnotetext{
${ }^{116}$ Okusitino Mahina, "Ta, Va, and Moana: Temporality, Spatiality, and Indigeneity," 169. For a list of previous works by Māhina and other contributing scholars see reference and page number given. 117
} 
and $v \bar{a}$ to demonstrate this point ${ }^{118}$. The outcome of how tā and $v \bar{a}$ are interpreted epistemologically extends to "all things, in nature, mind and society" where everything within these spheres "stand in eternal relations of exchange", leading to either conflict or order ${ }^{119}$. He then goes on to say that order is a form of conflict and that $t \bar{a}$ and $v \bar{a}$ are abstract dimensions of fuo (form) and uho (content). Making both tā and $v \bar{a}$ and fuo and uho inseparable because they are "concrete dimensions of $t \bar{a}$ and $v \bar{a} . .$. indivisible in mind as in reality ${ }^{\prime 120}$.

Māhina uses his $t \bar{a}-v \bar{a}$ theory of reality to "critique the contradictory spatiotemporal, substantial-formal (and functional) relationships within and across anthropology as an academic discipline and culture as a human practice ${ }^{\prime 121}$. Early in his article Māhina establishes that the constructs of space and time as understood from a Moanan perspective in comparison to the West do not align when directly compared. Māhina states, "generally, in the Moana, time and space are culturally ordered and historically altered in plural, cultural, collectivistic, holistic and circular modes $^{\prime 122}$. This is a direct opposite understanding of time and space comprehended in the West, which Māhina claims are thought of as "singular, technoteleological, individualistic, atomistic and linear ${ }^{\prime 123}$. While this proclamation of how the West interprets and understands the constructs of space and time is valid and encompasses much of western mentality. it is key to note that this is also a

\footnotetext{
${ }^{118}$ Hufanga 'Okusitino Māhina, "Ta, Va, and Moana: Temporality, Spatiality, and Indigeneity," Pacific studies 33, no. 2-3 (2010): 169-70.

${ }^{119}$ Ibid., 169.

${ }^{120}$ Ibid.

${ }^{121}$ Ibid.

${ }^{122}$ Ibid., 170.

${ }^{123} \mathrm{Ibid}$.
} 
generalised statement that does not consider some western scholarship that does in fact clearly align with the understandings of time and space in the Moana. Examples of western scholarship that do align with time and space ideologies in the Moana, will be highlighted and discussed further into this research.

The relevance that this article has to my topic is through the understanding of the $t \bar{a}-v \bar{a}$ theory of reality being a symbiotic circular connector where past histories and experiences inform future directions. This is in contrast to the western ideology of space and time as a linear progressive system. Māhina claims that the western ideology of space and time segregates the past, present and future within a linear expansion. The West does not utilize time and space ideologies to process the value of interconnections between past and present and future experiences. Māhina advocates for a symbiotic understanding of time and space that the Moana presents, stating "herein, people are thought to walk forward into the past and walk backward into the future, both taking place in the present, where the past and the future are constantly mediated in the ever-transforming present ${ }^{124 "}$. For this reason the past will inevitably lead and the future will follow, explaining that the past must be used as guidance for how people situate themselves in the present and is to be used as a guide for the future. Māhina sees the past and the future as symmetrically negotiated, being complimentary to each other rather than singular and disengaged from each other.

\footnotetext{
${ }^{124}$ Ibid., 170.
} 
By critiquing the intercultural conflicts between the West and the Moana, Māhina argues that the singular and linear order of space and time in the West skews the organisation and production of education ${ }^{125}$. He argues that education should not be training students how to do but should be guiding students in how to be thinkers and doers ${ }^{126}$. He describes the structure of western education as having resulted in the Moana being consumer and not producer led ${ }^{127}$. For students to become producer-led thinkers and doers requires the teacher to embody the role of a mentor and build a symbiotic relationship with the students. In this situation the teacher is not imposing knowledge onto the student but rather guiding. By demonstrating the interconnection of all things as an embodiment of knowledge. The students can begin situating themselves within knowledge, forming their own connections in specific areas of interest, and developing a passion for what they are truly interested $\mathrm{in}^{128}$.

If we were to approach Oceanic creative practice through the ideals that the $t \bar{a}-v \bar{a}$ theory of reality presents then this will allow the Moana to begin to shift into the role of a producer led region, with people of the Moana being the producers. This argument is not unlike the advocacy made by Wendt and Hau'ofa for people of Oceania to take claim of their region and to develop a new Oceania led by indigenous voices embodying indigenous knowledge.

\footnotetext{
${ }^{125}$ Ibid., 171.

126 Ibid.

${ }^{127}$ Ibid.

${ }^{128}$ I will further elaborate on this approach to education in my discussion of Fredrick Froebel and kindergarten education in chapter 3 .
} 
A section in Māhina's article that relates to Oceanic creative practice is the section about art as genealogy of times and spaces. Art is used to articulate his critique on cultural and historical tensions in the literacy of genealogies, he states "in Tonga, at least in ancient times, most if not all, forms of social activity were classified under the three types of arts". Māhina defines the three types of art as being faiva (performance), tufunga (material) and nimamea'a (fine) $)^{129}$. He connects these terms to $t \bar{a}-v \bar{a}$ by explaining that the three terms for these types of art directly translate as: do-time in space (faiva), beat space (tufunga) and hand-marking-time-space $\left(\text { nimamea }^{\prime} a\right)^{130}$. It is clear from these translations that time and space $(t \bar{a}-v \bar{a})$ are strongly linked to the understanding of art in Tongan culture. The author views art as "a transformation of $t \bar{a}-v \bar{a}$ (time-space) where fuo-uho (form-content) is symmetrically mediated to produce potupotutatau (harmony). ${ }^{1131}$ Furthering this explanation of creative practices, Māhina states that "all forms of human activity were produced with both quality and utility" this understanding parallels Tongan artistic production "where both quality and utility were mutually, symbiotically in coexistence ${ }^{\prime 132}$. Just as there is good (vā lelei) and bad ( $v \bar{a}$ kovi) social relations within society, there can also be "good (mālie) and bad (palakū) works of art" ${ }^{133}$. This is dependent on the balance of extrinsic and intrinsic qualities held within the creative work. Māhina outlines the extrinsic qualities as "symmetry (tatau), harmony (potupotutatau) and beauty (mālie)" and the intrinsic qualities of "warmth

\footnotetext{
${ }^{129}$ Māhina, "Ta, Va, and Moana: Temporality, Spatiality, and Indigeneity," 185.

130 Ibid.

${ }^{131}$ Ibid., 184.

${ }^{132}$ Ibid., 185.

133 Ibid., 186.
} 
(māfana), fieriness (vela), and climaxed elation (tavēlangi) ${ }^{\prime 134}$. To achieve this outcome the art and artist must be focused on the importance of production, embodying the role of the thinker and doer. To be considered good, the creative work must balance all six terms. However, these terms don't just describe art but also embody the Tongan culture in all forms of human activity. Both Tongan culture and art must be enacted in a way that is beautiful and useful and as a result is harmonious.

${ }^{134}$ Ibid., 185. 


\section{Theory of Articulation}

The theory of articulation, a cultural studies approach to understanding phenomena, was developed from the work of Italian Marxist Antonio Gramsci (1891-1937). The theory of articulation is further substantiated by Stuart Hall (1932-2014) an influential Jamaican-born cultural studies scholar. Hall immigrated to England in 1951 to study at Oxford University ${ }^{135}$. Hall defines articulation, as "the form of the connection that can make a unity of two different elements...the so-called 'unity' of a discourse is really the articulation of different, distinct elements which can be rearticulated in different ways because they have no necessary 'belongingness ${ }^{\prime \prime \prime 136}$. Taking inspiration from works written by Stuart Hall, cultural studies academics Lawrence Grossberg, Jennifer Daryl Slack and others also discuss the theory of articulation as an organic approach, which aids in understanding that elements of ideology connect fluidly in between areas, changing according to certain contextual influences ${ }^{137}$. The development of scholarship around articulation is not limited to applications in cultural studies but can be used to help guide us on how to best understand structure in many other disciplines, including Oceanic creative

\footnotetext{
${ }^{135}$ For a full description on how Stuart Hall has contributed to the development of the theory of articulation see: J D Slack, "The Theory and Method of Articulation in Cultural Studies," in Stuart Hall: Critical Dialogues in Cultural Studies, ed. David \& Chen Morley, Kuan- Hsing(New York and London: Routledge, 1996), 121. The formation of a diasporic intellectual: An interview with Stuart Hall, "Chen, Kuan-Hsing," in Stuart Hall: Critical Dialogues in Cultural Studies, ed. Stuart Hall, David Morley, and Kuan-Hsing Chen(New York; London: Routledge, 1996), 489.

${ }^{136}$ Lawrence Grossberg, "On Postmodernism and Articulation: An Interview with Stuart Hall," ibid., 141.

${ }^{137}$ Ibid. Slack, "The Theory and Method of Articulation in Cultural Studies." James Procter, Stuart Hall(Routledge, 2004). For a comprehensive overview of how the theory of articulation informs critical dialogues in Cultural Studies see: Stuart Hall, David Morley, and Kuan-Hsing Chen, Stuart Hall: Critical Dialogues in Cultural Studies(New York; London: Routledge, 1996).
} 
practice $^{138}$. Articulation repels notions of reductionism and essentialism in the dissemination of ideas ${ }^{139}$. Articulation is understood as a process in which we take what appears to be a unified idea or understanding and break it down to the individual, the particular and/or the definable pieces.

Stuart Hall successfully uses a metaphor to illustrate articulation as a methodology. Hall portrays articulation as a lorry with articulated carriages ${ }^{140}$. As this research is based in a New Zealand context, I will describe Hall's articulated lorry as an articulated truck to more easily envision this metaphor. In this metaphor the truck's cab is the topic because it is the driver of all other elements connected behind it. All of the trailers that follow the truck cab therefore become the elements that are connected to the topic. The key success to the articulation metaphor is that each trailer has the ability to be unhooked, moved or taken away completely as the topic evolves in response to changes in context. The reference to a vehicle to describe articulation also indicates that all topics and the elements attached to it are moving as they develop and that there can also be an infinite number of trailers (elements) that can be attached to it. Articulation describes a free, ever-evolving state in which all elements move through, suggesting that the relationships between subject areas and elements remains ever fluid and at times quite dynamic.

\footnotetext{
${ }^{138}$ James Clifford, "Indigenous Articulations," The Contemporary Pacific 13, no. 2 (2001). Teresia Teaiwa, "Militarism, Tourism and the Native: Articulations in Oceania" (PhD, University of California, Santa Cruz, 2001).

${ }^{139}$ Grossberg, "On Postmodernism and Articulation: An Interview with Stuart Hall," 142.

140 Ibid., 141.
} 
By using the example of $20^{\text {th }}$ Century Western design history I have visually depicted how an idea of how ideology is understood through a linear dissemination (figure 3) and how the same idea is then disseminated through articulation theory, evolving it into an expanded construct (figure 4). It is key to note that the example shown in figure 2 only begins to describe the complexity of constructs disseminated in the theory of articulation. It does not define exactly what a disseminated articulated structure looks like but instead it depicts a moment within the evolution of ideas. Hall defines a complex structure as "a structure in which things are related, as much through their differences as through their similarities...It also means- since the combination is a structure (an articulated combination) and not a random association- that there will be structured relations between parts, i.e., relations of dominance and subordination ${ }^{141}$. This statement describes structures thought of within the theory of articulation not just as a dissemination of parts it but also explains that there are relationships that occupy the space in between parts are also articulated to substantiate order. The comprehension of articulation once applied to a topic is endless in the amount of possible connections that can be made to further develop this structure. This structure can also evolve and develop over time to hookon new carriages or unhook carriages that are no longer applicable to the topic.

\footnotetext{
${ }^{141}$ Stuart Hall, "Race, Articulation, and Societies Structured in Dominance," in Black British Cultural Studies: A Reader, ed. Houston A Baker Jr, Manthia Diawara, and Ruth H Lindeborg(University of Chicago Press, 1996), 38.
} 


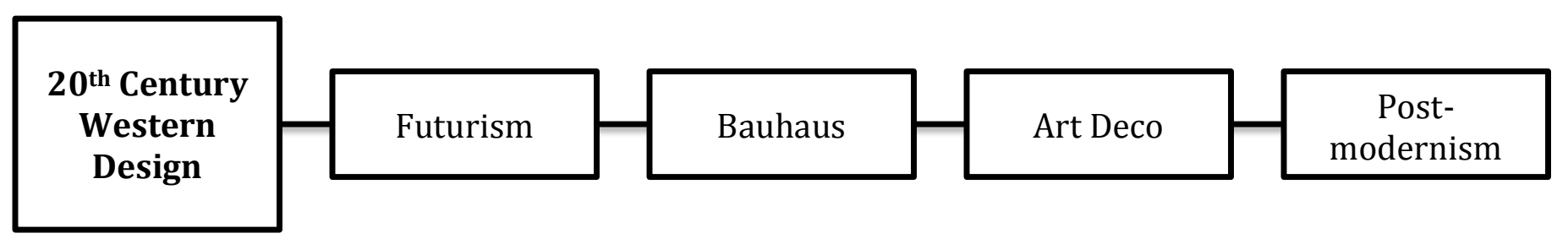

Figure 4: Simple Structure

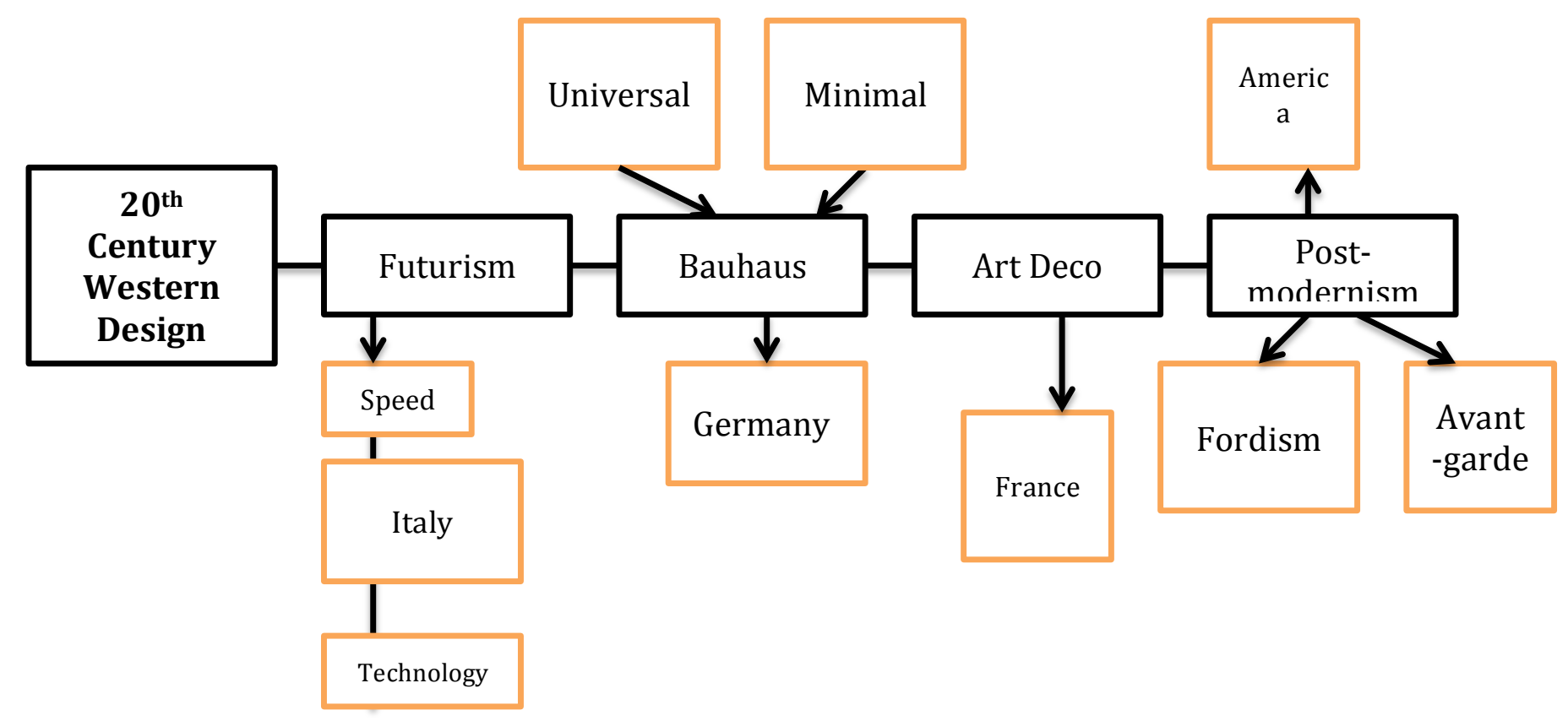

Figure 5: Complex Structure 
A key aspect to the use of articulation theory in relation to Oceanic creative practice is how this theory focuses on the process of identifying connections. Articulation theory is therefore not focused on the act of separating but rather the bringing together of relevant and relayed components to make a whole. In an interview conducted by Lawrence Grossberg, Hall states, "the theory of articulation asks how an ideology and inevitable thoughts which belong to it; it enables us to think how an ideology empowers people, enabling them to begin to make some sense or intelligibility of their historical situation ${ }^{14^{2}}$ This therefore eliminates any state of presumption that may otherwise occur in an essentialist or reductionist approach. Articulation theory emphasizes the importance of the continuous organic growth of ideology where all elements respond to space and time, never being anchored to a specific point indefinitely.

Articulation theory presented by cultural studies offers a cyclical view on the formation of ideology that is ever changing. Jennifer Daryl Slack, an American cultural studies academic, researches into communication, technology and the environment from a cultural studies approach. Her 1996 essay titled "The theory and method of articulation in cultural studies" furthers Hall's explanation of articulation, and describes articulation as a" deceptively simple concept...but when theory and method are understood...as developing in relation to changing epistemological positions, and political conditions as well as providing guidance for strategic intervention, it becomes impossible to parse out a neatly packaged theory

${ }^{142}$ Ibid. 
or clearly delineated method ${ }^{\prime 143}$ Furthering this statement Slack says that articulation is "a complex, unfinished phenomenon that has emerged and continues to emerge genealogically ${ }^{\prime \prime 14}$. In her essay Slack begins to describe the genealogy of the theory of articulation, clearly outlining the "ways in which the re-articulation of articulation" is held amidst theory, method, epistemology, politics and strategy ${ }^{145}$. The purpose of the discussion of articulation as understood in these constructs is to highlight the continued usefulness of theory when developing ideas in all areas of scholarship and beyond.

Teresia Teaiwa and James Clifford also reference the developments Hall has made within the theory of articulation in order to address issues from a Pacific studies standpoint. Both scholars explore the interdisciplinary quality of articulation theory through the eyes of the indigenous. Teaiwa uses articulation to navigate between three seemingly unrelated subject areas, demonstrating the abstract qualities of articulation as a method to move between political and economic structures and discourses related to militarism and tourism within Pacific Island sites ${ }^{146}$.

Clifford discusses nativism, "indigenism" and "diasporism", evaluating each paradigm through the lens of the theory of articulation, exploring through articulation "an emergent "Native Pacific Cultural Studies"'147. Before beginning his discussion of the usefulness of the theory of articulation to a Native Pacific Cultural

\footnotetext{
${ }^{143}$ Grossberg, "On Postmodernism and Articulation: An Interview with Stuart Hall," 142.

${ }^{144}$ Slack, "The Theory and Method of Articulation in Cultural Studies," 114.

145 Ibid., 126.

${ }^{146}$ Teaiwa, "Militarism, Tourism and the Native: Articulations in Oceania."

${ }^{147}$ Clifford, "Indigenous Articulations," 471-82.
} 
studies, Clifford states "to think of indigeneity as "articulated" is, above all, to recognise the diversity of cultures and histories that currently make claims under this banner ${ }^{148}$. Clifford advances Hall's metaphor of the articulated truck explaining, "an articulated ensemble is more like a political coalition or, in its ability to conjoin disparate elements, a cyborg ${ }^{\prime 149}$. By describing an articulated formation as a cyborg Clifford refutes the understanding of culture as a living body. Clifford explains that he is dissatisfied by the way culture is likened to a living body because it indicates that without "critical organs" such as "indigenous languages, traditional religions, or kinship arrangements" indigenous cultures wouldn't survive ${ }^{150}$. He aptly points out that within the Pacific diaspora, indigenous societies have endured and adapted to "conjoin with disparate elements" and thrive as a cultural cyborgs ${ }^{151}$.

The theory of articulation as conveyed by Hall situates articulation in an everchanging state of hooking and unhooking elements responding to contextual and historical changes. For the people of Oceania it can be successfully argued that culture is a living and ever changing cyborg, responding and adapting to contextual changes, but place is your homeland, which keeps you rooted in your culture. It is key to note that there have been extensive discussions surrounding the idea of place for the indigenous people of Oceania. As discussed in the previous chapter in an elaboration of work by Gegeo, the Kwara'ae concepts kula ni fuli ('the place in which I belong') and kula ni tua ('the space in which I inhabit') helps us to think around the connection to place of indigenous people, allowing one to be rooted in one specific

\footnotetext{
${ }^{148}$ Ibid., 478.

149 Ibid.

150 lbid.

${ }^{151}$ Ibid.
} 
space but also occupy other spaces for any amount of time ${ }^{152}$. Hau'ofa in his essay "Our sea of islands" also suggested that 'place' for Oceanic people can be thought of as not just embedded in land, but also in the connecting ocean ${ }^{153}$. Oceanic people are seafarers historically, so identifying place as the ocean allows us to think about place in a dynamic and moving way, similar to how Hall describes the operation of articulation theory being ever-changing and fluid.

${ }^{152}$ D W Gegeo, "Cultural Rupture and Indigeneity: The Challenge of (Re)Visioning "Place" in the Pacific," ibid.: 493-94.

${ }^{153}$ Epeli Hau'ofa, "Our Sea of Islands," ibid.6, no. 1 (1994): 153. 


\section{Chapter three (Creative Constructs):}

"If new ideas are to assume artistic form, physical, sensual, spiritual and intellectual forces and abilities must all be equally available and act in concert"

- Johannes Itten ${ }^{154}$

Introduction

By comparing traditional Pacific methods of teaching and learning with the more formalized and well-established techniques of aesthetic and creative education within European and colonial models of design pedagogy, this chapter will discuss commonalities that exist between these constructs. This chapter will establish the value $v \bar{a}$ has to aesthetic education and Oceanic creative practice. Focusing on the use of holistic and nature based ideologies to transfer knowledge, this research will investigate the ideals of eighteenth century educational reformist Friedrich Froebel (1782-1852). These ideals were later developed within the nineteenth century German design academy, the Bauhaus and reflected in philosophies conversed by American architect Richard Buckminster-Fuller. This chapter discusses how vā is currently imbued in the creative practices, beginning with a case study discussion about how a painted series by Lily Laita and the art of Tongan lalava (binding), imbues $v \bar{a}$. The discussion will then shift to assess the relevance of interstitiality as highlighted by Pacific studies scholar Graeme Whimp compared to $v \bar{a}$, when trying to describe a consortium for the Oceanic creative community in New Zealand. This chapter aims to highlight the shared aims and beliefs between Oceanic creative

\footnotetext{
${ }^{154}$ Johannes Itten, Design and Form: The Basic Course at the Bauhaus and Later(John Wiley \& Sons, 1975), 9.
} 
practice and a western-based model of modern design education that I posit enable reciprocity and respect. I will postulate that vā offers a space between Oceanic creative practice and modern design pedagogy to connect and thrive both as separate yet indelibly connected constructs.

\section{Western design education:}

The emergence of design as an academic discipline traces back to Europe, at the time of the industrial revolution ${ }^{155}$. The vast majority of modern design pedagogy reflects a working model embedded in western ideals. Although met with criticism by the Arts and Crafts movement, design production transformed to focus more intently on mass-production and the machine aesthetic, playing into the hands of economic gain ${ }^{156}$. The industrial revolution instigated a shift to the cheap and fast production of products, this therefore broadened the accessibility of design to a much larger portion of European society ${ }^{157}$. During this time there was a shift in class structure, European history saw the emergence of a new middle class ${ }^{158}$. The move away from hand-crafted to machine mass-manufacturing, caused further devaluation of artifacts hand-crafted by primitive cultures. Contrasting this discussion, this chapter will reveal three prolific characters that have each played a key role in the history of western design.

\footnotetext{
${ }^{155}$ Charles I Jones, "Was an Industrial Revolution Inevitable? Economic Growth over the Very Long Run," Advances in macroeconomics 1, no. 2 (2001): 32. ${ }^{156}$ lbid.

${ }^{157}$ Ruth Schwartz Cowan, "The" Industrial Revolution" in the Home: Household Technology and Social Change in the 2oth Century," Technology and Culture (1976): 2.

${ }^{158}$ Ralf Dahrendorf, Class and Class Conflict in Industrial Society(Stanford University Press, 1959), 6.
} 


\section{Froebel's Gifts}

At this stage it is prudent to draw attention to an alternative cultural source. This is the role of Froebel's gifts in kindergarten education. German pedagogue Friedrich Froebel instigated the revolution of aesthetic education in both Europe and America known as Froebel's gifts. Soon after the death of Froebel in 1830 came the immergence of the Arts and Crafts era led by Augustus Pugin (1812-1852), writer John Ruskin (1819-1900) and later William Morris $(1834-1896)^{159}$. Honesty in materials, an emphasis on craft and a clear connection with nature were all principles embedded in the Arts and Crafts era in European history ${ }^{160}$. The modernism era in the 1930 's, which saw the birth of the Bauhaus a school that aligned closely with the ideals of the Arts and Crafts movement. This research will not discuss the details of the Arts and Crafts movement but it should be noted that this movement is a pivotal moment in western design history and the culmination of the Bauhaus ${ }^{161}$.

"Froebel's philosophy embraced a Christian pantheism, one that assumed that all things in nature (animal, vegetable, and mineral) are connected. Thus Froebel was concerned with showing the interrelationships between living and inanimate things." ${ }^{162}$ This quote by Eugene Provenzo Jr., an American academic whose research focuses on education, explains the philosophy of Frobel's spiritual grounding which evidently was reflected in his gifts. Froebel's gifts built an

\footnotetext{
${ }^{159}$ Oscar Lovell Triggs, The Arts \& Crafts Movement(Parkstone International, 2014), 7.

160 Ibid., 13.

${ }^{161}$ Magdalena Droste, Bauhaus, 1919-1933(Berlin: Taschen, 2002), 10.

${ }^{162}$ Eugene F Provenzo Jr, "Friedrich Froebel's Gifts: Connecting the Spiritual and the Aesthetic to the Real World of Play and Learning," American Journal of Play 2, no. 1 (2009): 87.
} 
understanding of visual complexity by using simple geometric forms such as spheres, cubes and cylinders through to more complex crystal like patterns and formations. The gifts were intended to promote three essential groups known as the three realms: nature (life), forms of knowledge (science), and forms of beauty $(a r t)^{163}$. Froebel published written documentation about seven of the gifts. In total there are said to be twenty "gifts", beginning initially with gifts and progressing into occupations ${ }^{164}$. The difference between a gift and an occupation is that a gift can be returned back to its original form. For the purpose of this research I will follow Norman Brostermann's example in his book Inventing Kindergarten and refer to all twenty of Froebel's educational items as the gifts ${ }^{165}$.

The simplicity of the gifts, presented in a minimalist aesthetic was an essential element to Froebel's philosophy, as simplicity allowed for diverse interpretations from children. Froebel's aim behind developing his gifts was to encourage children to explore, to find an answer to a problem and interpret information in their own way rather than let their thinking be streamlined and solely directed by the teacher $^{166}$.

\footnotetext{
${ }^{163}$ N Brosterman, Inventing Kindergarten(New York: Harry N. Abrams Inc, 1997), 37.

${ }^{164}$ Provenzo Jr, "Friedrich Froebel's Gifts: Connecting the Spiritual and the Aesthetic to the Real World of Play and Learning," 87.

${ }^{165}$ Brosterman, Inventing Kindergarten, 35.

${ }^{166}$ Provenzo Jr, "Friedrich Froebel's Gifts: Connecting the Spiritual and the Aesthetic to the Real World of Play and Learning," 97.
} 
At the time, this shift in thinking was a radical change in western education.

Previous to this, the teacher was considered the leader in group education, not the supporter for each child's individual educational journey ${ }^{167}$. The foundation of kindergarten lived within the three realms of nature, knowledge and beauty and encouraged the children to understand these realms from a holistic perspective. Here each realm was respected and regarded of equal importance.

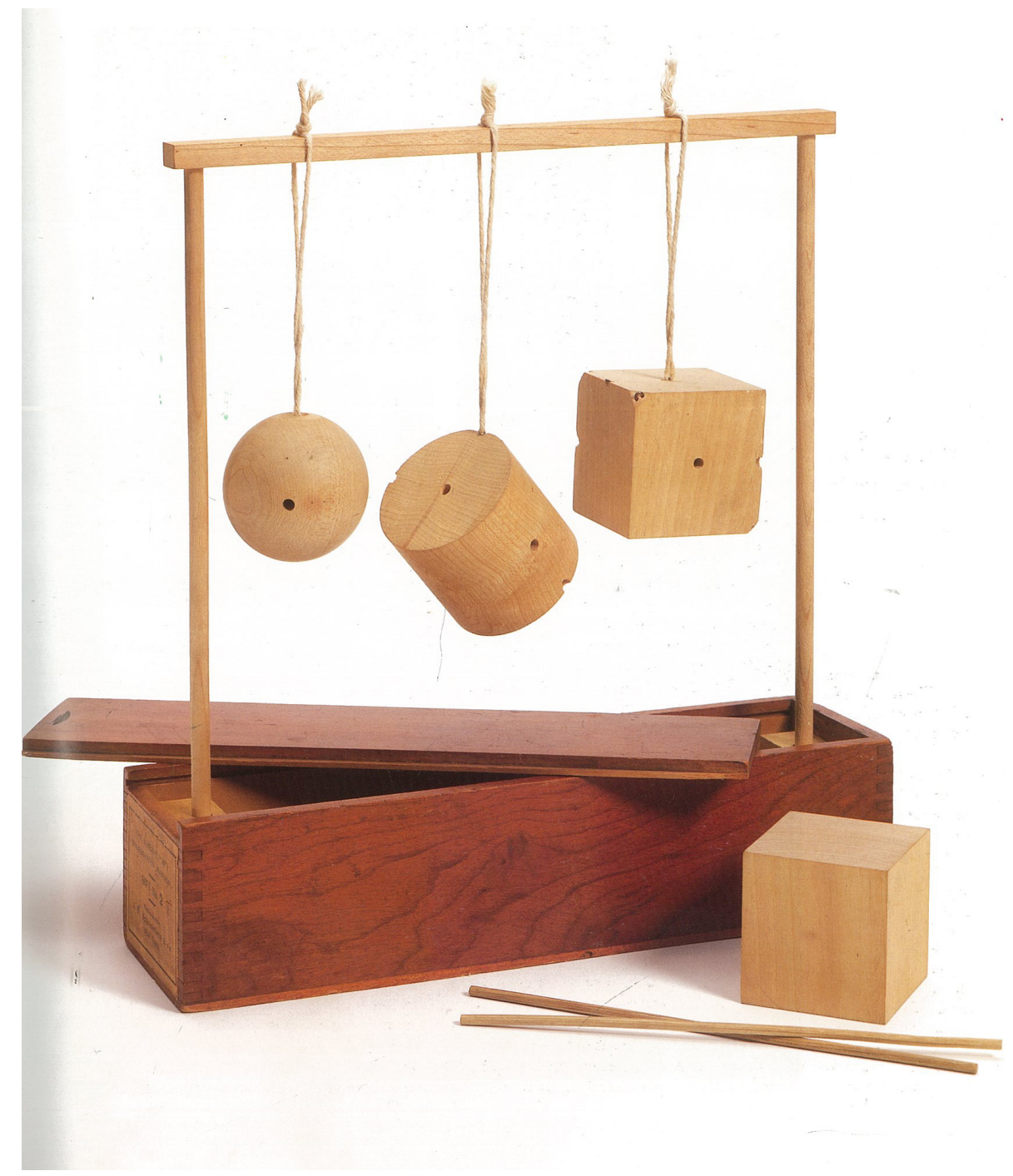

Figure 6: Froebel's second gift ${ }^{168}$

\footnotetext{
${ }^{167}$ Brosterman, Inventing Kindergarten.

${ }^{168}$ Norman Brosterman, Inventing Kindergarten.(New York: Harry N. Abrams, 1997), 47
} 
Perhaps one of the most interesting gift to highlight for the purpose of this research is the second gift. Show in figure 1 the gift displayed three wooden three-

dimensional shapes, a sphere and cube and cylinder all hanging from a frame. The educational purpose of this gift is to demonstrate that "seemingly opposite and opposed things can be synthesized or combined together through dialectic process to create a new unity ${ }^{\prime 169}$. Froebel's underlying message, conveyed through all of his gifts, was to highlight the dialectic process of creating a new unity ${ }^{170}$. The second gift is a visualization of this philosophy through displaying the simple visual relationship between the cube and the sphere in the form of the cylinder, which was strategically placed between the cube and sphere. The cylinder becomes the physical demonstration on how two shapes with completely opposite aesthetic qualities can come together to create a successful a new unity in the form a cylinder. Upon further interaction with this gift it was often demonstrated by the teacher, that by simply drilling a hole through the center of the cylinder and inserting a rod in the hole, the cylinder could be spun on its axis giving the illusion of a cube. The same process could be done with the cube giving the illusion of a sphere. This simple demonstration allowed the children to see and understand the process of creating a unity between seemingly unconnected parts ${ }^{171}$.

\footnotetext{
${ }^{169}$ E Provenzo Jr, "Friedrich Froebel's Gifts: Connecting the Spiritual and the Aesthetic to the Real World of Play and Learning," American Journal of Play 2, no. 1 (2009): 90.

${ }^{170}$ This idea draws a close similarity to a philosophy believed in by Wilhelm Friedrich Hegel (17701831), a German Romantic era philosopher. Hegel's philosophy was widely circulated in German academia around the time of Froebel and so it is speculated by Provenzo that Froebel potentially took inspiration from Hegel.

${ }^{171}$ Provenzo Jr, "Friedrich Froebel's Gifts: Connecting the Spiritual and the Aesthetic to the Real World of Play and Learning."
} 
The most relevance Froebel's gifts have to this research is the way in which Frobel translated such abstract ideas of interconnection in the natural world, into educational tools easily comprehendible by young children. The integration of Froebel's kindergarten philosophy, seen through his gifts, embodied unity and built a connection between the children and nature ${ }^{172}$.

Froebel's gifts moved in succession from the simple, to the complex in form and aesthetic understanding "from solid, to plane, to line, to point, and then reversed to arrive back in three dimensions with activities in 'peas-work' and modeling clay" ${ }^{173}$. The craftsmanship seen in many Pacific Island artifacts deal with the same aesthetic values as Froebel's gifts, while also promoting an interconnected relationship to nature. Key examples already discussed in the research is the dentate stamping seen on Lapita pottery, which is also clay in materiality, and the many symbols imprinted on tapa and tattoo seen throughout the region of Oceania. An upcoming discussion on the art of Tongan lalava (lashing) also presents a strong interrelation with the materials and processes embodied in Froebel's gifts. Each practice specifically dealing with and interpreting solid, plane, line and point in their aesthetics to express an indigenous narrative within each artifact. Just as vā is about the connections between people and things, Froebel also believed in interconnection and unity and sought to encourage the cultivation of these principles from an early age taught through visual making methods.

\footnotetext{
${ }^{172}$ Brosterman, Inventing Kindergarten, 22.

173 Ibid., 36.
} 
The gifts have a clear aesthetic connection to nature. The relationship between the parts and forms seen in nature is abstractly conveyed, but once understood, the visual connections are strong. Building an understanding between the children and nature was an essential outcome that Froebel promoted in his curriculum ${ }^{174}$. To strengthen the children's connections to the physical world a garden was integrated into the kindergarten schoolyard. From day one the children were encouraged to involve themselves in the life of the garden ${ }^{175}$. Each of the children was taught how to care for different plants, the purpose of this practice was for the children to observe the growth of a life. Through the observation of the cyclical nature of the natural world the children could come to understand the participatory role every plant, animal and human had to the art of living ${ }^{176}$. The children were responsible for caring for and nurturing the plants, and as a result instilled a responsibility of caring and nurturing relationships between people too. This approach taught the children the interconnectedness of all things and the inherent reliance separate entities have on nurturing other supportive connections.

\section{Bauhaus Masters}

The Bauhaus is described as the "most famous experiment in art education of the modern era." ${ }^{177}$ Many of the Bauhaus teachings continue to be central within the modernist design educational approaches still delivered within Western (and many

\footnotetext{
174 Ibid., 22.

175 lbid., 32

${ }^{176}$ Ibid., 32

${ }^{177}$ Marcel Franciscono, "Walter Gropius and the Creation of the Bauhaus in Weimar: The Ideals and Artistic Theories of Its Founding Years," (1971): 843.
} 
non-Western) aesthetic programmes ${ }^{178}$. Two highly influential design Bauhaus educators grew from Froebel's kindergarten, these being Johannes Itten (18881967) and Lazlo Moholy-Nagy (1895-1946). Both educators greatly contributed to the makings and future interpretations of modern aesthetic pedagogy in the present day ${ }^{179}$. Itten and Moholy-Nagy were both Bauhaus teachers who lead the preliminary course at the school. Itten was the first director of the Bauhaus first year programme, Moholy-Nagy replaced Itten as the head teacher of the preliminary course upon Itten's resignation in $1923^{180}$. Although both Itten and Moholy-Nagy approached teaching from different artistic backgrounds both teachers believed in similar design principles. As a result the fundamental design principles that framed the preliminary course did not shift much between the change in teachers.

\section{Johannes Itten}

Johannes Itten began his studies in art at Stuggart in 1913 "under Adolph Hözel, a leading German color theorist and educator" $[\mathrm{sic}]^{181}$. Before progressing to his role in the Bauhaus, Itten pursued his career as an artist and educator and eventually opened a private art school in Vienna in $1916^{182}$. Similar to the kindergarten philosophy derived by Froebel, Itten detested a hierarchical approach to teaching where students were expected to copy aesthetic styles of prominent artists guided by teachers that stuck strictly to a rigid syllabus. Itten instead sought to encourage 
the individual growth in students and guide them in their organic path through learning. Itten did not believe the teacher should embody the role of the absolute example to their students. This approach he believed resulted in the students becoming copies of their teacher and not developing into their own identity ${ }^{183}$. In his role as the head teacher in the Bauhaus preliminary course, Itten chose instead to provide a first year experience that fostered creativity and imagination. Itten states "if new ideas are to assume artistic form, physical, sensual, spiritual and intellectual forces and abilities must all be equally available and act in concert"184.

Figure 7: Bauhaus Preliminary Syllabus $1923^{185}$

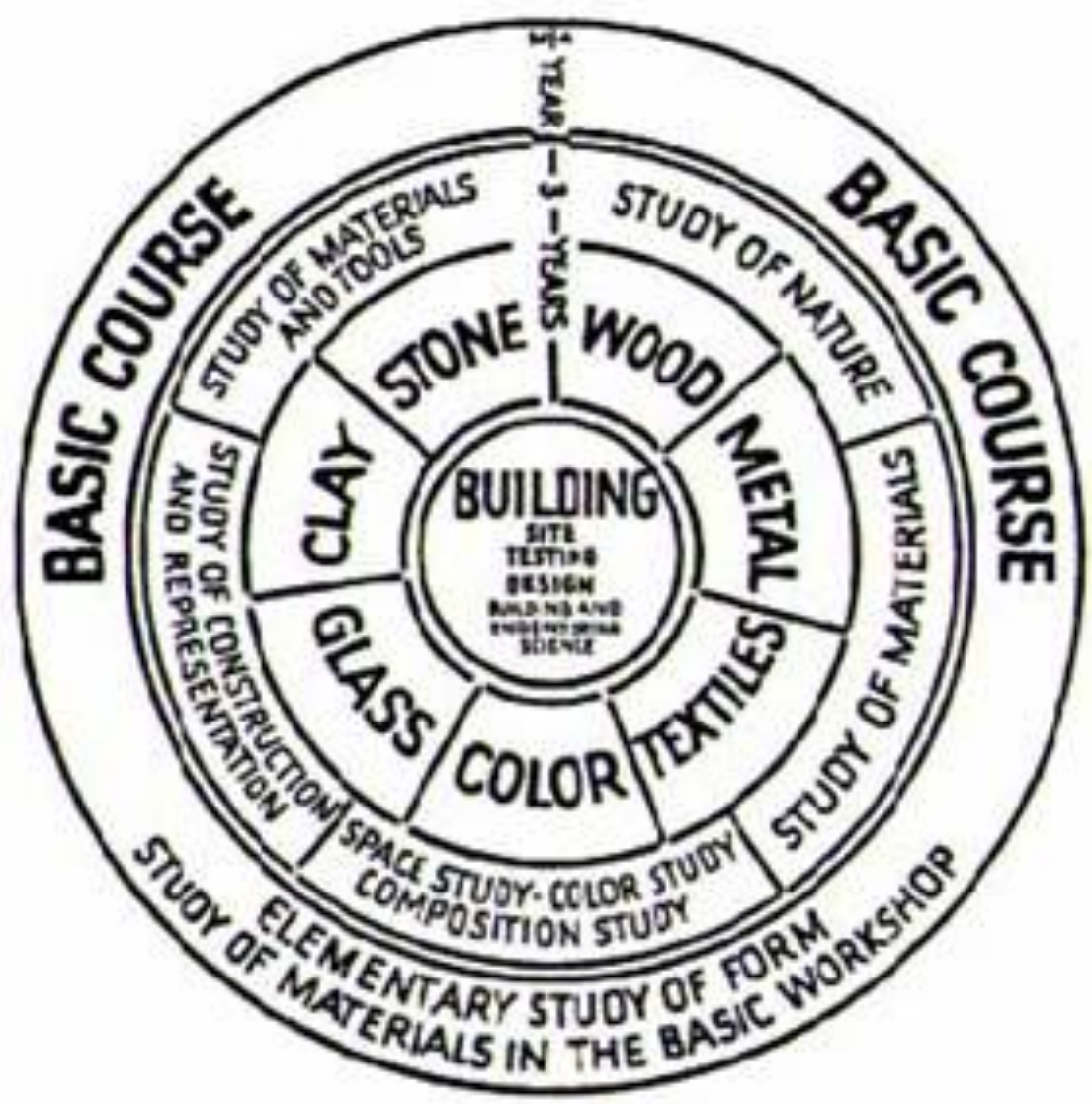

\footnotetext{
${ }^{183} \mathrm{lbid}$.

${ }^{184}$ Ibid., 9.

${ }^{185}$ Johannes Itten, Design and Form: The Basic Course at the Bauhaus and Later. (Ravensburger:Wiley \& Sons inc), 1975,8
} 
Figure 1. visualises the Bauhaus syllabus in 1923, Itten purposefully began all courses offered by the Bauhaus with all students enrolled in a 'basic course'. It was not until the students had been exposed to a universal creative experience that they were allowed to progress into their desired specialized areas ${ }^{186}$. As a result of this perspective held by Itten, the preliminary course at the Bauhaus focused on expanding the growth of creativity and imagination through the engagement of the senses and opening up the students to a plethora of sources of creative inspiration ${ }^{187}$. The goal behind the structure of the program was to expose students to all creative disciplines in the hope that after exploring and dabbling in many different creative areas, each student would choose a creative path that most suited their own interests and not follow the style of their teacher.

These ideas closely align with the approach Froebel demonstrated through the ordering of his gifts; first beginning with conveying the inter-connection of all things and finally progressing to dealing with very specific material and form creation processes. Although Itten didn't directly use or reference Froebel's gifts in his teaching methods at the Bauhaus, the correlation between two the developments of aesthetic education is strong.

\footnotetext{
${ }^{186}$ Itten, Design and Form: The Basic Course at the Bauhaus and Later, 7.

${ }^{187}$ Ibid., 8.
} 


\section{Laszlo Moholy-Nagy}

Laszlo Moholy-Nagy as previously stated took the position of director of the preliminary course at the Bauhaus upon Itten's resignation in $1923^{188}$. Moholy-Nagy kept this position until 1925 , he was also the head of the metal workshop in the Bauhaus until eventually leaving in 1928 to establish his own studio in Berlin ${ }^{189} .1937$ saw Moholy-Nagy move to America for a new position as the director of the New Bauhaus, an institution now known as the Illinois Institute of Technology ${ }^{190}$. While Moholy-Nagy wasn't as focused on the sensory element in his teaching style, his pedagogical philosophies and beliefs in creative practice still stemmed from the same roots as Johannes Itten. Moholy-Nagy believed in a holistic, broad view approach to artistic practice and firmly believed that the artist could influence people into new ways of seeing.

Further into his career, as director of the New Bauhaus in America Moholy-Nagy further developed his thoughts around the role and potential of an artist. Similar to Okusitino Māhina, Moholy-Nagy became increasingly interested in the nature of time-space relationships. ${ }^{191}$ In his book Vision in Motion he states:

"Heading toward a kinetic, time-spatial existence; toward an awareness of the forces plus their relationships which define all life and of which we had

\footnotetext{
${ }^{188}$ Bauhaus-Online, "Laszlo Moholy-Nagy," http://bauhaus-online.de/en/atlas/personen/laszlomoholy-nagy.

${ }^{189}$ Ibid.

${ }^{190}$ Ibid.

${ }^{191}$ For more information on Laszlo Moholy-Nagy's thoughts and work around time and space refer to Time and Space in the work of Laszlo Moholy-Nagy a journal article written by Dianna Kirkpatrick.
} 
no previous knowledge and for which we have as yet no exact terminology...Space-time stands for many things: relativity of motion and its measurement, integration, simultaneous grasp of the inside and outside, revelation of the structure instead of the façade. It also stands for a new vision concerning materials, energies, tensions and their social implications $^{192}$

This statement is not dissimilar to Albert Wendt's definition of $v \bar{a}$ that "holds separate entities and things together in the Unity-in-All, the space that is context, giving meaning to things ${ }^{\prime 193}$. This quote also relates strongly to the $t \bar{a}-v \bar{a}$ list of tenets put forward by Māhina being; "All things are on a single level of reality...ta-vā are socially arranged in different cultures...nature mind and society stand in eternal relations of exchange...order is in itself an expression of conflict...fuo (form) and uho (content), which are, in turn concrete dimensions of ta and vā...fuo and uho are indivisible ${ }^{194}$. Although said differently, the three authors are describing a unity in all things where relationships fill the perceivably blank space of disconnection between all things.

Also in line with ideas of the theory of articulation, as discussed in the previous chapter, Moholy-Nagy interpreted understanding as "seeing, feeling and thinking in relationship and not as a series of isolated phenomena" ${ }^{195}$. Moholy-Nagy aptly titled his book vision in motion to resonate with his ideas of understanding all phenomena

\footnotetext{
${ }^{192}$ László Moholy-Nagy, Vision in Motion(P. Theobald, 1969), 268.

${ }^{193}$ Wendt, "Afterword: Tatauing the Post-Colonial Body," 402.

${ }^{194}$ Māhina, "Ta, Va, and Moana: Temporality, Spatiality, and Indigeneity," 169.

${ }^{195}$ Moholy-Nagy, Vision in Motion, 1-2.
} 
in a constantly changing, moving environment where creative practitioners have the potential to begin to understand a "genuine space system, a dictionary for space relationships ${ }^{196}$. The starting point he believed was developing our 'vision in motion', Moholy-Nagy successfully agues this by stating "How rarely does one actually see in sharp focus! There is an interplay of advancing and receding forms in every movement. One of them is always 'out of focus'"197

These thoughts presented through quotes written by Moholy-Nagy demonstrate a powerful interplay between his own philosophical grounding and $v \bar{a}$. While trying to define his ideas around time-spatial existence he points out that there is no exact terminology for what he was trying to describe. Perhaps he should have searched further into the realm of Pacific indigenous knowledge and understandings to find enlightenment.

\section{Richard Buckminster-Fuller}

Richard Buckminster-Fuller was not associated with the Bauhaus, he was a visionary academic that worked between disciplines his whole career. Brosterman argues that Buckminster-Fuller and other artists and designers have been greatly influenced by Froebel's kindergarten in their approaches to creative practice ${ }^{198}$. BuckminsterFuller is credited with popularizing the geodesic dome in the 1950's and worked in a plethora of creative academic environments, publishing extensively until his death

\footnotetext{
196 "The New Bauhaus and Space Relationship," American Architect and Architecture 151(1937): 104. ${ }_{197}$ Sibyl Moholy-Nagy and Walter Gropius, Moholy-Nagy: Experiment in Totality(MIT press, 1969), 83.

${ }^{198}$ Brosterman, Inventing Kindergarten.
} 
in $1983^{199}$. The point of connection between Froebel, Itten and Moholy-Nagy is that Buckminster-Fuller also came through the Froebelian kindergarten system and as a result there are similarities between his approach to aesthetic education and Froebel's approach ${ }^{200}$. "'Space' is meaningless. We have relationships- but not space $^{\prime 201}$ is a quote written by Buckminster-Fuller that resonates with MoholyNagy's ideas of space-time and also with the many Pacific scholars that have defined vā in their work.

Buckminster-Fuller has an acute awareness of nature and the living world beyond human life and uses this understanding to think through his worldview. Much of this worldview fed into his understanding of design as 'design-science' an interconnected stream of communication between science and design to see nature as the source our creative inspiration. In his book Utopia or Oblivion BuckminsterFuller challenges design scientists to approach their role through an allencompassing, whole view where the focus is not to the details but rather "to organize themselves to study whole industries and the relationship of total industry to general society needs ${ }^{\prime 202}$. This statement is not unlike John Ruskin's quote written in 1892 during the arts and crafts era, "it is not, truly speaking, the labor that is divided; but the men:...so that all the little pieces of intelligence that is left in a man is not enough to make a pin, or a nail, but exhausts itself in making the point of

\footnotetext{
${ }^{199}$ Fuller, Richard Buckminster. The artifacts of R. Buckminster Fuller: a comprehensive collection of his designs and drawings in four volumes. Edited by James Ward. Garland Publ. 5

${ }^{200}$ Goulish, Matthew. "Unwinding Kindergarten." Performance Research 7, no. 4 (2002): 93

${ }^{201}$ R. Buckminster Fuller, Utopia or Oblivion: The Prospects for Humanity(London: Allen Lane, 1970), 31.

${ }^{202}$ Ibid., 337.
} 
a pin, or the head of a nail" ${ }^{203}$. Buckminster-Fuller attaches himself to science because it is a discipline that examines the natural world and strives to understand how nature operates beyond the human. This argument is introduced in Utopia and Oblivion through Buckminster-Fuller's initial discussion of human's disconnection with the universe.

Buckminster-Fuller states that he does not believe in the word creativity, "the word creation implies adding something to the universe. And I don't think man adds to the universe ${ }^{\prime 204}$. Through the indigenous Pacific perspective of refocusing nature at the heart of creation it shifts the perception of adding to the universe, to focus more on a process of situating ourselves within the balance of the universe. Within this context, instead of humans expressing their dominance over the physical world there is a shift in power relations. We become part of an articulated whole, where human production participates in part of the process between entities in flux, hooking and unhooking to maintain a universal balance in nature. Man has a participatory position in this case where there is a conscious state of adding and subtracting within a bigger context- a universal context that goes beyond what we know in our physical world. Within this process it is our responsibility to maintain our connection and keep our world balanced in the universe that surrounds us.

\section{Nature Ideology}

\footnotetext{
${ }^{203}$ Ruskin, John. The stones of Venice.-3 vol. Vol. 11. J. Wiley \& Son, 1867.

${ }^{204}$ Fuller, Utopia or Oblivion: The Prospects for Humanity, 23.
} 
Froebel, Itten, Moholy-Nagy and Buckminster-Fuller each played a vital role in the development of design pedagogy throughout their academic careers. Their views contrasted that of current mainstream design thought and instead tended to support a more holistic approach to aesthetic education where creativity was given the opportunity to evolve naturally, without the imposing hierarchical structures often seen in modern aesthetic education. This holistic approach that grew from Froebel and was then encountered by Itten, Moholy-Nagy and Buckminster-Fuller during their own educational experiences which also align closely with indigenous understandings throughout the Pacific region and therefore becomes the point of connection between western aesthetic education and Oceanic creative practice. The defining link between western design and Oceanic creative practice lies within Froebel, Itten, Moholy-Nagy and Buckminster-Fuller and their strong alliance with nature, which influenced both their philosophical approach to design and their final creative out-puts. The space in-between western education and Oceanic creative practice is filled through the mutual relationship between these three western design educators who have also grounded their creative inspiration in nature. The introduction of western artistic education through the eyes of Froebel demonstrates the presumption that all of western ideology separates nature and culture, is not wholly true. A more unified understanding of nature and culture offered by indigenous cultures in Oceania can also resonate in western artistic pedagogy. The recognition of these commonalities between European and Oceania approaches to artistic education streamlines an avenue in which Oceanic creative practice goes beyond the indigenous and becomes universal in its application 
Case Study: Lily Laita Va i Ta Taeao Lalata E Ma GAgana

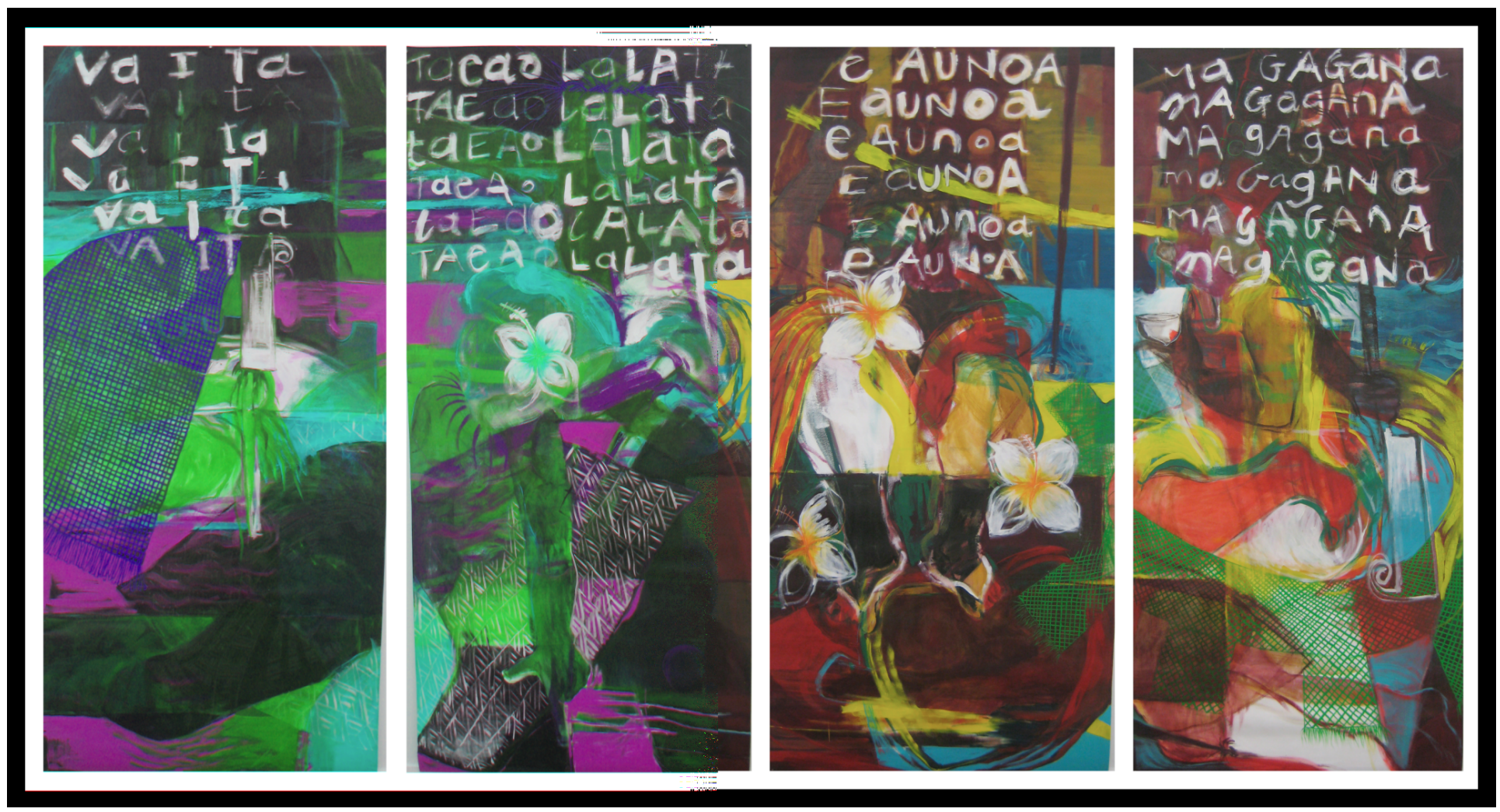

Figure 8: Lily Laita- Va i Ta Taeao Lalata E Ma GAgana painted panels ${ }^{205}$

Bernida Webb-Binder researches into the comparisons between African diaspora art and Pacific diaspora art to examine the commonalities and differences between how artists from these ethnicities express ideas of identity through their creative works. In an evaluation of Lily Laita's Va i Ta Taeao Lalata E Ma GAgana painted panels, Webb-Binder states that "vā constitutes a realm where personal and cultural

\footnotetext{
${ }^{205}$ Bernida Webb-Binder, "Pacific Identity through Space and Time in Lily Laita's Va i Ta".(2009): 26
} 
stories of identity through space and time are imparted" ${ }^{206}$. This statement highlights that $v \bar{a}$ is not just the connector between people or things but it also tracks back to help inform the way in which identity is shaped in people ${ }^{207}$. WebbBinder explains the major themes that Lily Laita uses to distinguish vā in her painted panels. The first being the performance of Pacific identity within $v \bar{a}$, expressed through the layering of paint mediums to give a multidimensional quality ${ }^{208}$. The second theme embedded in the painted panels is the understanding of $v \bar{a}$ from a holistic perspective, where time and space are living experiences rather than stagnant elements of the past ${ }^{209}$. The third theme visually builds on the idea of the second theme. Laita employs the use of words and layout to offer the work as both a series of individual paintings that offer connecting themes linking them together to make one whole work ${ }^{210}$. The purpose of this skewed imagery is to depict the events shown within the separated panels as being representational of both the past and the present.

Within traditional Pacific Art the presence of $v \bar{a}$ is more physical, vā is less so represented in the aesthetics of the works but more so embodied within the every aspect of the form. For example as Māhina explains in his article, art is the genealogy of times and spaces. He goes on to explain that genealogy is the intersection of lines or linage (time) in space $(v \bar{a})$ through the act of social

\footnotetext{
${ }^{206}$ Bernida Webb-Binder, "Pacific Identity through Space and Time in Lily Laita's Va I Ta," (2009): 27.

207 Ibid., 25.

${ }^{208}$ Ibid., 27.

${ }^{209}$ Ibid.

210 Ibid., 28.
} 
activities $^{211}$. Art is in turn a visual embodiment of human activity and is the physical evidence of social activity.

An example of this is the art of traditional Tongan lalava (binding), the thread most commonly used in lalava is a combination of red and black coloured sennit threads $^{212}$. Red is seen as representative of female and the black is seen as male ${ }^{213}$. When woven together the red and black colours also embody the natural, physiological and social realms in Tongan culture. Specifically the bringing together of red and black in the social realm represent $v \bar{a}$ lelei (good relation) and $v \bar{a}$ kovi (bad relation) indicating that lalava, a form of traditional Tongan art practice directly embodies the co-existence of good and bad relations in society resulting in a balanced relationship within $v \bar{a}^{214}$. Symmetry in Tongan lalava is important because it results in harmony in the overall form, when an object is visually harmonious then it is considered beautiful ${ }^{215}$. Mahina explains that once beauty is evoked in an object in Tongan culture it is considered to have moved from a state of chaos to an ordered state $\mathrm{s}^{216}$.

An artist that Mahina highlights in his article is a Tongan sculptural artist Sopolemalama Filipe Tohi who is a master of the practice of lalava. Since his migration to New Zealand Tohi has experimented with the art of lalava on varied scales and with different materials (e.g. steel piping). Within his work Tohi

\footnotetext{
${ }^{211}$ Māhina, "Ta, Va, and Moana: Temporality, Spatiality, and Indigeneity," 184.

${ }^{212}$ Ibid., 176.

${ }^{213}$ Ibid.

${ }^{214}$ Ibid.

${ }^{215}$ Ibid., 184.

${ }^{216}$ Ibid.
} 
maintains the ideals of symmetry and harmony within each of his forms and successfully moves the art of lalava from a tradition art to a contemporary expression of lalava.

This is in contrast Lily Laita's contemporary painting Va i Ta Taeao Lalata E Ma Gagana which is also based on the ideals set in vā but it does not show the same symmetry and uses a wider range of colours for the depiction of imagery. However Laita still engages with the physical layering and overlapping of materials to create a variety of space in her paintings. Laita uses imagery and phrases to connect with the space in-between, "where Pacific identity is negotiated and expressed in a New Zealand context" and layers all of these elements so that they intertwine in all four of the panels ${ }^{217}$. Each of the elements exist by themselves but once they are presented in a way that asks the audience to try and make sense of all of the elements as part of one unity. Laita explores notions of identity as a universal expression but also as an individual expression of a mix of her own heritages. The underlying argument that Webb-Binder is constructing within the explanation of Lily Laita's painting is that through vā and the engagement with the space inbetween, Pacific artists living in New Zealand have the potential to effectively visually negotiate and narrate their identity journeys through their art forms ${ }^{218}$.

\footnotetext{
${ }^{217}$ Webb-Binder, "Pacific Identity through Space and Time in Lily Laita's Va I Ta," 25.

${ }^{218}$ Ibid., 30.
} 


\section{Discussion: Interstitial Space vs. Vā in Oceanic Creative Practice}

An article written by Graeme Whimp titled "Working in the space in-between:

Pacific Artists in Aotearoa/New Zealand" evaluates the work of several different

Pacific Island artists that are based primarily in New Zealand. The purpose of this

article is to explore whether the artists are "influenced by essentialist or pluralist

impulses" and also to establish the cultural space that the artists have been able to express in their artist identities ${ }^{219}$. Although Whimp doesn't specifically address the concept of vā in his article he presents alternative views on the connections between practicing Pacific Island artists in New Zealand. Whimp evaluates the workings of the space in-between, through two perspectives in this article. Firstly he rightly describes Pacific Art and Pacific artists as often being categorised as the multicultural, separated third party in New Zealand ${ }^{220}$. Whimp then describes the connection between Pacific Island artists as being a mutual connection of "otherness", he then references Sean Mallon's quote to further iterate his point by saying "Every flower is unique, but also part of an often stereotyped and homogenized whole ${ }^{\prime 221}$. Whimp explains that he is not satisfied using vā to describe the space in-between for Pacific Art and Pacific artists because vā indicates separation as a space that connects but Pacific Art is more of "a space isolated from the other competing but inaccessible communities" ${ }^{222}$. Whimp goes on to explain that the most appropriate word to best describe the space defined and occupied by

\footnotetext{
${ }^{219}$ Graeme Whimp, "Working in the Space Between: Pacific Artists in Aotearoa/New Zealand," (2009): 9.

220 lbid., 18.

${ }^{221}$ Sean Mallon and Pandora Fulimalo Pereira, Speaking in Colour: Conversations with Artists of Pacific Island Heritage(Museum of New Zealand, 1997), 71.

${ }^{222}$ Whimp, "Working in the Space Between: Pacific Artists in Aotearoa/New Zealand," 19.
} 
Pacific art and artists in New Zealand is interstitiality, a word first developed in the 1920 's by Frederic Thrasher ${ }^{223}$. Interstitiality can be defined as a cultural space that separates itself from other cultural or contextual influences to discover new, innovative ways of collaboration. Whimp argues that in order to develop and embody a true identity for Pacific Art, this calls for a true understanding of Pacific artists and their work, away from outside influences. The argument that Whimp constructs presents a polar opposite view to Webb-Binder in her discussion of Lily Laitais paintings. Whimp argues that Pacific Art is categorized as the 'other' in the New Zealand art scene and therefore more focused on disconnecting spaces in order to grow the Pacific Art community.

Whimp presents a pessimistic argument, separating Pacific Art and it's artists from being tied to other cultural and contextual influences, which is not helpful in the ever-evolving identity of creative practices in the Oceanic creative sector. Following the sole path of total decolonization in creative practices in the New Zealand context doesn't allow for the recognition of a hybrid identity in an artist's work. By saying that Pacific artists should move into a new realm of collectively separated from any other cultures or contexts does not allow for positive connections to be made between other contexts or cultures that may be equally influential to the artist. Furthermore if artists were to move into an interstitial cultural space and separate themselves from other cultural contexts it will encourage the growth within their own cultural space but it will not encourage understanding between the Pacific Art cultural space and other cultural spaces.

\footnotetext{
${ }^{223}$ Ibid.
} 
Staking a claim to an interstitial cultural space for Oceanic artists based in New Zealand isolates the artists, protecting them from outside influences and conflict, which Whimp proposes, is a good thing. He believes artists once separated can develop more naturally, dig their own paths without multiple outside influences carving the way for them. Conflict in response to outside influences has the potential to play an integral part to the diversity of identities seen in diasporic artists of Oceania. As Mahina proposes through his tā-vā theory of reality, conflict and order work together because order is in fact conflict within itself $f^{224}$. Whimp ties interstitial cultural space to Pacific Art in New Zealand because it brings forward strategies of selfhood, an order and stability to justify the work produced by Pacific $\operatorname{artists}^{225}$.

Emphasizing and highlighting conflict that Oceanic creative practitioners encounter is where the essence and interest lies to negotiate the conflict between hybrid identities and how to manage each of those identities collectively and individually in creative practices. The conflict between people of Oceania expressing themselves through creative production can cause conflict, whether this is intentional or not it may ultimately shed light on views that perhaps need to be addressed or readdressed. Conflict keeps cultures evolving, it instigates change and opinion to establish the true being of an individual and a society.

\footnotetext{
${ }^{224}$ Māhina, "Ta, Va, and Moana: Temporality, Spatiality, and Indigeneity."

${ }^{225}$ Whimp, "Working in the Space Between: Pacific Artists in Aotearoa/New Zealand," 20.
} 


\title{
Chapter four: Va-ticulation
}

\author{
"An articulated ensemble is more like a political coalition or, in its ability to conjoin \\ disparate elements, a cyborg" \\ - James Clifford ${ }^{226}$
}

This chapter will establish the relevance of $v \bar{a}$ when thought of in relation to the $t \bar{a}-$ $v \bar{a}$ theory of reality and the theory of articulation, as a means to establish and maintain connections within a framework for Oceanic creative practice. This study will then compare aspects of Froebel, the Bauhaus' tenets and Buckminster-Fuller, in relation to the spatial strategy vā and identify commonalities. I will argue that the core principles embedded in vā offers an approach to aesthetic education that parallels Froebel, the Bauhaus masters and Buckminster-Fuller. By aiming to highlight the complementary aspects of vā, tā-vā and articulation and the parallels between vā and Western creative practice discussed in previous chapters. This chapter aims to highlight the shared aims and beliefs between Oceanic creative practice and a western-based model of modern design education that I postulate enable reciprocity and respect. Advancing the relevance of these concepts, I will posit a new term titled "va-ticulation" as a creative construct to help understand the relevance of connections within Oceanic creative practice. This chapter will ratify vā-ticulation as a vital spatial strategy to translate how connections outline an initial framework to identify Oceanic creative practice by.

${ }^{226}$ Clifford, "Indigenous Articulations," 478. 


\section{Vā and aesthetic education}

A key aspect to the indigenous knowledge of Polynesian people of Oceania is $v \bar{a}$, this term has been extensively explored in previous chapters in this research. As established through the earlier discussions $v \bar{a}$ as defined by Wendt is a space that relates $^{227}$. Connections exist within $v \bar{a}$ as relationships, this demands a deeper connection, more permanent and less susceptible to changes of external pressure. This process of recognizing connections sees connections in a symbiotic form where there is a "unity-in-all" giving meaning to context ${ }^{228}$. Vā will be once again discussed in this chapter to further explore the relevance $v \bar{a}$ has to approaching a framework for Oceanic creative practice.

The relevance of $v \bar{a}$ within the New Zealand context was discussed through Lilomaiava-Doktor where she interlinked $v \bar{a}$ and malaga (migration) explaining that migration is seen as physically moving between connections within $v \bar{a}^{229}$. By arguing that the paths of migration first set out by the ancestors of Oceania and then seen again in the second wave of Oceanic migration into urban centers, was a response to contextual changes. The people of Oceania historically responded to changes in the global culture through migration and continue to respond to shifts in modernity in the same way ${ }^{230}$. This process of migration is not to seen as a dislocation but rather a balancing of relations between Oceania, balancing and harmonizing the $v \bar{a}$.

\footnotetext{
${ }^{227}$ Wendt, "Afterword: Tatauing the Post-Colonial Body," 402.

${ }^{228}$ Ibid.

${ }^{229}$ Lilomaiava-Doktor, "Beyond "Migration": Samoan Population Movement (Malaga) and the Geography of Social Space (Vā)," 1.

${ }^{230}$ Ibid.
} 
The particular act of teu le va, the Samoan term for nurturing and caring for relationships, embodies the Pacific approach to education ${ }^{231}$. Strength in relationships can only be realised in the active engagement of looking after the $v \bar{a}$ between the animate and/or inanimate. Teu le vā (Samoan) or Tauhi vā (Tongan) is the focused process of identifying, looking after, nurturing and caring for relationships between two people. Teu le vā portrays the value in relationships and within its practice recognises behavioral boundaries dictated by social hierarchies ${ }^{232}$. Teu le vā or tauhi vā is acted through to clean up and rebalance the vā between two people and so this concept holds a valid place within Oceanic creative practice to maintain order ${ }^{233}$. By identifying the fragility of relationships within $v \bar{a}$. The process of teu le vā allows relationships to exist as sinuous connections where relationships are mitigated within the responsibilities imbued by teu le vā and connections have the ability to bend and twist before a relationship breaks.

This section will discuss vāand its surrounding constructs such as teu le vā when researching within Pacific communities. Understanding how to teu le vā in research and educational situations "allows us to understand an issue, phenomenon, or culture from perspectives of both the researcher and the researched"1234.

Melani Anae emphasises the need for a more level platform between the positions of the researcher in comparison to the participant in their research ${ }^{235}$. By arguing

\footnotetext{
${ }^{231}$ Anae, "Teu Le Va: Toward a Native Anthropology," 223.

${ }^{232}$ Ibid., 224 .

${ }^{233}$ Ibid.

${ }^{234}$ Ibid.

235 Ibid.
} 
that this platform is built from "mutual trust and understanding" a method that is delicate and so should be treated respectfully ${ }^{236}$. The $v \bar{a}$ between the participant and the researcher must be nurtured and handled gently for the research outcome to be successful. Anae states, "Put simply it is about regarding our vā with others as sacred, thus valuing, nurturing and if necessary, tidying up relationships we have as Pacific researchers with those above, below and beside us in order to achieve positive outcomes for all"237. This approach can also be used to focus on how relationships between Oceanic creative practitioners can be cared for through teu le $v \bar{a}$, which will help Oceanic creative practice to evolve as a community.

In this case the Pacific researchers are Oceanic creative practitioners and the participants are embodied as either: another creative practitioner, the creative subject, or the community. Operating through teu le vā protects "tapu "spaces" of human relationships in our research praxis" ${ }^{\prime 238}$ The understanding of the teu le vā process is established through Oceanic creative practitioners valuing the relationship that connects them, as sacred.

If pedagogical structures were to be under the operation of teu le vā the structure would shift from a linear 'top down' format to a rounded holistic approach of teaching and learning. In this structure the connection between the teacher and the students can be thought of as a sacred connection or vā tapuia. This idea brings with it the participation in teu le vā to ensure a harmonious learning environment. In this

\footnotetext{
${ }^{236}$ Ibid.

${ }^{237}$ Ibid.

${ }^{238}$ Ibid., 234.
} 
holistic approach to a pedagogical structure, the teacher is a guide to assist in the natural development of the student, guiding their curiosity and encouraging pause moments to stop, reflect and find moments of clarity and connection. For the student, in order to maintain a holistic learning environment the teacher must be considered valuable. An effort from both the student and the teacher must be made in order to achieve the position of mutual respect.

Vā tapuia embodies the kinship connections and the genealogical strength of relationships within the $v \bar{a}$. The understanding of $v \bar{a}$ tapuia is important to Oceanic creative practice because it recognises strength not only kinship connections but connections that emit the strength of genealogical relationships within $v \bar{a}$. This idea is pertinent to the definition of Oceanic creative practice as it allows connections within the practice to grow and exist within $v \bar{a}$.

\section{Tā-vā and articulation in Oceanic creative practice}

Māhina's tā-vā theory of reality further substantiates vā through identifying the interconnection of $t \bar{a}-v \bar{a}$ (time-space). Understood as interconnected through many levels of reality Māhina's tā-vā theory of reality begins to describe the comparable qualities between $v \bar{a}$ and the theory of articulation. Like Māhina, Slack also discusses articulation as existent multiple levels of reality. According to Slack articulation is interpreted through epistemology, ideology, theory, method ${ }^{239}$. The last two levels described by Slack being politics and strategy, which could also be

\footnotetext{
${ }^{239}$ Slack, "The Theory and Method of Articulation in Cultural Studies," 126.
} 
translated to mean conflict and $\operatorname{order}^{240}$. Māhina explains his theory as existent within a cyclical understanding engaged with through the Moana ${ }^{241}$. This comprehension of $t \bar{a}-v \bar{a}$ perceives the past, present and future as implicit of the past being situated at the front, the future at the back and the present as a symmetrical representation of both tenses ${ }^{24^{2}}$. Through the deconstruction of the tāa-vā theory of reality both art and culture must be facilitated in existence as beautiful, useful and as a result harmonious ${ }^{243}$.

The theory of articulation outlines a starting point for the development of a framework that embodies connections within Oceanic creative practice. The metaphor of the articulated truck presented by Hall, and Clifford's depiction of articulation as a cyborg outline how a framework for Oceanic creative practice might be approached. The bringing together of seemingly disparate elements into an articulated whole provides a useful platform for Oceanic creative practice to stem from as it does not, preempt an outline for a complete framework. Allowing the framework for Oceanic creative practice to exist and grow within a constant flux of discussion. These metaphorical concepts of articulation also remain open to all possible interrelated connections, allowing Oceanic creative practice to co-exist within both.

Hall's explanation of the theory of articulation instigating a complex structure relates to the understanding of how relationships within vā correlate to a heirachical

\footnotetext{
${ }^{240}$ Ibid.

${ }^{241}$ Māhina, "Ta, Va, and Moana: Temporality, Spatiality, and Indigeneity," 169.

${ }^{242}$ Ibid., 170.

${ }^{243}$ Ibid., 186.
} 
structure that prompts certain rituals and and/or behaviors when conversing with someone of higher status then yourself. Hall states while articulating an ideology there is a multidimensional complexity within the articulation of parts. In an articulated formation there is also space between structured parts that describe "relations between parts, i.e., relations of dominance and subordination" ${ }^{244}$ This analogy recognises that within an articulated structure, the order of parts is prescribed through contextual relations which may be constructs or power relations or may be other influences. This approach demands the consideration of parts in relation to others, prescribing that when thinking through articulation theory structures must be thought of through a big picture, all-encompassing view.

In the initial defining quote for articulation stated earlier in this research Hall states that within articulation phenomena have "no necessary 'belongingness" ${ }^{\prime \prime 24}$. Although this view is helpful when bringing seemingly separate elements together into a unity, it is not helpful when trying to incorporate articulation theory into a framework that integrates western and indigenous ideologies. Fluidity within and between elements is good but within Oceanic creative practice, in line with the argument constructed by Whimp, there is a need to outline a space that brings together creative practitioners within the New Zealand context ${ }^{246}$. Once elements have been brought into the framework of Pacific creative practice vā should enrich the connections and progress these connections into relationships within Oceanic creative practice. Relationships also respond to contextual changes when fostered

\footnotetext{
${ }^{244}$ Hall, "Race, Articulation, and Societies Structured in Dominance," 38.

${ }^{245}$ Grossberg, "On Postmodernism and Articulation: An Interview with Stuart Hall," 141.

${ }^{246}$ Whimp, "Working in the Space Between: Pacific Artists in Aotearoa/New Zealand."
} 
through $v \bar{a}$ these relationships demonstrate a sinuous quality within connections that will stretch and morph before unhooking.

\section{Froebel and the Bauhaus' tenets and $v \bar{a}$}

The philosophy and belief in interconnection held by Froebel embody the principles of the Polynesian indigenous concept of $v \bar{a}$. The overall role of $v \bar{a}$ is to maintain a unity within a group through nurturing connections. This, in line with Froebel's philosophies, is achieved by recognizing the interconnection between all people, nature and/or things.

Strong connections can be made between the philosophy of Froebel's kindergarten and $v \bar{a}$. Both of these concepts share a foundation of unity, yet were being developed on complete opposite sides of the globe, in very different cultures and time frames. The comparisons between Froebel's ideals and vā demonstrate the interconnection of the concept of $v \bar{a}$ not only between cultures within Oceania but also on an international scale. This supports the argument that vā can be understood and engaged with for generations to come, even when generations of people of Oceania have migrated out of Oceania and into urban centers.

By evaluating the relevance of framework for Oceanic creative practice, this chapter has revisited the indigenous concept that is vā and discusses what vā contributes to the methods and teaching of Oceanic creative practice. More specifically this chapter highlighted the indigenous Samoan concept of teu le vā as fundamental 
when engaging with pedagogical strategies in Oceanic creative practice. Through comparing indigenous Pacific approaches to methods of education within European and colonial approaches it is clear that both $v \bar{a}$ and concepts introduced through Froebelian kindergarten focus on a holistic method of understanding where all things sit in unity.

Although much of European design education is embedded in a singular, capitalist approach, I have discussed four prolific creative education academics that oppose this approach, instead choosing a more holistic method to aesthetic education. The purpose of introducing these academics into this research is to demonstrate that the holistically grounded collective core values embedded in $v \bar{a}$ are directly linked to ideals presented by Fredrick Froebel and a number of prolific western design educators that followed, namely Bauhaus educators and Buckminster-Fuller. It is key to note that although these educators were perceived as groundbreaking philosophical thinking at the time, indigenous ideology, specifically indigenous understandings of $v \bar{a}$ had been established in Oceania long before the emergence of design as an academic discipline.

\section{Vā-ticulation}

Although both articulation and $v \bar{a}$ focus on connections, vā could never be successfully described as a lorry. Vā conceptualizes a social space between two people and/or things. The existence of $v \bar{a}$ is not dependent on making a link but 
more the act of maintaining the link known as teu le vā or Tauhi vā. The communal and collective qualities embedded in Polynesian cultures are the result of $v \bar{a}$; identified, maintained and nurtured through tauhi vā and teu le vā/ tauhi vā. It is at this point where $v \bar{a}$ is most useful when thought about in relation to articulation. $V \bar{a}$ gives weight to connections, so instead of simply hooking and un-hooking in response to contextual changes in time and space, $v \bar{a}$ allows connections to take on a more sinuous quality.

When thinking about Oceanic creative practice, there are some core values to the practice that should be regarded as vā tapuia, and should be considered as an essential connection within the framework. At this point in the research the core values that I identify as inseparable are elements that (so far) make up the structure for the framework which are as follows: $v \bar{a}$, not only does this indigenous understanding constitute the heart of a framework for Oceanic creative practice but it lives within the framework, at this point in the development it is pertinent to keep $v \bar{a}$ within Oceanic creative practice to maintain collective connections. Mahina's tā$v \bar{a}$ theory of reality supports $v \bar{a}$ and situates space within time, encouraging an understanding of connections as being constantly negotiated within the context of Oceanic creative practice. The theory of articulation defines the framework for Oceanic creative practice as a complex structure where, like va tapuia, not only articulates a diffusion of connections but understands each connection as an articulated construct within the larger framework. This understanding is pertinent in Oceanic practice because it ensures that the framework for Oceanic creative practice will understand the genealogy of each connection that exists within it. 
Connections and disconnections, whether traditional, historical, philosophical, sacred, measurable or spiritual, will enrich the understanding of how vā-ticulation is relevant to creative practice in Oceania and aid in the clarification of what is and how we articulate Oceanic creative practice. This chapter has established the value $v \bar{a}$ has as the head, heart and hands of Pacific creative practice. By highlighting the intrinsic relationship between Pacific creative practice and a western based model of modern design education, this research posits that the connection that vāticulation has to creative production is unbreakable and pertinent to the successful management of the present and the future of Oceanic creative practice. 


\section{Chapter 5: Creative Oceanic Examples}

"'Oku hange 'a e tangata, ha fala 'oku lālanga"

-Society is like a mat being woven ${ }^{247}$

This chapter will establish va-ticulation as the heart from which to define a framework that characterizes Oceanic perspectives and methods of creative practice. Connections in this research have been identified through an articulated approach, connecting the seemingly separate discourses of western aesthetic education and Oceanic indigenous knowledge into a new unity that is Oceanic creative practice. This chapter will weave together fundamental connections established in the discussion of va-ticulation to form an initial framework for Oceanic creative practice. To demonstrate how these connections when woven together relate to Oceanic creative practice, this section will also discuss the creative work of five creative practitioners; Filipe Tohi, Robin White, Greg Semu, Hohepa Thompson and David Hakaraia. These practitioners, through their respective creative practices all work and interpret indigenous themes differently but yet they all represent valid approaches to be considered within the framework for Oceanic creative practice. Through the discussion of each of these practitioners and their work, I will specifically highlight how the core principles of this research, brought together by vā-articulation, are inter-woven into a framework for Oceanic creative practice.

\footnotetext{
${ }^{247}$ Traditional Tongan proverb translated by Heather Leslie Young: Heather E Young Leslie, "'"...Like a Mat Being Woven"," Pacific Arts Journal 3(2007): 115.
} 
Framework: Mat

The cultivation of a collective community depends on unity. This means that everyone and everything must exist in harmonious balance. In this woven framework all Oceanic creative practitioners sit on the mat, existing between particular relationships within Oceanic creative practice. Earlier in this research the idea of a complex structure was introduced through the discussion of the theory of articulation. Here it is explained by Hall that within the parts of an articulated structure, there are also "structured relations between parts". Within the framework for Oceanic creative practice the structured relations between parts is interplayed through the understanding of tapu or sacred relationships within vā-taupia.

Through vā-taupia connections are ordered through the understanding of the genealogy of creation ${ }^{248}$. Creativity is the genealogical connection between all Oceanic creative practitioners. Creative practitioners are placed on the mat, specifically positioned through the negotiation of hierarchies between other practitioners and also between sacred relationships between animate and inanimate relations interwoven within the mat framework. In this understanding all Oceanic creative practitioners sit on the mat as a unified group. $V \bar{a}, v \bar{a}$-tapuia and teu le vā/tauhi vā now exist on two interconnected levels. Between the connections established in vā-ticulation discussed in this thesis, and between the creative pracitioners that have formed a relationship between the mat framework through their creative work.

${ }^{248}$ Efi, "Keynote Address: Bio-Ethics and the Samoan Indigenous Reference," 116-18. 
Framework: Heirachy

The mat as a flat interwoven structure that represents the harmony of a society, through the understanding of the Tongan proverb discussed above. This also represents the harmonious balance within hierarchies embedded into a society. In order to instill harmony and unity within the mat the weaver(s) must negotiate tensions and manipulate the strands to weave together connections. In Tongan weaving, these terms are defined as fokotu'u (upright) and fakatokoto (reclined) ${ }^{249}$. There are the pieces pandanus leaf that are intersected during the weaving process, to result in the creation of a symmetrical, beautiful and therefore harmonious surface that becomes the mat ${ }^{250}$. As discussed earlier in this thesis Māhina describes the balance between symmetry and beauty to result in harmony as not only a process in the creation of art but also in the process of creating a society ${ }^{251}$. Meaning that the negotiation of tensions within the weaving process is synonymous with that of tensions within the formation of a society. The woven framework that embodies Oceanic creative practice as inherently composed through the complex understandings of $v \bar{a}$. Hierarchy, as described through the ideals of $v \bar{a}$ is established through genealogical connections conveyed through vā taupia. Teu le vā (Samoan) or tauhi vā (Tongan) nurtures and cares for these connections and relationships made between entities to harmonise the $v \bar{a}$.

\footnotetext{
${ }^{249}$ Young Leslie, "'"...Like a Mat Being Woven"," 124.

${ }^{250}$ Māhina, "Ta, Va, and Moana: Temporality, Spatiality, and Indigeneity," 185.

${ }^{251}$ Ibid.
} 
To teu le vā is to also identify genealogical connections between yourself and another entity, once this connection has been established it is pertinent that both people and things invested in the connection work to nurture their relationship. If a kinship connection is established, the relationship is seen as an indispensible connection. Once a relationship is acknowledged, teu le vā or tauhi vā is interplayed to maintain the relationship. Within the woven framework for Oceanic creative practice teu le vā is engaged in the weaving process to bring connections together in harmonious unity. Vā-tapuia and teu le vā/tauhi vā also exist between creative practitioners, who are positioned sitting on top of the woven mat framework. In the case of Oceanic practice, kinship-type connections should also extend to include identifying practitioners within the same creative discipline i.e. painting, graphic design, sculpture etc. If a discipline specific kinship-type connection is established between practitioners, creative practitioners need to maintain these relationships through teu le vā/tauhi vā to maintain the unity within Oceanic creative practice. Teu le $v \bar{a}$ is also engaged to outline behavioral boundaries when socializing with a senior creative practitioner. The more senior practitioners of Oceanic creative practice are the protectors and mentors of Oceanic practice and so should be treated with the utmost respect. Under this mentality it is necessary for all Oceanic creative practitioners to recognise the existing relationships between each other and to nurture these relationships through the teu le vā process. 


\section{Framework: conclusion}

Woven together through ideologies derived from $v \bar{a}$, an indigenous spatial strategy, this framework becomes a place where intersecting discourse between indigenous knowledge and western ideology can culminate, existing on one single complex level of reality. This understanding challenges a linear approach to structure where everything is chronologically ordered to pertain to time. In this woven mat structure, time interweaves all of the interpretations of $v \bar{a}$ presented in this research into a platform or springboard for Oceanic creative practitioners to develop from. Every creative practitioner situated on the mat exists within a space where past, present and future practitioners intersect and can move around on the mat operating in the $v \bar{a}$ of Oceanic creative practice. The woven mat is a metaphor for how $v \bar{a}$ interprets the space between as points of connection that intersect and across time and contextual changes. To counteract the idea that the mat can be constraining, the mat can be added to and expanded. However this requires the practitioners situated on the mat to engage in weaving more material into the mat to expand it. This of course will require a group of people to negotiate tensions to weave together connections to maintain symmetry, beauty and harmony in the mat. This is a metaphor for all practitioners working as a unified collective, to maintain harmony and successfully develop as a collective. The mat is a metaphor for a framework and provides a foundation for understanding the ideologies embedded in Oceanic creative practice. Oceanic creative practitioners and their 
work are positioned on the mat and should use the idea of a woven mat-like framework as a point of grounding within their own practices.

\section{Key creative practitioners and their work}

\section{Sopolemalama Filipe Tohi}

New Zealand-based Tongan artist and tufunga lalava (master of lalava) Sopolemalama Filipe Tohi, born in 1959, is highly skilled in the practice of lalava (lashing), a traditional Tongan way of binding seen in traditional housing. As a tufunga lalava Tohi is considered a senior creative practitioner within Oceanic creative practice. In this position a more junior creative practitioner should treat Tohi with respect interplayed through the understanding of tauhi vā. Tohi was raised in Tonga and immigrated to New Zealand in 1978 with his mother. Tohi developed an interest in drawing from an early age. In an interview published in Speaking in Colour he states "I drew in kindergarten, and in school time" although it wasn't until adulthood that Tohi began to feel and think of himself as an artist ${ }^{252}$. Tohi evolved as an artist through experiences and tutoring at Rangimarie Arts and Craft Centre but did not emerge as an artist through a tertiary education system ${ }^{253}$. From the time Tohi moved to New Zealand he was constantly negotiating between his Tongan heritage, new exposure to Māori culture, and western ways of approaching and understanding the role of art and artist. It wasn't until a return trip

\footnotetext{
${ }^{252}$ Mallon and Pereira, Speaking in Colour: Conversations with Artists of Pacific Island Heritage, 102. ${ }^{253}$ Ibid., 106.
} 
to Tonga in 1987 that he begun to establish himself as an artist, in the western sense, during this trip he connected with older Tongan craftsman and artists and began to explore the Tongan way through his own artforms in New Zealand ${ }^{254}$. Throughout his creative career Tohi has worked with a number of mediums including but not limited to: stone, coconut sennit, pencil, paint, steel and wood. In line with Mahina's discussion of the "past being placed in front of people as a guidance in the present" ${ }^{255}$. Tohi works with a diverse range of mediums in his practice of the art of lalava, experimenting with new materials as part of his creative process in the present "but of course the past will give you work for the future"256 Throughout his career as an artist, Tohi is most well known for experimenting with a range of different materials to recreate lalava in a more contemporary form ${ }^{257}$. As well as using the traditional sennit (coconut husk fiber) he has also completed lalava pieces using wool, stone, metal, and has even used paint to recreate lalava in 2dimensional form. Tohi is constantly experimenting with non-traditional lalava materials but yet still manages to maintain strong ties to the indigenous knowledge that is used to tell the unique stories within each of his pieces ${ }^{258}$. The binding is compiled in a way that creates specific patterns along beams and narrates and conveys cultural knowledge. Tohi's work is perhaps one of the best examples of contemporary Oceanic sculpture that draws upon traditional understanding but aims to display this in a new, contemporary form. The stance Tohi takes in his work is a position that should be adopted by all Creative Oceanic practitioners. In order to

\footnotetext{
${ }^{254}$ Ibid., 107.

${ }^{255}$ Māhina, "Ta, Va, and Moana: Temporality, Spatiality, and Indigeneity," 170.

${ }^{256}$ Mallon and Pereira, Speaking in Colour: Conversations with Artists of Pacific Island Heritage, 108.

${ }^{257}$ Ibid.

$25^{8}$ Ibid.
} 
progress culture you must recognise the context from which it has come and always connect back to the past through your work.

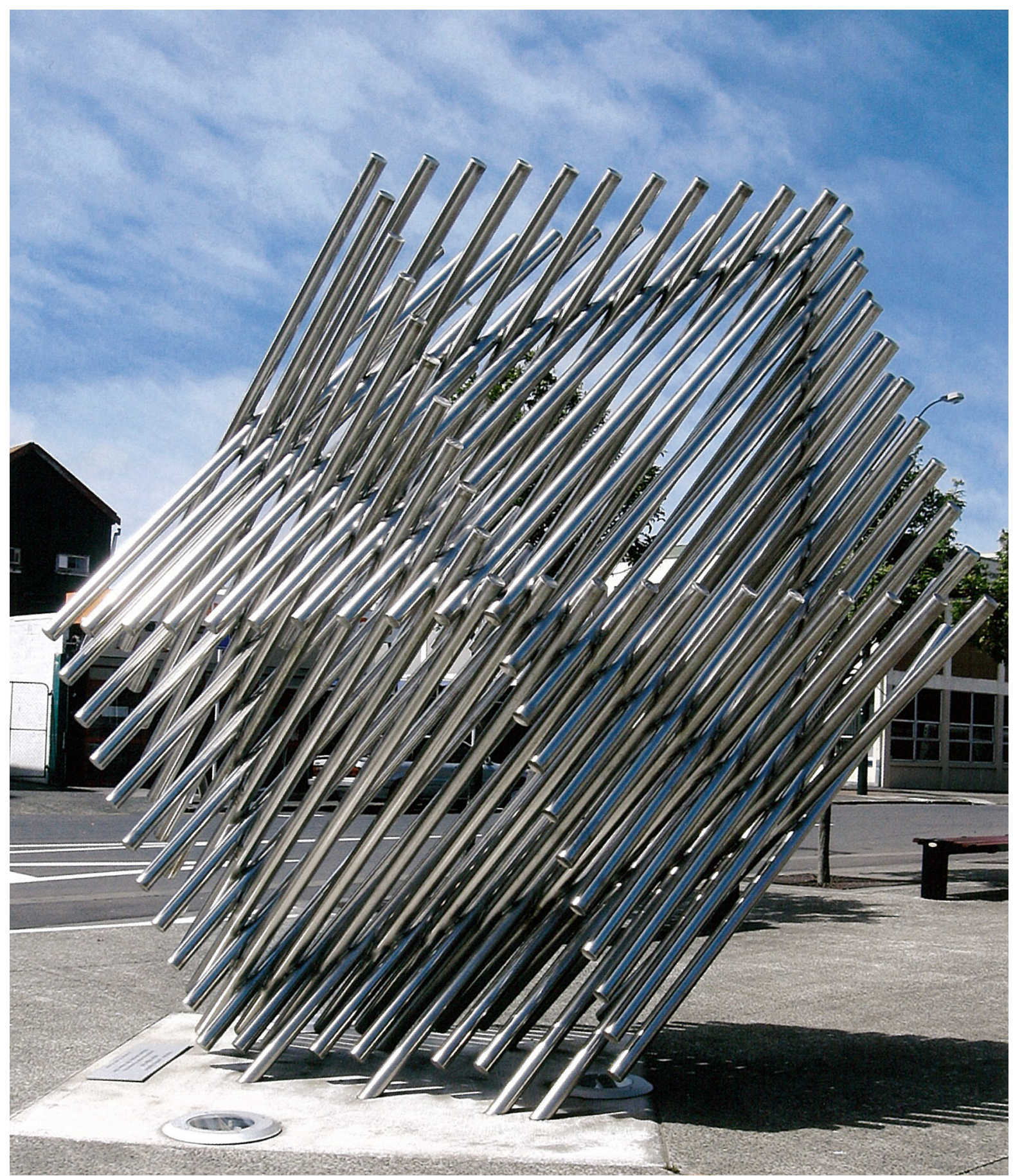

Figure 9. Sopolemalama Filipe Tohi, Hautaha (Coming together) $2004^{259}$

259 Peter Brunt., et al, Art in Oceania: A New History (London: Thames \& Hudson) 2012, 493 


\section{Robin White}

Dame Robin White is a non-Pacific New Zealand born artist born in 1946. White is rooted in New Zealand and views herself as a New Zealander and was quoted early on in her career to say "I don't feel like a colonist. My family has been here for many generations - my father's lineage goes back to the Māori and my mother's goes back to the first settlers in the Bay of Plenty area I really do feel this is my country. ${ }^{260}$ White has also established herself as a senior creative practitioner, though in contrast to Tohi this has culminated through her long standing her contributions to the New Zealand art community. One key influence on her approach to her practice is her Ba'Hai faith where one of the key principles in Ba'Hai religion is unity in all ${ }^{261}$. White graduated from the Elim School of Fine Arts in 1967. White's interest and connection to Oceania and in Oceanic methods of craft stems from her experiences living in Tarawa, Kiribati for 17 years with her family from $1982^{262}$. This time marked a shift in her approach and perspective in her art practice; of particular relevance to this research was a shift from her work as an individual artist to a keen interest in collaborative and collective art projects. White specializes in painting but has used her skills to experiment in the art of weaving and tapa making throughout the more recent years in her practice. White engages with Oceanic craft practice as part of a collective group of women that she brings together to make large tapa pieces.

\footnotetext{
260 "Robin White," ART New Zealand, http://www.art-newzealand.com/lssuesıto40/environrw.htm.

${ }^{261}$ Damian. Skinner, \& Bolton, Lissant, "Continuity and Change in Customary Arts," in Art in Oceania: A New History, ed. P. Brunt, Thomas, N., Mallon, S., Bolton, L., Brown, D., Skinner, D., \& Kuchler, S. (London: Thames \& Hudson Ltd, 2012), 496.

${ }^{262}$ Abby Cunnane, "Beginning, and Beginning," (2011), http://old.citygallery.org.nz/assets/NewSite/Exhibitions/Hirschfeld-Gallery/2011/Robin-White/Robin-Whiteessay.pdf.
} 
Robin has worked in these collective groups in Fiji and most recently in Tonga with a Tongan artist named Ruha Fifita ${ }^{263}$. White has described the collective making of tapa in her practice as "working in the space between...between cultures, between traditions, and learning how to operate in that space ${ }^{264}$. Although not specifically stated in this quote there is a clear connection between this statement and our understanding of $v \bar{a}$ as explained throughout this research. As with traditional Oceanic craftspeople, White has engaged with the methods of weaving and tapa making to create works that hold a narrative and although they feature traditional symbols and motifs, they are often interpreted into more contemporary imagery ${ }^{265}$. Although not ethnically from Oceania, White has successfully integrated her practice into what can be seen as Oceanic creative practice. Not only does she deal with Oceanic motifs and symbols in her work but she immerses herself into communities in Oceania and invites Oceanic people, skilled in their own craft, to collaborate with her. White's approach in her practice embodies ideas of unity and the importance of establishing and maintaining relationships that contributed to the work.

\footnotetext{
${ }^{263}$ Skinner, "Continuity and Change in Customary Arts." "Robin White," http://citygallery.org.nz/exhibitions/robin-white.

264 "Robin White".

265 "Continuity and Change in Customary Arts," 496.
} 


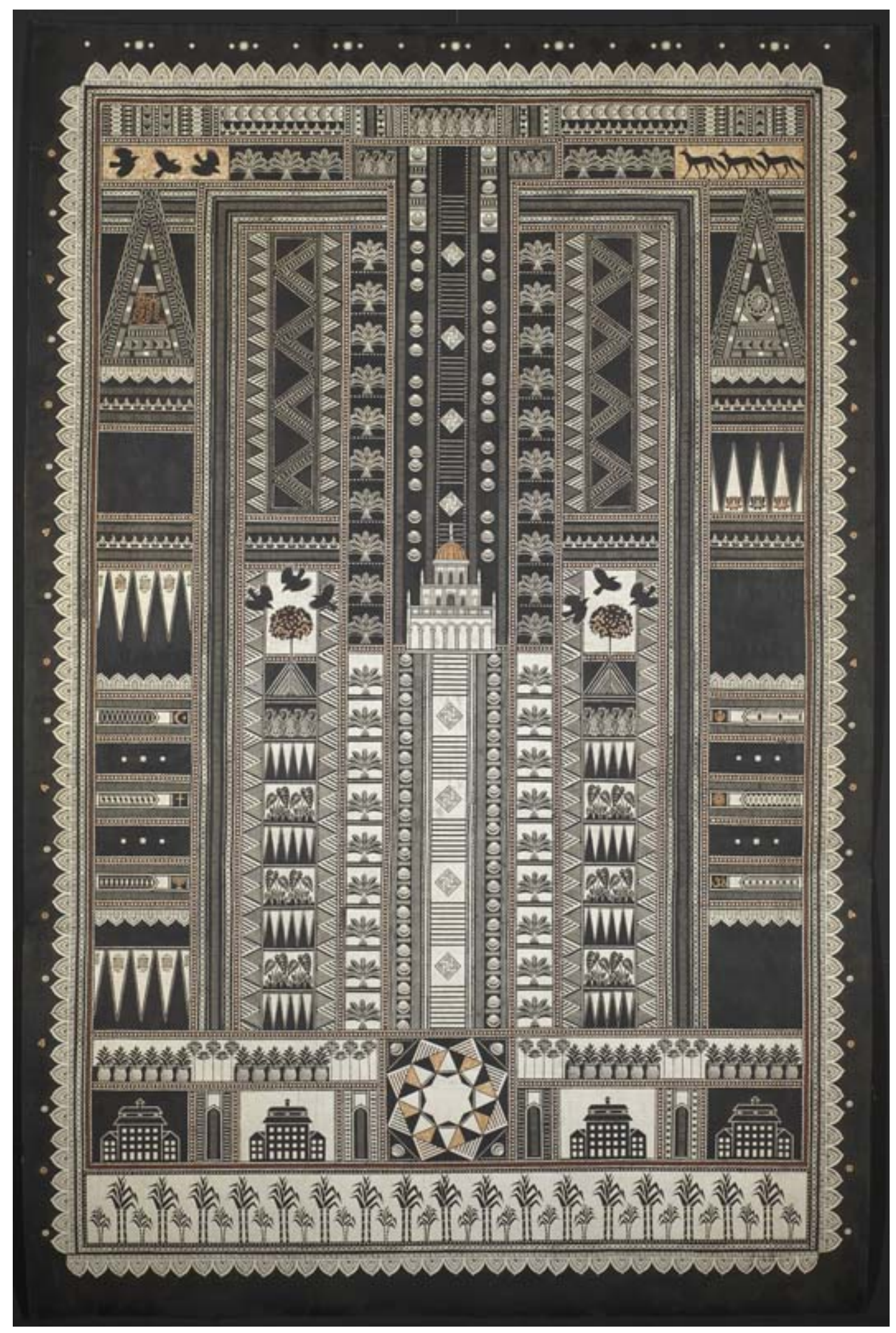

Figure 3: Robin White Teitei vou (A new garden) $2009^{266}$

\footnotetext{
${ }^{266}$ Robin. White, Toki, Leba., \& Jione, Bale., Teitei Vou (a New Garden) (Detail), 2009. The cloth illustrated, called a taumanu, is one of nine components in the complete work, which includes mats
} 


\section{Greg Semu}

New Zealand born Samoan Greg Semu is a self-taught photographer who works with strong and often confronting imagery of cultural displacement and the tensions between colonialism and primitivism. These themes in Semu's work reflect his life experiences, growing up a Samoan-New Zealander in a Catholic family, moving to New York when he was twenty five, continuing on to France for a number of years and eventually settling, for now, closer to home to in Australia ${ }^{267}$. Being always familiar with the notions of 'outsider,' Semu states that the reason behind shifting to such vastly different areas of the globe is that "It's just that whole sort of displacement thing - trying to find a place called home you know? And I'm still looking ${ }^{\prime 268}$. Semu originally started his career as a model. However, he was soon drawn to the photography side. His mentor at the time, New Zealand cinematographer, photographer, and director Kerry Brown ${ }^{269}$. As a result Semu describes himself as a commercial art photographer composing his scenes the fashion shoot way, complete with "actors, art department, wardrobe, hair and make-up ${ }^{\prime 270}$. Semu presents critical images that engage with the issues around colonialism and invites the audience to think about the effects this had on culture. One of Semu's images, titled The Last Cannibal Supper...cause tomorrow we become Christians (2010), depicts the scene of the famous The Last Supper painting by Leonardo Di Vinci but instead of European people, Semu features himself and local

made of woven pandanus with commercial wool, woven barkcloth and sari frabric, $390 \times 240 \mathrm{~cm}$. Art in Oceania: A New Hisotry.

${ }^{267}$ Steve Kilgallon, "Art Rewards 'Are There'," Sunday Start Times, 3oth October 2011.

${ }^{268}$ Lily Hacking, "A Fantasy of Paradise," Art Zone: Exhibitions, galleries, artists2011.

${ }^{269}$ Ibid.

${ }^{270}$ Ibid. 
Kanak people characterizing Jesus and his disciples ${ }^{271}$. The Tjibaou Cultural Centre in Noumea, New Caledonia, commissioned this piece ${ }^{272}$. The scene brings forward the realization of conversion in Oceanian societies during colonialism as being both virtuous and problematic for Oceanian culture. The interesting aspect to this particular piece by Semu is the subtle underlying commentary running through the work having placed himself in the center of the work as Jesus. Semu poses openly displaying his array of Samoan tattoos and part of his pe'a while the rest of the kanak people are mostly all adorned with foliage and headresses. The lighting has also been focused down specifically on Semu to make only his figure appear lighter then all of the other people in the image. Is this a commentary not only on the effects of Christianity on primitive Oceanic cultures but also on the fact that in many parts of Oceania, Christianity was introduced by converted Oceanic missionaries, not European missionaries ${ }^{273}$.

Semu's approach to Oceanic creative practice focuses on the space in-between primitivism and colonial contact, asking his audience to think about how displacement in history effects our present situation. "Too many people take photographs. They take and they don't give back. I'm just not comfortable with that. For me it is better to give than to receive. ${ }^{\prime 274}$ As an artist Semu gives his

\footnotetext{
${ }^{271}$ For a full interview about this piece and other images in the series see: Karen Jacobs, Chantal Knowles, and Chris Wingfield, Trophies, Relics and Curios?: Missionary Heritage from Africa and the Pacific(Sidestone Press, 2014), 139-43.

${ }^{272}$ Hacking, "A Fantasy of Paradise."

${ }^{273} \mathrm{~N}$. Thomas, "European Incursions," in Art in Oceania: A New Hisotry, ed. P. Brunt, Thomas, N., Mallon, S., Bolton, L., Brown, D., Skinner, D., \& Kuchler, S.(London: Thames \& Hudson Ltd, 2012), 284 .

274 "Better to Give: The Greg Semu Archive," Auckland Art Gallery, http://www.aucklandartgallery.com/whats-on/events/2012/june/better-to-give-the-greg-semuarchive.
} 
audience a critical perspective on displacement in Oceania allowing his audience to focus on particular moments in history and place themselves in the spaces inbetween the depicted moment and asks the audience to reflect on their current position. "As an artist, when people walk up to your space you want them to feel it straight away... It's like entering the underworld, pulotu is what we call it." ${ }^{275}$

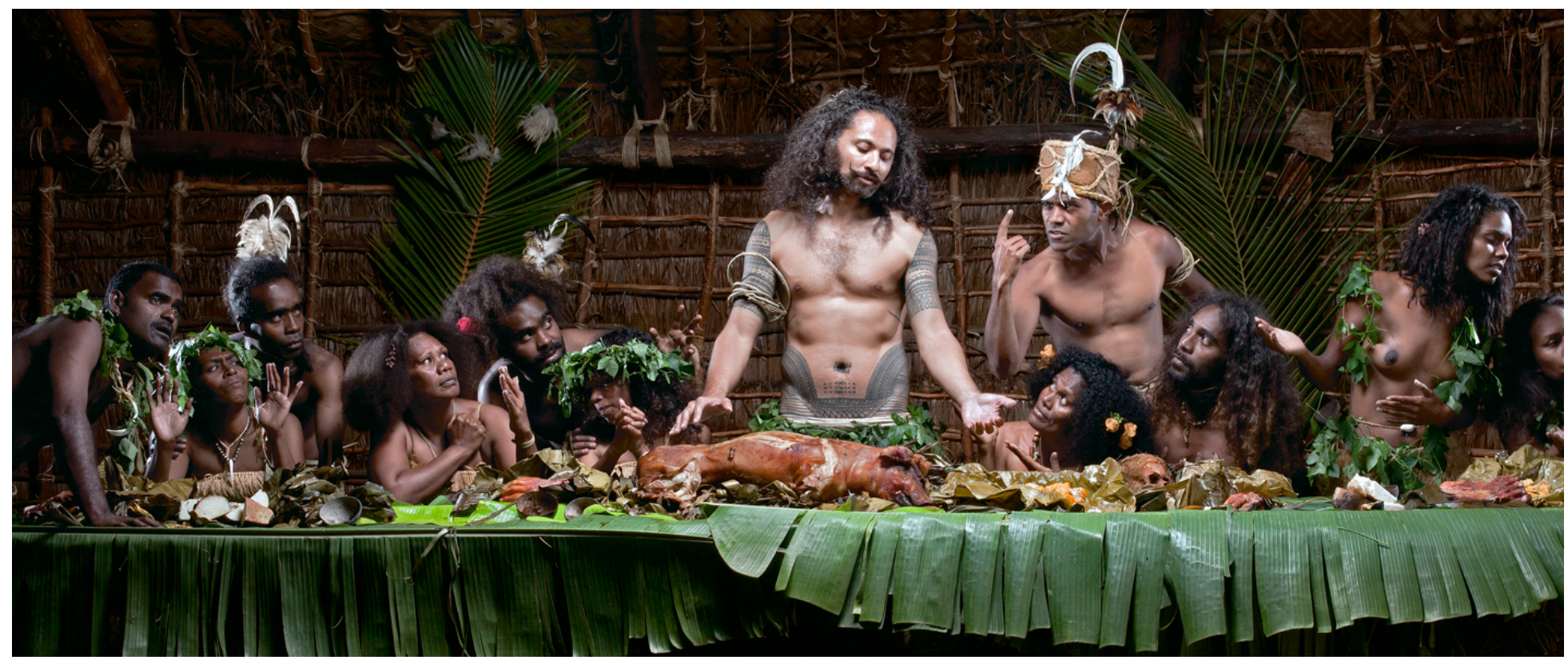

Figure 9: The Last Cannibal Supper... cause tomorrow we become Christians, $2010^{276}$

\footnotetext{
${ }^{275}$ Hacking, "A Fantasy of Paradise."

${ }^{276}$ Greg Semu, The Last Cannibal Supper...Cause Tomorrow We Become Christians, 2010. $100 \times 286 \mathrm{~cm}$. Trophies, Relics and Curios?: Missionary Heritage from Africa and the Pacific.
} 


\section{Hohepa Thompson}

Hohepa Thompson, an artist behind the clothing brand Hori, is originally from Wellington and studied at Victoria University Wellington. He has since lived and worked as an art and design teacher in Masterton and now lives in Australia. The inherent theme behind Hori is "through Print, fashion \& design HORI is dedicated to provoke conversation about different NZ themes \& issues that I feel strongly about $^{\prime 277}$. The first series by Hori was shown as part of the 2012 Miromoda Māori Fashion Design competition in New Zealand Fashion Week (NZFW) ${ }^{278}$. This series immediately put Hori in the spotlight because of a controversial image on a t-shirt in the collection which depicted the face of Māori activist Tame Iti as Osama bin Laden $^{279}$. The image caused much debate amongst the Māori art community around the question of whether the image qualified as art or insult ${ }^{280}$. The underlying intentions behind Thompson's work is to highlight particular social and political topics in the Māori community and use art to instigate conversations around these topics. Thompson recently showed a collection of his work in an exhibition in Wellington in October 2014. This exhibition, titled Dirty Laundry, showed a myriad of installation work, screen-printed objects and live models and clothing that showcase his work over the last two years ${ }^{281}$. The exhibition was a depiction of the "dirty laundry" the Māori community has accumulated in recent times, highlighted

\footnotetext{
${ }^{277}$ Hohepa Thompson, "About Hori," http://www.thehori.com/about.

278 "Designer's Tame Iti T-Shit Draws Controversy," Fairfax, http://tvnz.co.nz/national-news/designers-tame-iti-t-shirt-draws-controversy-4975261.

${ }^{279}$ For more information on this controversy see: Rachel Wattie, "Maori Fashion Courts Stylish Controversy," Stuff.co.nz, 18th July 2012. URL link: http://www.stuff.co.nz/life-

style/fashion/7294551/Maori-fashion-courts-stylish-controversy

280 "Designer's Tame Iti T-Shit Draws Controversy".

${ }^{281}$ "Dirty Laundry," Urban Dream Brokerage, http://urbandreambrokerage.org.nz/dirty-laundry.
} 
through honest and realistic critical imagery. Another example where Thompson has used conflict as the driver behind his work is in the latest 2014 NZFW where Hori was once again exhibited as one of the finalists in the Miromoda Māori Fashion Design competition ${ }^{282}$. The collection Hori showed this time focused on the statistic that $51 \%$ of the population in the New Zealand penitentiary system is Māori, yet Māori only comprise $14 \%$ of the overall population. Each model walked down the runway wearing a kumikino hori bandana and holding a circular placard showing portrait images of Māori criminals on one side and a key word associated with criminal activity on the other for example, murder ${ }^{283}$. Each model threw away their placard on their walk back down the runway as a metaphor for letting go of these media induced criminal stereotypes and regaining pride and positive representation in Māori culture. Although Thompson's work is often criticized and seen as further stereotyping Māori people, Hori as a brand injects much needed conflict into Māori creative production. As Mahina explains as part of $t \bar{a}-v \bar{a}$ theory of reality, conflict and order operate in unity. Conflict helps to maintain balance and connect to the reality of a context. Artists such as Thompson are necessary in Oceanic creative practice to maintain a point of criticality and instigate conflict in our creative approaches within the New Zealand context. The benefits of conflicting ideas being interpreted creatively is that the idea or problem enters into a space in-between, where there is an openness around discussing content and potential ideas for addressing the problem. When interviewed about his Dirty Laundry exhibition

\footnotetext{
${ }^{282}$ Hohepa Thompson, interview by Ripeka Timutimu, 2nd October, 2014.

${ }^{283}$ The full runway show of Miromoda Māori Fashion show can be viewed here: http://www.Maoritelevision.com/news/regional/nzfw-full-miromoda-fashion-show Hori's collection features at about 5:00 minutes into the video.
} 
Thompson said the work "Was created so you could look at different issues and use

the art to talk about (those) issues." ${ }^{284}$

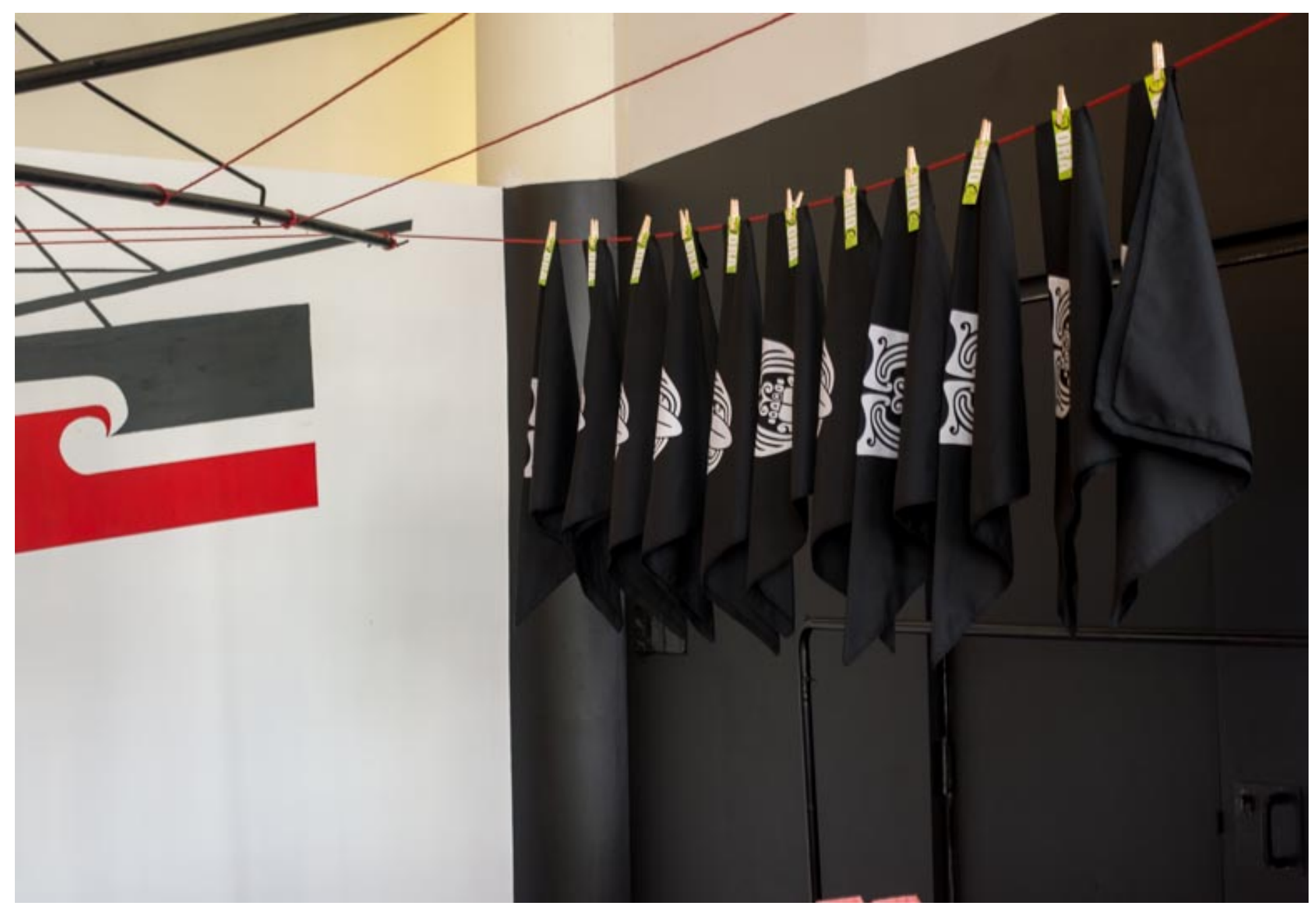

Figure 10: Kumikino hori bandanas pegged on a washing line in the HORI Dirty Laundry exhibition ${ }^{285}$

\footnotetext{
${ }^{284}$ Thompson, "'Hori' Artist Airs Our 'Dirty Laundry' in Wellington."

Full interview can be found here: http://www.Māoritelevision.com/news/regional/hori-artist-airs-outdirty-laundry-wellington, accessed $30^{\text {th }}$ January 2014

${ }^{285}$ Gabrielle McKone, "Dirty Laundry" photograph, 2014, Urban Dream Brokerage,

http://urbandreambrokerage.org.nz/dirty-laundry/ (accessed March 9, 2015).
} 


\section{David Hakaraia}

David Hakaraia is a Māori industrial designer who studied both his undergraduate and Masters of Design degrees at Victoria University Wellington under the Industrial Design program. Since completing his degree Hakaraia predominately worked as a freelance designer as well as in the university environment tutoring courses and also mentoring Māori and Pacific students through his role as co-ordinator for Te Rōpu Âwhina in the Schools of Architecture and Design ${ }^{286}$. Being one of the few contemporary Māori designers as opposed to an artist, Hakaraia features both traditional and modern fabrication techniques in his work, typically a combination of both methods. A big focus of his designs is in depicting narratives in a visual form. Hakaraia states that "these stories have captured his imagination and he relishes expressing them in ways that depart from a customary tribal style, creating a design approach that is distinctly his own ${ }^{287}$. Hakaraia is acutely aware of the damning effects modernity have had on Māori creative production. For this reason he seeks to explore how, in the present day, contemporary production techniques can be used towards a positive and more holistic approach. An approach in contemporary creation that pays homage to key principles and narratives embedded in traditional Māori creative forms. In a recent interview Hakaraia states "this work gives me the opportunity to show people how contemporary design and Māori culture can be

\footnotetext{
${ }^{286}$ Te Rōpu Āwhina is an on campus support whānau for Science, Engineering, Architecture and Design disciplines which was start by Liz Richardson (dean of equity) in 1999 more information can be found here http://www.victoria.ac.nz/science/Awhina/.

287 "Hakaraia Designs," http://www.hakaraia.co.nz/\#!about.
} 
combined to create something visually innovative but with the same high level of integrity and importance that the original art forms of Māori have always displayed"288. As a designer Hakaraia has focuses on mainly producing furniture and lighting designs that are made using laser-cutter, CNC (computer controlled cutting machine) and 3-D printing technologies. These furniture pieces, although made using modern techniques, are used by Hakaraia to produce intricate Māori patterns as seen in traditional carving and to carve land forms, all relating back to narratives embedded in Māori mythology and indigenous principles.

One furniture piece made by Hakaraia that demonstrates this is his Ranginui and Papatūānuku table. This piece is a physical embodiment of the moment in a Māori creation myth where their son Tāne Mahuta separates the deities Ranginui and Papatūānuku, resulting in Ranginui becoming the sky and Papatūānuku becoming the earth. The glass top of the table being held up but the convex shaped wood in the center represents Ranginui or the $s k y^{289}$. The steam bent wooden body of the table is Tāne Mahuta, the bent shape of the body represents Tāne Mahuta separating his parents ${ }^{290}$. The four cast hydro-stone footings are a representation of Papatūānuku, which are bound to the legs of the table with string. This represents the connection between Tāne Mahuta and Papatūānuku and how "they are bound together like the roots of a tree into the earth"291.

\footnotetext{
288 "Artist Profile: David Hakaraia," Kura Aotearoa Art + Design, http://www.kuragallery.co.nz/category/artists/david-hakaraia.

${ }^{289}$ David Hakaraia, "Te Reo Tataki O Te Ringa: Maori Narratives and Contemporary Technology " (MDes, Victoria University of Wellington, 2012), 24.

${ }^{290}$ Ibid.

${ }^{291}$ Ibid., 24-25.
} 
Hakaraia's designs are a great example of how indigenous knowledge can be interpreted into modern forms without losing touch with the essence of Māori culture that is embedded into every aspect of his designs. Hakaraia's approach of thinking through Māori ideology to guide him through his design process promotes a form of contemporary Māori discourse that leads Māori creative practice out of stagnant unchanging forms and into relevant modern designs that move with the development of culture through space and time.

Figure 11: David Hakaraia, Ranginui and Papatūānuku table ${ }^{292}$

292 Image Courtesy of the artist David Hakaraia 


\section{Discussion: Oceanic creative practitioners}

Each Oceanic creative practitioner discussed in this chapter offers different approaches to working within Oceanic creative practice. Sopolemalama Filipe Tohi approaches creative practice directly through the past by closely working with Tongan lalava. Tohi experiments with the traditional forms and combinations of lashing techniques, reinterpreting these techniques using seemingly unconventional weaving materials such as steel piping, stone and wood. This process undertaken by Tohi demonstrates how indigenous traditional craft forms can be revived in a contemporary sense while still embodying the same principles and communicating the same narratives. Tohi's work mitigates the space between indigenous and contemporary art through simply changing the scale and material of traditional Tongan lalava.

The essence to Tohi's work is that he does not change the artform of lalava but instead seeks to use new materials to express the intricate form of visual language instilled in Tongan lalava. All of Tohi's works are examples of how traditional symbolism and form can be taken into a contemporary space without losing cultural meaning. In a recent blog written by Scott Hamilton about the exhibition Tukutuku Kafa Mei Lotomoana: Survey Part Two, featuring a range of Tohi's work, Hamilton states, "where European modernism was often based upon a self-conscious rejection of all earlier forms of culture, Tohi's (counter) modernism unapologetically 
incorporates the ancient design traditions of Oceania"293 Tohi's work offers a highly successful way of engaging with the contemporary while still remaining connected to indigenous knowledge.

Robin White offers ideas of how to approach creative collaboration within Oceanic creative practice. Just as Tohi has, White successfully experiments with the traditional by situating her work in the cultural traditions of tapa making, more specifically in making masi and ngatu (Fijian and Tongan tapa). White collaborates with groups of women from these Island nations in order to produce the large pieces and as a collective they create the work incorporating both traditional and new symbolism printed on the work. White travels to specific villages and participates in the complete making process. Collaboration in Oceanic creative practice should be grounded in collectivity resulting in a successful project based on the active participation of all members in the creation process. In this approach a successful project is measured through the harmonious unity based on the contribution and representation of each member in the work.

Semu's work offers an approach in Oceanic creative practice that is concerned with political conflict. Semu offers moments of reflection about critical points of conflict in Oceania's colonial history. Although moving forward, Oceania is still very much affected by colonialism. Oceanic creative practice has the potential to question the cause and effect of past situations in order to express resistance to our current

\footnotetext{
${ }^{293}$ Read more: http://eyecontactsite.com/2014/og/filipe-tohi-and-the-art-of-lashing\#ixzz3QSn2Tqeo Under Creative Commons License: Attribution Non-Commercial
} 
situation. Resistance is a process of instigating conflict; if Oceanic creative practitioners can work through this conflict to achieve order and beauty perhaps these forms will contribute to changing decolonized mindsets throughout Oceania. Semu's work is an example of mitigating colonial conflicts seen throughout Oceanic histories and serves as a form of passive resistance in the quest to find a new Oceania.

Offering a similar approach to Oceanic creative practice as Semu, Hohepa Thompson and his brand HORI also confront political conflict as a result of colonial integration. Thompson's work mainly focuses on the stereotypes that have emerged through media portrayals of Māori people. Thompson uses these stereotypes to confront the realities and truth behind why these portrayals exist. Thompson uses conflict in his creative work to confront the Māori community about the implications and reality of how Māori people are represented in modern day society. Thompson's work draws the audience into an uncomfortable, confronting space that demands a strong response. When creative works respond to society in such a rebellious way it sparks an immediate strong response. Oceanic creative practice needs radicals and extreme creative works to provoke and stir Oceanic societies.

Within the woven framework for Oceanic creative practice the conflict instigated through Thompson's creative work does not yet aid in the harmonious balance between beauty, symmetry and harmony. However, creative production is a space where boundaries are pushed in order to establish a polemic response from 
communities. This approach once again injects conflict into society to provoke change. In his work Thompson just provokes and doesn't answer, leaving society to work through the conflict to once again find order. Thompson is the epitome artists negotiating with a bi-cultural identity. Through his creative work Thompson is attempting to negotiate the relationship between his Māori and European heritages. As a result Thompson's creative work addresses both Māori and European culture as a whole within his own identity, he does not privilege one culture over the other in his creative practice. In this approach Thompson has chosen to focus on the conflict between Māori and European cultures in New Zealand. Thompson's work exists within the process of the weaver(s) negotiating the tensions within strands and manipulating them to be integrated into the weave. For Thompson's work to sit harmoniously on the mat of Oceanic creative practice there needs to be further commentary or suggestion through his work on how to address the societal problems identified in his creative work.

David Hakaraia is similar to Tohi in his approach to creative practice. Hakaraia focuses on bringing forward narratives in his furniture designs that are inspired by Māori mythology but are embodied in contemporary forms and materials. Narrative is a key component of traditional Oceanic craft throughout history and so it is pertinent that as modern Oceanic people we maintain the element of narrative in future creative works. It has been established that Māori and other groups throughout Oceania developed and changed their tools and making methods in response to changing times and contexts. Narrative however, remained throughout all creative works. The value of incorporating mythology into creative production 
lies in the inherent indigenous principles and ideologies embedded in myths. Connecting to myths in the production of Oceanic creative work engrains these indigenous principles into present spaces and makes a connection back to the past. As discussed earlier in this research it was highlighted that through indigenous understanding we should always walk into the future facing backwards because the past leads the future.

A contemporary Oceanic identity has already been integrated in the character of Oceanic people residing in New Zealand and there are many Oceanic people connecting to their identities through their creative work. The migration into urban centers in places such as New Zealand has provoked a reinterpretation of culture for many. What the New Zealand context is lacking in creative industries is a clear framework from which all Oceanic creative practitioners can draw understandings. This chapter has established that the essence to Oceanic creative practice lies in the importance of connections within a community. Vā has been identified as an approach through indigenous knowledge of understanding connections and the importance of unity. The framework for Oceanic creative practice has been described as a woven mat in this chapter. The process of weaving a mat is likened to the intermingling of social entities resulting in the growth of a society. This research has analysed the importance of interweaving creative practitioners and creative works in order to grow a community within Oceanic creative practice. Oceanic creative practitioners have been identified in this chapter to begin the process of interweaving not only their work but also their differing but yet intertwining approaches within Oceanic creative practice. In conclusion this chapter has 
evaluated both traditional and contemporary creative practitioners and their outputs to translate how principles embedded in vā can form a framework for Oceanic creative practice. 


\section{Epilogue}

"We are not interested in imitating (western art) and asking our artists to perform dances for tourists. It is time to create things for ourselves, to create established standards of excellence which match those of our ancestors...The development of new art forms that are truly Oceania, transcendent of our national and cultural diversity, is very important in that it allows our creative minds to draw on far larger pools of cultural traits than those of our individual national lagoons."

- Epeli Hau'ofa ${ }^{294}$

At the beginning of this research a chant was presented in Māori. This chant is a pardon that is spoken before Māori people cut the leaves of a plant. The pardon is to "ask the gods to forgive us for ending the life of the leaves to be picked from the kawakawa tree" or any other plant species that is to be used for the benefit of humans ${ }^{295}$. This chant as described by Tui Atua Tupua Tamasese Ta'isi Efi decribes not only a Māori indigenous ritual but a also ritual in many Polynesian cultures that recognises the "existence of tapu in the plant and between the plant and humans ${ }^{\prime 296}$. The purpose of writing this chant at the beginning of this thesis was to represent the beginning process of picking, preparing and weaving together strands of knowledge into a woven framework that characterises Oceanic creative practice. Choosing a Māori version of this chant establishes this research as embedded into the earth of Aotearoa New Zeland. The purpose of this research is to begin a

\footnotetext{
${ }^{294}$ Epeli Hau'ofa. "Red Wave Collective," October Gallery, 2006.

${ }^{295}$ Efi, "Keynote Address: Bio-Ethics and the Samoan Indigenous Reference," 117.

${ }^{296}$ Ibid.
} 
conversation about unity within Oceanic creative practice. As the final line of the chant states "Uhi wero tau mai te mauri hau mai e. - Let it be placed upon, Let it be debated, so that through this the life essence may come through strongly".

My overall research question was:

How can indigenous visual spatial strategies be used to assist in the definition of a framework that helps characterise Oceanic perspectives and methods of creative practice?

This epilogue will reflect on how connections have been established and woven together within this thesis to form a framework for Oceanic creative practice.

"Oceania is vast, Oceania is expanding, Oceania is hospitable and generous, Oceania is humanity rising from the depths of brine and regions of fire deeper still, Oceania is us. ${ }^{297}$

\section{Chapter one: Migration}

"We have to write our history of the Pacific as the history of Native and Stranger Bound Together because we are bound together by that past reaching into the present." $[\mathrm{sic}]^{298}$

This chapter introduced indigenous symbols depicted on Lapita pottery, and explained, through the research done by Kirch, Green and Mead, the symbols seen

\footnotetext{
${ }^{297}$ Ibid., 160.

${ }^{298}$ Dening, "Mr Bligh's Bad Language: Power, Passion and Theatre on the Bounty," 178.
} 
on Lapita pottery do in fact pertain to a visual code of grammar ${ }^{299}$. Kirch suggests that this visual code was not only carried through generations of Lapita but was most likely developed into other forms of creative production ${ }^{300}$. He argued that a number of these symbols are illustrated in, what is now considered, traditional tattoo and tapa designs from the same regions that Lapita people settled in. The arts of tattooing and tapa making are still practiced in Island nations but these creative practises are now considered traditional expressions of Oceanic creative practice. With the more recent migration of many Oceanic people into urban contexts a further shift has occured in what is now considered contemporary visual expressions of Oceania.

Abstraction is a key feature within Oceanic creative practice both historically and contemporarily. Stevenson emphasises that by "referencing astronomical, navigational and environmental knowledge, these abstract concepts became mnemonic devices that allowed for the dissemination of cultural knowledge $\mathrm{e}^{\prime 301}$. Artists such as Filipe Tohi and Robin White have engaged with abstract forms of expression through their creative careers as a mode of simultanenously connecting between the past and present.

Tohi, whose works are abstract creative forms reinterpret lalava formations, are also categorically contemporary abstract forms. In a recent review of a Tohi exhibition, Mark Amery writes "From a European art perspective the work strongly evokes the

\footnotetext{
${ }^{299}$ Patrick Vinton Kirch, The Lapita Peoples: Ancestors of the Oceanic World (Cambridge, Mass: Blackwell Publishers, 1997), 125.

300 Ibid., 131-32.

${ }^{301}$ Stevenson, The Frangipani Is Dead: Contemporary Pacific Art in New Zealand, 1985-2000, 84.
} 
op art of the 1960s, yet Tohi's take from his study in an ancient Pacific craft shifts this into new ground - the old centre is displaced" ${ }^{\prime 302}$.

White's creative work directly deals with the art of tapa. White derives her own symbols inspired by her surrounding contexts expressed through tapa symbols and motifs. These symbols are then applied to tapa cloth that White has made with a collective of women in whatever island she was working in at the time e.g. Fiji, Tonga etc.

Parralleling Whites approaches in her creative works, Stevenson affirms that "Pacific Islanders however, believe that tradition embodies knowledge, the interpretation of which was and is constantly changing...As such the interplay between abstraction and tradition becomes complex in the current environment as artists choose which traditions to draw upon"1303. As the Pacific art movement in New Zealand has grown since its emergence in the 1980s, many artists have been inspired by traditional Oceanic creative practices but are also influenced by European creative expressions resulting in a fusion of two very different approaches to creative practice. This fusion has often resulted in creative outputs that challenge the current understanding of modern abstraction through notions of Oceanic creative practice.

It has been established through this research that creative expressions are snapshots of time and space. David Gegeo was introduced in the Migration chapter

${ }^{302}$ Ibid., 85 .

${ }^{303}$ Ibid. 
to help understand issues of identity that are intrinsically connected to creative expression. Gegeo discusses that one can physically occupy a space while still remaining rooted in (a potentially distant) place. This aids in the understanding of how and why Oceanic creative practitioners in New Zealand produce creative work with both Oceanian and European visual associations. The ability to remain rooted in place while physically occupying a new separate space requires Oceanic people to nurture the relationship they feel between them and their homeland. The indigenous spatial strategy $v \bar{a}$ bestows a perspective of unity-in-all. This perspective provides a basis for understanding how an individual nurtures the connection between themselves and their homeland. The work produced by Oceanic creative practitioners narrates the connection between an individual and their homeland.

\section{Chapter two: Vā}

"Herein, people are thought to walk forward into the past and walk backward into the future, both taking place in the present, where the past and the future are constantly mediated in the ever-transforming present ${ }^{\prime \prime 304}$

Understanding sacred relationships as vā taupia, maintains order in the genealogy of all things animate and inanimate. Teu le vā/ tauhi vā is the act of nurturing and protecting these sacred relationships negotiating between place and space to balance in harmony. This requires relationships not to be concieved as a single linear series of connections but as a complex structure of interconnected relationships that respond to both space and time. Okusitino Māhina's tā-vā theory of reality

${ }^{304}$ Hufanga Okusitino Mahina, "Ta, Va, and Moana: Temporality, Spatiality, and Indigeneity," Pacific Studies 33, no. 2 (2010): 170. 
presents a set of ideologies pertaining to the relationship of space and time that embody vā-ticulation from an indigenous Tongan perspective.

\section{Chapter three: Creative Constructs}

"If new ideas are to assume artistic form, physical, sensual, spiritual and intellectual forces and abilities must all be equally available and act in concert ${ }^{\prime \prime 305}$

With the intersection of western creative approaches being integrated into contemporary Oceanic practice in New Zealand, it is necessary to understand how Western and Oceanic discourse are interconnected to think of how both contribute to understanding Oceanic creative practice. This research presented one point of connection between these creative approaches in the Creative Constructs chapter of this research. This chapter analysed the value of $v \bar{a}$ in Oceanic creative practice and also introduced four western artistic educators. Fredrick Froebel and Froebelian kindergarten was at the forefront of the discussion in this section. Froebel's philosophy of being connected to nature and believing in the unity of all things perfectly parallels the philosophies of $v \bar{a}$. Through this philosophy Froebel derived 20 gifts to be systematically presented to children in his kindergarten education system as part of educating them through notions of play. Three prolific artistic educators emerged from Froebelian kindergarten, Bauhaus masters Johannes Itten and Laszlo Moholy-Nagy, and the American architect and futurist Richard Buckminster-Fuller. Each artistic educator, throughout their careers, has demonstrated how Froebelian kindergarten has similarly influenced their

\footnotetext{
${ }^{305}$ Itten, Design and Form: The Basic Course at the Bauhaus and Later, 9.
} 
approaches and philosophies as creative practitioners. The discussion of these western educators established a fundamental link between western artistic pedagogy and Oceanic creative practice. This link was made through comparing of approaches between these western creative practitioners with the philosophies embedded in vā.

\section{Chaper four: Vā-ticulation}

"An articulated ensemble is more like a political coalition or, in its ability to conjoin disparate elements, a cyborg" ${ }^{\prime 306}$

Vā-ticulation as an indigenous spatial strategy helps us to understand the connection between an individual and their homeland. The culmination of vāticulation understands that the connections between entities take the form of relationships to be nurtured. This creates mindful connections that are sinuous in quality and maintain necessary parts of relationships while still remaining relevant in response to contextual changes over time.

The recognition of the connections between things is a crucial aspect as to why vāticulation is so relevant to Oceanic creative practice. Works produced by Oceanic creative practitioners need to contribute to a relationship and not just exist in space. Identifying that relationships exist between inanimate things makes creative practitioners accountable to produce new work that contributes to the harmony of surrounding connections

${ }^{306}$ Clifford, "Indigenous Articulations," 478. 


\section{Chapter five: Oceanic Creative examples}

"'Oku hange 'a e tangata, ha fala 'oku lālanga"

-Society is like a mat being woven ${ }^{307}$

The final chapter concluded the key points of $v \bar{a}$ as valid to this research and presented a metaphor of a woven mat as the precedent for a framework for Oceanic creative practice. An indigenous Tongan proverb says "'Oku hange 'a e tangata, ha fala 'oku lālanga" which translates to mean "society is like a mat being woven" ${ }^{308}$. Likening a framework for Oceanic creative practice to a mat being woven is inspired from this Tongan proverb. I envision Oceanic creative practice as a growing society interlinked by $v \bar{a}$. All animate and inanimate phenomena live in the $v \bar{a}$ of Oceanic creative practice, $v \bar{a}$ is a process of weaving connections together to form relationships, which in time formulates a collective. The purpose of this research was not to formulate a litmus test about who qualifies to be part of Oceanic creative practice, but rather to identify approaches, both indigenous and otherwise, that help creative practitioners of Oceania to be aware of and strengthen their surrounding connections to grow into a society.

"Those who make the ocean their home and love it, can really claim it as their own. Conquerors come, conquerors go, the ocean remains, mother only to her children.

\footnotetext{
${ }^{307}$ Traditional Tongan proverb translated by Heather Leslie Young: Young Leslie, "'"...Like a Mat Being Woven"."

308 Ibid., 115.
} 
This mother has a big heart though; she adopts anyone who loves her. ${ }^{1309}$ I would like Oceanic creative practice to be perceived through this perspective. For anybody to work in Oceanic creative practice they must love it in its totality and she in turn will weave you into her mat. Love is the epitome of any relationship; to love is to respect, to vow to protect and most importantly to commit to a lifetime of nurture. Harmony and beauty exist in love, it is the true balance that we strive for in our existence.

"Action is the product of the qualities inherent in nature. It is only the ignorant man who misled by personal egotism, says: 'I am the doer'"- Bhagavad-Gita

Much of the visual culture of Oceania depicts symbolism or uses materials directly related to the flora, fauna and ocean that surround the region. Creativity in this context of Oceania does not mean the doer but more so the responder, the communicator of the space and time between rock (inanimate) and human (animate). The cultures of Oceania work in partnership with nature. Many Oceanic creation stories narrate close relationships, even kinship, between humans, flora, fauna, and inanimate objects ${ }^{310}$. Creativity is instigated through a response to inspiration. Nature is often the inspiration behind Oceanic artefacts. Oceanic creative practice is therefore bound to nature in the most unbreakable way, for the deeply embedded indigenous belief systems communicate that without nature humankind simply would not exist.

\footnotetext{
${ }^{309}$ Hau'ofa, "Our Sea of Islands," 155-56.

${ }^{310}$ Efi, "Keynote Address: Bio-Ethics and the Samoan Indigenous Reference," 118-19.
} 
Creativity is the genealogical link between all Oceanic creative practitioners.

Through the earlier discussion of the Lapita people and their journeys throughout Polynesia it has been established that Polynesian people living in New Zealand historically stem from one unifying cultural group. Expanding beyond Polynesia, Hau'ofa argues all Pacific people should recognise a unifying oceanic identity, not as Pacific people but as people of Oceania. Supporting this belief, Albert Wendt also contends that the creation of a new Oceania is in the hands of our artists, our creative people. Erenora Puketapu-Hetet, an acclaimed Maori weaver and academic, states "The ancient Polynesian belief is that the artist is a vehicle through whom the gods create ${ }^{\prime \prime 311}$. By channelling indigenous knowledge and experience through their art work, creative outputs and creative practitioners lay the cornerstones of a future that is working towards the creation of a new Oceania.

Shifting from a Pacific perspective to a western mid-2oth century one, BuckminsterFuller states that he does not believe in the word creativity because he thinks, "the word creation implies adding something to the universe. And I don't think man adds to the universe ${ }^{\prime \prime 312}$. Through the indigenous Oceanic perspective of refocusing nature at the heart of creation, Buckminster-Fuller's perception of man adding nothing to the universe is altered to focus more on the process of situating ourselves within the balance of the universe. Within this context, instead of humans expressing their dominance over the physical world there is a shift in power relation. We become part of an articulated whole, where human production participates in part of the process between entities in flux, hooking and unhooking to maintain a

\footnotetext{
${ }^{311}$ Erenora Puketapu-Hetet, Maori Weaving(Auckland, N.Z: Pitman, 1989), 2.

${ }^{312}$ R Buckminster Fuller, Utopia or Oblivion (Overlook Press, 1973), 46.
} 
universal balance in nature. Humans have a participatory position in this case where we consciously add and subtract within a bigger context, a universal context that goes beyond what we know in our physical world. Within this process it is our responsibility to maintain our connection and keep our world balanced in the universe that surrounds us.

Although not based in New Zealand it is important to this research to highlight the Oceania Centre as one of the very few arts schools in the Pacific region that is grounded in the realm of Oceanic scholarship and is dedicated to fostering all forms of Oceanic creative practice. The Oceania Centre for Arts, Culture and Pacific studies was established at the University of the South Pacific (USP) at the Laucala campus in Suva Fiji in 1997. Epeli Hau'ofa was appointed the first director of the centre and remained director until his passing in $2009^{313}$. At the time of the center opening of it was operated independently from the other programs within Faculty of Islands and Oceans and now Faculty of Arts and Law. The Oceania Centre for Arts, Culture and Pacific studies is now an all encompassing Centre not limited to one specific field of creative practice but is open to art, performance, music, Culture, and Pacific studies ${ }^{314}$. The Centre is a place of unity, with the unifying theme being the ocean, which has shaped cultures. The Centre is an inspirational space to respond to the common, yet diverse experiences Oceanic people have had and

\footnotetext{
${ }^{313} \mathrm{P}$ Brunt, "Contemporary Pacific Art and Its Globalisation," in Art in Oceania, ed. P. Brunt, Thomas, N., Mallon, S., Bolton, L., Brown, D., Skinner, D., \& Kuchler, S.(London: Thames \& Hudson Ltd, 2012), 418.

${ }^{314}$ A history on the Oceania Centre can be found here: http://www.usp.ac.fj/index.php?id=8708
} 
continue to have with the sea $\mathrm{a}^{315}$. The intention of the Oceania Centre is to provide a space where Pacific people could walk into an environment and create artistry amongst other artists and performers ${ }^{316}$. The Oceania Centre is a place for all Pacific people to come and collaborate and express their emotions and thoughts of their experiences both personally and culturally. Hau'ofa's vision for the Oceania Centre can be viewed as the further realisation of what Wendt heralded, decades earlier, when he spoke of "This artistic renaissance is enriching our cultures further, reinforcing our identities/self-respect/and pride, and taking us through a genuine decolonisation; it is also acting as a unifying force in our region...these artists, through their work, are explaining us to ourselves and creating a new Oceania."1317

As a process of development, the Oceania Centre became an example of regional identity. Hau'ofa's vision was to seek a form of identity that encompassed Oceania as collaborative people within their own national identities. The Oceania Centre aligns with the ideals discussed in this research. This ideal being the Ocean as an expression of regional identity and a connector between creative practitioners, a space to encourage and educate Oceanic creative practitioners. The Oceania Centre is a prime example of an education facility that fosters Oceanic creative practice. I would urge that the philosophical foundations of the Oceania Centre be considered as an inspirational beacon for education facilities tied to Oceanic creative practice

\footnotetext{
${ }^{315}$ Epeli Hau'ofa, "The Ocean in Us," Voyaging Through the Contemporary Pacific, Lanham, MD: Rowman and Littlefield (2000): 129.

${ }^{316}$ Brunt, "Contemporary Pacific Art and Its Globalisation," 418.

${ }^{317}$ Albert Wendt, "Towards a New Oceania," Mana Review: A South Pacific Journal of Language and Literature 1, no. 1 (1976): 60.
} 
and which New Zealand could emulate for the benefit of creative practitioners in Aotearoa. 


\section{Oceanic creative practice manifesto}

\section{Walk into the future facing backwards}

The future is inspired by the past. We learn from past failures and find motivation from past successes. The past is your conscience for the future, let it guide you while you navigate your way and use it as a method of finding your way into the future.

\section{Embrace identity}

Take the time to get to know who you are as a person, understand how your background and past experiences have shaped who you are. Only then can you begin to understand what your creative identity might look like. My experience in my undergraduate degree showed me that my culture was an intrinsic part of my creative identity. As soon as I embraced this within my creative practice suddenly everything became more interesting and felt like it had a relevant purpose. No one finds a true interest by imitating what already exists. Use your identity as inspiration to explore what you are truly interested in.

\section{Stay rooted in place}

This is said in a metaphoric sense. Your roots are connections that run deep into a home soil. For many people in New Zealand that home soil may not actually be here, you may be rooted in another place. The connection you feel with a particular space is a powerful bond between you and all of the experiences that you have within that country. Keep building on these connections even if you have moved to 
another country; in fact creating new connections to your main homeland roots adds more interesting facets to your overall identity. Just make sure you are aware of the strength of these connections. Roots become complex when you feel equally grounded in your indigenous homeland and the land that you current reside in. Either way, just like a tree you must maintain these connections and give them the means to grow healthily.

\section{Nature and Culture are not separate}

The basis of indigenous knowledge is grounded in nature. Nature and culture throughout eras in creative disciplines have drifted apart; the rise of westernization has wedged a gap between the two entities. For design to continue on its path of being a point of difference within societies it is important to trace back to a time where nature and culture exist as unified elements. This connection should be celebrated in unity through creative practice and not be seen as unconnected

\section{There is no beginning or end to traditional culture}

What constitutes traditional culture? At what point in time did it graduate to the level of traditional? Once something is considered traditional can it not be built upon? If something is traditional can it be re-enacted in another place? As Albert Wendt argues in the essay "Towards a New Oceania," "usage determines authenticity": tradition will never remain relevant if it isn't integrated into the 
everyday. Traditional culture is not a practice that is locked away in the fine china cabinet only to be brought out on those 'special occasions'.

Yes there are defining practices and aesthetic aspects of culture that are identified as customary but what we now consider traditional would have once been contemporary. Traditional culture should evolve, developing and growing with its people.

\section{Symbols tell stories}

Island cultures of Oceania have grown from visual roots. Oral traditions and visual symbolism retell genealogy and mythology of Oceania. Now with the colonial experience intertwined with indigenous understandings, we have many more modes of communication but as people of Oceania we should always remain conscious that our roots stem from visual and oral forms. Oral traditions and symbols were used to tell stories and contained the philosophical understandings of indigeneity in Oceania. Oceanic creative practice should ground us in our visual roots. The narrative of indigenous symbols should continue to be carried through the generations of Oceanic creative production.

\section{Vā is essential to Oceanic creative practice}

$V \bar{a}$ connects everything in unity. Vā occupies the space in-between entities and nurtures connections through forming relationships. Oceanic creative practice responds through creative methods to capture moments in space and time and establish visual representations of relationships in the physical world. Creative 
works produced within Oceanic creative practice become snapshots of space and time that narrate the growth of a collective.

\section{Think of connections like tendons}

Vā teaches us to nurture connections and maintain balanced, harmonious relationships. In order to achieve balance throughout contextual changes, connections must be considered tensile in quality. Connections important to Oceanic creative practice should demonstrate the ability to move and stretch before being unhooked from Pacific creative practice. This ensures that connections are intertwined with meaning and cannot be easily unhooked resulting in the displacement of Oceanic creative practice.

\section{Success is collective}

The creation of a New Oceania is not possible through the work of an individual. Collective communities and interconnected relationships are the foundations of Oceania and so should also be maintained in Oceanic creative practice. The ocean connects the land and therefore connects the people. Just like the complex ocean trade networks that were established by Oceanic ancestors navigating between islands, Oceanic creative practice should be striving to make similar creative relationships across geography, national boundaries, and languages. 
Do it for love

Do it for the love of Oceania. "I belong to Oceania- or, at least, I am rooted in a fertile portion of it- and it nourished my spirit, helps to define me, and feeds my imagination...The love affair is endless ${ }^{\prime 3^{18}}$. Oceanic creative practitioners are not part of the collective because they passed some sort of identity litmus test. They are Oceanic practitioners because the love of their practice and the love of Oceania. Love is testament to the enjoyment, respect and motivation you feel towards your creative practice and ultimately towards the development of Oceanic creative practice as a society. That is all we need to create a new Oceania.

${ }^{318}$ Wendt, "Towards a New Oceania," 102. 


\section{Bibliography}

"2006 Census Data- Quickstats About Culture and Identity." edited by Statistics New Zealand: Statistics New Zealand, 2006.

'Ilaiu Talei, Charmaine "'Inasi: Tonga's Reason for Its Western Fale." Paper presented at the Cultural Crossroads: 26th Society of Architectural Historians Australia New Zealand Conference, Auckland, 2-5 July 2009.

Anae, Melani. "Fofoa-I-Vao-'Ese: The Identity Journeys of Nz-Born Samoans." ResearchSpace@ Auckland, 1998.

- - . "Teu Le Va: Toward a Native Anthropology." Pacific studies 33, no. 2-3 (2010): 222-40.

"Artist Profile: David Hakaraia." Kura Aotearoa Art + Design. Kura Gallery, n.d. Web. 15 Dec. 2014. <http://www.kuragallery.co.nz/category/artists/davidhakaraia>.

Bauhaus-Online. "Laszlo Moholy-Nagy." http://bauhausonline.de/en/atlas/personen/laszlo-moholy-nagy.

"Better to Give: The Greg Semu Archive." Auckland Art Gallery, Auckland, New Zealand, 18 June - 8 November 2012. http://www.aucklandartgallery.com/whats-on/events/2012/june/better-togive-the-greg-semu-archive.

Birren, Faber. "Foreward and Evaluation." In The Elements of Color, edited by Johannes Itten: John Wiley \& Sons, 1970.

Brosterman, N. Inventing Kindergarten. New York: Harry N. Abrams Inc, 1997. 
Clifford, James. "Indigenous Articulations." The Contemporary Pacific 13, no. 2 (2001): 468-90.

Cowan, Ruth Schwartz. "The" Industrial Revolution" in the Home: Household Technology and Social Change in the 20th Century." Technology and Culture (1976): 1-23.

Cunnane, Abby. "Beginning, and Beginning." Beginning, and Beginning, City Gallery, 2011, http://old.citygallery.org.nz/assets/new-site/exhibitions/hirschfeldgallery/2011/robin-white/robin-whiteessay.pdf.

Dahrendorf, Ralf. Class and Class Conflict in Industrial Society. Stanford University Press, 1959.

Dening, Greg. "Mr Bligh's Bad Language: Power, Passion and Theatre on the Bounty." Cambridge University Press, Cambridge, 1992.

Wattie, Rachel. “Maori Fashion Courts Stylish Controversy." Stuff.co.nz, 18 July 2012. "Dirty Laundry." Urban Dream Brokerage, Wellington, New Zealand, 27 September 12 October 2014. Web. 21 Jan. 2015.

http://urbandreambrokerage.org.nz/dirty-laundry.

Droste, Magdalena. Bauhaus, 1919-1933. Berlin: Taschen, 2002.

Efi, Tui Atua Tupua Tamasese. "Keynote Address: Bio-Ethics and the Samoan Indigenous Reference." Paper presented at the K. Mila-Schaaf (2008), Workshop Report. Regional Pacific Ethics of Knowledge Production Workshop, 2007.

Fairbairn-Dunlop, Peggy, and Gabrielle Sisifo Makisi. Making Our Place: Growing up Pi in New Zealand. Palmerston North, N.Z: Dunmore Press, 2003. 
Franciscono, Marcel. "Walter Gropius and the Creation of the Bauhaus in Weimar:

The Ideals and Artistic Theories of Its Founding Years." (1971).

Fuller, R. Buckminster. Utopia or Oblivion: The Prospects for Humanity. London: Allen Lane, 1970.

Gegeo, D W. "Cultural Rupture and Indigeneity: The Challenge of (Re)Visioning "Place" in the Pacific." The Contemporary Pacific 13, no. 2 (2001): 467-507.

- - . "Indigenous Knowledge and Empowerment: Rural Development Examined from Within." The Contemporary Pacific 10, no. 2 (1998): 289-316.

Golson, Jack. "Report on New Zealand, Western Polynesia, New Caledonia and Fiji." (1961).

Green, Roger C. "Lapita." The prehistory of Polynesia 60 (1979).

——-. "Lapita Design Analysis: The Mead System and Its Use; a Potted History." Lapita Design, Form and Composition (1990): 33-52.

Green, Roger Curtis. New Sites with Lapita Pottery: And Their Implications for an Understanding of the Settlement of the Western Pacific. University of Auckland, Department of Anthropology, 1978.

Grossberg, Lawrence. "On Postmodernism and Articulation: An Interview with Stuart Hall." In Stuart Hall: Critical Dialogues in Cultural Studies, edited by Stuart Hall, David Morley and Kuan-Hsing Chen, 131-50. New York; London: Routledge, 1996.

Hacking, Lily. "A Fantasy of Paradise." Art Zone: Exhibitions, galleries, artists, 2011. Hakaraia, David. "Te Reo Tataki O Te Ringa: Maori Narratives and Contemporary Technology " MDes, Victoria University of Wellington, 2012. 
"David Hakaraia Design." David Hakaraia Design. N.p., n.d. Web. 20 Jan. 2015. <http://www.hakaraia.co.nz/\#!about>.

Hall, Stuart. "Cultural Identity and Diaspora." Framework, no. 36 (1990): 222-37.

- - . "Race, Articulation, and Societies Structured in Dominance." In Black British Cultural Studies: A Reader, edited by Houston A Baker Jr, Manthia Diawara and Ruth H Lindeborg, 16-66: University of Chicago Press, 1996.

Hall, Stuart, David Morley, and Kuan-Hsing Chen. Stuart Hall: Critical Dialogues in Cultural Studies. New York; London: Routledge, 1996.

Hall, The formation of a diasporic intellectual: An interview with Stuart. "Chen, KuanHsing." In Stuart Hall: Critical Dialogues in Cultural Studies, edited by Stuart Hall, David Morley and Kuan-Hsing Chen, 484-503. New York; London: Routledge, 1996.

Hann, Michael. Symbol, Pattern and Symmetry: The Cultural Significance of Structure. A\&C Black, 2013.

Hau'ofa, Epeli. "The Ocean in Us." The Contemporary Pacific (1998): 392-410. _-_. "Our Sea of Islands." The Contemporary Pacific 6, no. 1 (1994): 148-61. Hau'ofa, Epeli. "The Ocean in Us." Voyaging Through the Contemporary Pacific, Lanham, MD: Rowman and Littlefield (2000): 113-31.

Hunkin-Tuiletufuga, Galumalemana. "Pasefika Languages and Pasefika Identities: Contemporary and Future Challenges." In Tangata O Te Moana Nui: The Evolving Identities of Pacific Peoples in Aotearoa /New Zealand, edited by Cluny Macpherson, Paul Spoonley and Melani Anae, 196-211. Palmerston North, N.Z: Dunmore Press, 2001. 
Itten, Johannes. Design and Form: The Basic Course at the Bauhaus and Later. John Wiley \& Sons, 1975.

-_-. "Johannes Itten." (1957). Published electronically 2015. https://bauhausonline.de/en/pdf/atlas/personen/bauhaus-online_johannes-itten.pdf. Jacobs, Karen, Chantal Knowles, and Chris Wingfield. Trophies, Relics and Curios?: Missionary Heritage from Africa and the Pacific. Sidestone Press, 2014.

Jones, Charles I. "Was an Industrial Revolution Inevitable? Economic Growth over the Very Long Run." Advances in macroeconomics 1, no. 2 (2001): 1-42.

Ka'ili, Tevita O. "Tauhi Va: Nurturing Tongan Sociospatial Ties in Maui and Beyond." The Contemporary Pacific 17, no. 1 (2005): 83-114.

Kilgallon, Steve. "Art Rewards 'Are There'." Sunday Star Times, 30th October 2011.

Kirch, Patrick V. "Lapita and Its Aftermath: The Austronesian Settlement of Oceania." Transactions of the American philosophical society (1996): 57-70.

Kirch, Patrick V, and Terry L Hunt. "Radiocarbon Dates from the Mussau Islands and the Lapita Colonization of the Southwestern Pacific." Radiocarbon 30, no. 2 (1988): 161-69.

- - - "The Spatial and Temporal Boundaries of Lapita." Archaeology of the Lapita Cultural Complex: A critical review (1988): 9-31.

Kirch, Patrick Vinton. The Lapita Peoples: Ancestors of the Oceanic World. Cambridge, Mass: Blackwell Publishers, 1997.

Lilomaiava-Doktor, Sa'iliemanu. "Beyond "Migration": Samoan Population Movement (Malaga) and the Geography of Social Space (Vā)." Contemporary Pacific 21, no. 1 (2009): 1-32. 
Māhina, Hufanga 'Okusitino. "Ta, Va, and Moana: Temporality, Spatiality, and Indigeneity." Pacific studies 33, no. 2-3 (2010): 168-202.

Mallon, Sean, and Pandora Fulimalo Pereira. Speaking in Colour: Conversations with Artists of Pacific Island Heritage. Museum of New Zealand, 1997.

McCarthy, Conal. "Indigenous Material Culture, Colonial Arts and Crafts and New Zealand Museums." In Craft, Community and the Material Culture of Place and Politics, 19th-20th Century, 59-80. Farnham, Surrey: Ashgate Publishing Limited, 2014.

Mead, S. M., Lawrence Birks, Helen Birks, and Elizabeth Shaw. "Memoir No. 38. The Lapita Pottery Style of Fiji and Its Associations. Parts 3 \& 4: Pages 44-98." The Journal of the Polynesian Society 82, no. 4 (1973): 43-98.

Moholy-Nagy, László. "The New Bauhaus and Space Relationship." American Architect and Architecture 151 (1937): 23.

- - . Vision in Motion. P. Theobald, 1969.

Moholy-Nagy, Sibyl, and Walter Gropius. Moholy-Nagy: Experiment in Totality. MIT press, 1969.

Moorfield, John F. "Māori Dictionary." Taonga. Te Aka Online Māori Dictionary, 2003. Web. 11 Sept. 2016.

$<$ http://maoridictionary.co.nz/search?idiom=\&phrase=\&proverb=\&loan=\&ke ywords=taonga\&search=>.

Neall, Vincent E, and Steven A Trewick. "The Age and Origin of the Pacific Islands: A Geological Overview." Philosophical Transactions of the Royal Society B: Biological Sciences 363, no. 1508 (2008): 3293-308. 
Okusitino Mahina, Hufanga. "Ta, Va, and Moana: Temporality, Spatiality, and Indigeneity." Pacific Studies 33, no. 2 (2010): 168.

Procter, James. Stuart Hall. Routledge, 2004.

Provenzo Jr, E. "Friedrich Froebel's Gifts: Connecting the Spiritual and the Aesthetic to the Real World of Play and Learning." American Journal of Play 2, no. 1 (2009): 85-99.

Provenzo Jr, Eugene F. "Friedrich Froebel's Gifts: Connecting the Spiritual and the Aesthetic to the Real World of Play and Learning." American Journal of Play 2, no. 1 (2009): 85-99.

Puketapu-Hetet, Erenora. Maori Weaving. Auckland, N.Z: Pitman, 1989.

White, Robin. "Art and Conservation Are Synonymous." Art New Zealand Aug. 1977:

n. pag. Art New Zealand. Web. 02 Feb. 2015. <http://www.artnewzealand.com/Issues1to40/environrw.htm>.

Semu, Greg. "The Last Cannibal Supper...Cause Tomorrow We Become Christians." Trophies, Relics and Curios?: Missionary Heritage from Africa and the Pacific, 2010.

Skinner, Damian., \& Bolton, Lissant. "Continuity and Change in Customary Arts." Chap. 6 In Art in Oceania: A New History, edited by P. Brunt, Thomas, N., Mallon, S., Bolton, L., Brown, D., Skinner, D., \& Kuchler, S. , 466-96. London: Thames \& Hudson Ltd, 2012.

Slack, J D. "The Theory and Method of Articulation in Cultural Studies." Chap. 5 In Stuart Hall: Critical Dialogues in Cultural Studies, edited by David \& Chen Morley, Kuan- Hsing, 113-27. New York and London: Routledge, 1996. 
Spriggs, Matthew. "Dating Lapita: Another View." Lapita design, form and composition (1990): 83-122.

Stevenson, Karen. The Frangipani Is Dead: Contemporary Pacific Art in New Zealand, 1985-2000. Wellington, N.Z: Huia, 2008.

Teaiwa, T. "What Remains to Be Seen: Reclaiming the Visual Roots of Pacific Literature." Pmla-publications of The Modern Language Association of America 125, no. 3 (2010): 730-26.

Teaiwa, Teresia. "Militarism, Tourism and the Native: Articulations in Oceania." PhD, University of California, Santa Cruz, 2001.

Thaman, Konai Helu. "Tauhi Vaha'a: A Possible Foundation for Peace and Intercultural Understanding." Intercultural Education (2004): 32-36.

Thomas, N. "European Incursions." In Art in Oceania: A New Hisotry, edited by P. Brunt, Thomas, N., Mallon, S., Bolton, L., Brown, D., Skinner, D., \& Kuchler, S., 270-98. London: Thames \& Hudson Ltd, 2012.

Thompson, Hohepa. "WHO ? Ri." Hori. Big Cartel, n.d. Web. 29 Jan. 2015.-Timutimu, By Ripeka. "'Hori' Artist Airs out 'Dirty Laundry' in Wellington." Māori Television. N.p., 02 Oct. 2014. Web. 20 Jan. 2015.Triggs, Oscar Lovell. The Arts \& Crafts Movement. Parkstone International, 2014.

Wattie, Rachel. "Maori Fashion Courts Stylish Controversy." Stuff.co.nz, 18th July 2012.

Webb-Binder, Bernida. "Pacific Identity through Space and Time in Lily Laita's Va I Ta." (2009).

Wendt, Albert. "Afterword: Tatauing the Post-Colonial Body." Inside out: Literature, cultural politics, and identity in the new Pacific (1999): 399-412. 
- - . "Tatauing the Post-Colonial Body." SPAN: Journal of the South Pacific Association for Commonwealth Literature and Language Studies 42-43 (1996): 15-29.

- - - "Towards a New Oceania." Mana Review: A South Pacific Journal of Language and Literature 1, no. 1 (1976): 70-85.

Whimp, Graeme. "Working in the Space Between: Pacific Artists in Aotearoa/New Zealand." (2009).

White, Robin., Toki, Leba., \& Jione, Bale. "Teitei Vou (a New Garden) (Detail)." The cloth illustrated, called a taumanu, is one of nine components in the complete work, which includes mats made of woven pandanus with commercial wool, woven barkcloth and sari frabric. Collection Queensland Art Gallery: Art in Oceania: A New Hisotry, 2009.

Young Leslie, Heather E. "'...Like a Mat Being Woven"." Pacific Arts Journal 3 (2007): 115-17. 